\title{
Equifinality, sloppiness, and emergent structures of mechanistic soil biogeochemical models
}

\author{
Gianna L. Marschmannª,1,*, Holger Pagel ${ }^{\mathrm{a}}$, Philipp Kügler ${ }^{\mathrm{b}}$, Thilo Streck \\ ${ }^{a}$ Institute of Soil Science and Land Evaluation, Biogeophysics, University of Hohenheim, \\ 70599 Stuttgart, Germany \\ ${ }^{b}$ Institute of Applied Mathematics and Statistics, Mathematics, University of Hohenheim, \\ 70599 Stuttgart, Germany
}

\begin{abstract}
Biogeochemical models increasingly consider the microbial control of carbon cycling in soil. The major current challenge is to validate mechanistic descriptions of microbial processes and predicted system responses against experimental observations. We analyzed soil biochemical models of different complexity regarding parameter identifiability using information geometry, i.e. a model is geometrically interpreted as a manifold embedded in data space. The most complex model (PECCAD) was used as a test case to reveal parsimonious process formulations. All models showed sloppiness, i.e. most individual parameter values cannot be inferred from the observed data. We derived a less complex model formulation of PECCAD with effective inferable parameter combinations and identified structural model limitations. The complexity of identified effective models was systematically reduced with
\end{abstract}

\footnotetext{
*Corresponding author

Email addresses: gianna.marschmann@uni-hohenheim.de (Gianna L. Marschmann), holger_pagel@uni-hohenheim.de (Holger Pagel), philipp.kuegler@uni-hohenheim.de (Philipp Kügler), tstreck@uni-hohenheim.de (Thilo Streck)

${ }^{1}$ Schloss-Wolfsbrunnenweg 8, 69117 Heidelberg, Germany
} 
decreasing information content of data. Our results suggest that information geometry provides a powerful approach to derive effective descriptions of relevant biogeochemical processes and reduce structural model uncertainty. Keywords: equifinality, sloppiness, model reduction, effective modeling, model complexity

\section{Introduction}

Equifinality arises when many different model realizations lead to identical system behavior (Von Bertalanffy, 1968). It has been either identified as an integral part of the curse of dimensionality impeding parameter estimation in inverse modeling (Beven, 2006) or as a blessing in disguise justifying large-scale effective laws that integrate complex pore-scale characteristics and processes over space and time (Savenije, 2001). In any case, equifinality is a manifestation of an information gap between model complexity and data (Machta et al., 2013). Bridging this gap between high model complexity and limited available data is a major challenge in soil biogeochemical modeling (Wieder et al., 2015).

A primary goal of soil biogeochemical models is to identify the mechanisms that determine the flow of carbon $(\mathrm{C})$ through a system typically composed of microbial biomass, extracellular enzymes, soluble $\mathrm{C}$ and soil organic matter. Most soil C turnover models take the form of ordinary differential equations (ODE). While soil biogeochemical models were originally formulated as linear ODE (Sierra and Müller, 2015), the field has recently seen an expansion of nonlinear process formulations (Manzoni and Porporato, 2009; Wieder et al., 
2015; Allison, 2017). As a result of the empirical nature of these process laws (e.g. with respect to the mathematical formulation of substrate uptake kinetics (Tang, 2015)), soil biogeochemical models are gray-box models (Verghese, 2009; Transtrum, 2016a). They have a fixed, semi-empirical, and highly nonlinear model structure, but many unknown parameters. Most parameter values cannot be measured directly and must be inferred from data. Consequently, one of the main challenges in biogeochemical modeling is that bulk observations of soil carbon or respiration fluxes rarely contain enough information to reliably estimate model parameters (Sierra et al., 2015a; Wang et al., 2015; Pagel et al., 2016; Luo et al., 2017). Here, parameter equifinality is caused not by the low impact of individual parameters, but by compensation effects of parameter combinations (Brun et al., 2001; Luo et al., 2009; Kügler, 2012). A direct consequence of these parameter identifiability issues is that multiple models explain a set of observations equally well. In this regard, equifinality hampers system understanding, and structural model assumptions cannot be assessed with available data (Baveye et al., 2018; Sulman et al., 2018). Yet, model structure and the associated process complexity strongly affect predicted system behavior in response to external perturbations (Allison et al., 2010; Hararuk et al., 2015; Luo et al., 2016; Georgiou et al., 2017; Ballantyne IV and Billings, 2018; Shi et al., 2018). They also alter the relevance of parameters that influence the system (Sierra et al., 2015b; Vogel et al., 2018).

Instead of focusing on predictions, a subset of soil biogeochemical models summarize current micro-scale process information into complex sets of equa- 
tions. Starting from a complex model, this information can be leveraged by lumping microscopic parameters into effective macroscopic laws that describe feedbacks between microbial biomass, soil organic matter $\mathrm{C}$ and external environmental conditions (Manzoni et al., 2016). Equilibrium approximations, e.g., are valid if solute transport and enzymatic reactions in the soil system act on much shorter time scales than the turnover of bulk soil C pools (Wang et al., 2014). Often however, there a multiple options of writing down reduced models and rigorous coarse-graining steps in biogeochemical model development are difficult to justify based on expert knowledge and a priori assumptions on the separation of time scales alone (Kuehn, 2016; Getz et al., 2018). This is because erroneous application of quasi-steady state assumptions (Carvalhais et al., 2008; Tang and Riley, 2013) and model process formulations (Georgiou et al., 2017; Ballantyne IV and Billings, 2018) in biogeochemical modeling have been shown to decrease model performance. The apparent information gap between model and data calls for developing a framework in which a complex model that integrates existing micro-scale knowledge about soil processes can be systematically simplified. The initial complex model is very likely over-parameterized (Stigter et al., 2017), but should then be reduced to an effective model with emergent mechanisms that describe the data equally well and enable unique parameter inference.

Developing parsimonious process-based models is a challenging and computationally intensive task considering the high level of structural uncertainty in biogeochemical modeling (van Turnhout et al., 2016; Houska et al., 2017; Sheikholeslami et al., 2018). In order to bridge the gap between model com- 
plexity and data, some soil modeling studies have focused on developing better optimization algorithms for parameter estimation, sensitivity studies and uncertainty assessment (Wang and Chen, 2013; Mašić et al., 2016; Gharasoo et al., 2017). However, global sensitivity methods for initial parameter screening in complex soil biogeochemical models have produced ambiguous results in the calibration step (Pagel et al., 2014, 2016). Moreover, the results of sensitivity rankings are difficult to translate into model simplifications and the associated methods are usually benchmarked against low dimensional models with less than 20 parameters (Pianosi et al., 2016). Other studies have emphasized the need for better data collection strategies in order to make the inference problem better conditioned (Keenan et al., 2013), but it can be difficult to obtain comprehensive datasets on soil C stocks, fluxes and isotopes (Sierra et al., 2015a). An alternative strategy is to find a reduced representation of the original complex model that retains the ability to fit the data and reveals key model processes. While extensive literature on model reduction methods exist in mathematical biology (Snowden et al., 2017), we were motivated by recent efforts to build a unified geometric framework that has the potential to connect the areas of optimal experimental design and model reduction (Jeong et al., 2018). The framework fits our strategy of model building to start from a general complex modeling ansatz followed by successive simplifications. It has been applied across many fields of science (classical physics; Machta et al. (2013), nuclear physics; Nikšić and Vretenar (2016), engineering; Transtrum et al. (2018) and systems biology; Transtrum and Qiu (2016); Bohner and Venkataraman (2017); Lombardo and Rappel (2017)). Derived effective parameters of reduced models have been shown 
to reveal physically or biologically relevant mechanistic information about the system under study. Application in systems biology has helped identify important controls of adaptation in allosteric macromolecules (Bohner and Venkataraman, 2017), mechanisms of cardiac arrhythmias (Lombardo and Rappel, 2017) or minimal topologies in biochemical enzyme networks (Transtrum and Qiu, 2016). The Manifold Boundary Approximation Method (Transtrum and Qiu, 2014) that was used as a model reduction scheme unifies many common methods for model approximations such as continuum limits (Machta et al., 2013), singular perturbations (Chachra et al., 2012), balanced truncation (Paré et al., 2015), and steady-state and partial equilibrium assumptions (Transtrum and Qiu, 2016).

In the following, we give a brief description of five microbially-explicit nonlinear soil $\mathrm{C}$ models. In order to assess the severity of the parameter identification problem, we analyze the structure of the Hessian matrix which measures local model output sensitivities to variations around the respective published optimal parameter sets. We chose the simplest nonlinear microbial soil $\mathrm{C}$ model to illustrate in detail the process of model reduction using the Manifold Boundary Approximation Method. A more complex model is then used as a case study to show how to systematically tailor model complexity to the information content of different data sets, thereby elucidating key controlling mechanisms that give rise to the data. Based on this analysis, we go on to discuss general implications for soil biogeochemical modeling. 


\section{Material and methods}

\section{Description of analyzed models}

Biogeochemical models considered in this study can be written in ODE form as

$$
\frac{d \boldsymbol{y}}{d t}=\boldsymbol{f}(\boldsymbol{y}, \boldsymbol{p}, t)
$$

where $\boldsymbol{y} \in \mathbb{R}^{M}$ is a vector of state variables, $\boldsymbol{p} \in \mathbb{R}^{N}$ is a vector of unknown parameters and $t \in \mathbb{R}$ denotes the independent time variable. Given a set of initial conditions, $\boldsymbol{y}\left(t_{0}\right)=\boldsymbol{y}_{\mathbf{0}}$, Eq. 1 can be numerically integrated in order to obtain time courses of the model state variables. Soil biogeochemical systems are typically only partially observed (Kügler, 2012), i.e. observations are available only for a subset or a combination of the total number of state variables $M$ in the model. Moreover, initial conditions $\boldsymbol{y}_{\mathbf{0}}$ for some model variables have to be estimated from data. To ensure positive values and improve numerical performance, all calculations were performed on a logarithmic scale for $\boldsymbol{p}$.

We tested five biogeochemical models of increasing complexity: a) the minimal soil carbon model by German et al. (2012), b) the extended NICA model by Ingwersen et al. (2008), c) the MEND model by Wang et al. (2015), d) a trait-based microbial soil carbon model by Manzoni et al. (2014), and e) the PECCAD model by Pagel et al. (2014).

The simplest nonlinear model $(\mathrm{M}=2, \mathrm{~N}=4$; German et al. (2012)) can be expressed as a system that describes the turnover of soil $\mathrm{C}\left(C_{S}\right)$ and microbial biomass $\left(C_{B}\right)$ : 


$$
\begin{array}{r}
\frac{d C_{S}}{d t}=I(t)-\frac{V_{\max } C_{S}}{K_{S}+C_{S}} C_{B}+k_{B} C_{B} \\
\frac{d C_{B}}{d t}=Y \frac{V_{\max } C_{S}}{K_{S}+C_{S}} C_{B}-k_{B} C_{B} .
\end{array}
$$

Turnover depends on $\mathrm{C}$ input into the soil $(I(t))$, the first-order cycling rate of microbial biomass $\left(k_{B}\right)$ and nonlinear substrate uptake kinetics expressed in terms of the Monod model for microbial growth (e.g. Strigul et al., 2009). Here, $V_{\max }$ is the maximum growth rate, $K_{S}$ is the substrate affinity coefficient and $Y$ denotes the microbial $\mathrm{C}$ use efficiency.

More complex models (Ingwersen et al., 2008; Manzoni et al., 2014; Pagel et al., 2014; Wang et al., 2015) are refined by adding state variables beyond a bulk description of soil C. The soil C pool is partitioned into fractions of different quality as well as sorbed and dissolved phases. The microbial C pool is split into distinct functional types and activity levels. Wang et al. (2015) $(\mathrm{M}=10, \mathrm{~N}=19)$ explicitly describe the role of exoenzymes in soil C decomposition. Manzoni et al. (2016) $(\mathrm{M}=7, \mathrm{~N}=24)$ explicitly model the impact of soil moisture on $\mathrm{C}$ cycling and microbial physiology. Models differ further with respect to the functions used to describe $\mathrm{C}$ fluxes. For instance, the C submodel in Pagel et al. (2014) $(\mathrm{M}=12, \mathrm{~N}=59)$ applies non-linear multisubstrate Monod kinetics (Lendenmann and Egli, 1998), whereas substrate uptake and microbial growth in Manzoni et al. (2014) are simplified to a linear function $\left(\propto V_{\max } C_{S} C_{B}\right)$.

As the most complex representative, we analyzed the PECCAD model (PEsticide degradation Coupled to CArbon turnover in the Detritusphere; Pagel et al. (2014)) which simulates degradation of the herbicide 4-chloro-2-methyl- 
phenoxyacetic acid (MCPA) coupled to $\mathrm{C}$ turnover in soil. The model was designed to identify regulation mechanisms of accelerated pesticide degradation in soil in response to supply of fresh $\mathrm{C}$ from decomposing plant litter. In contrast to the original PECCAD model, spatial variations of state variables and transport processes were neglected in the present study. That is, we transformed the original system of 12 coupled partial and ordinary differential equations (Pagel et al. (2014, Table 1-2)) to an ODE system (PECCAD ODE, Fig. 1).

PECCAD ODE couples the dynamics of two pesticide pools (dissolved $C_{P}$ and sorbed phase $C_{P-s}$ ) to that of several $\mathrm{C}$ pools (readily available high quality $\mathrm{C} C_{h i q}$ and sorbed phase $C_{h i q-s}$, recalcitrant low quality $\mathrm{C} C_{l o q}$ and sorbed phase $C_{\text {loq-s }}$, insoluble soil organic matter $C_{I}$ ) and microbial populations (bacteria $C_{B}$, fungi $C_{F}$, specific pesticide degraders $C_{B P}$ ). The model simulates the physiological state of microorganisms $\left(r_{i}, i \in\{B, F, B P\}\right)$ to account for active and dormant biomass. Input of litter-derived dissolved organic $\mathrm{C}$ (DOC) and partitioning into high and low quality fractions was simulated with a time-dependent empirical litter decomposition function (Pagel et al., 2014, Online Resource 3).

Process equations, initial conditions, and parameter values for all models used in this study are available in Appendix A and B.

\section{Experimental data}

The original PECCAD model was validated with a series of microcosm experiments on the degradation of the herbicide MCPA in soil (see Pagel et al. (2016) for details). Briefly, homogenized soil was filled to a height of $30 \mathrm{~mm}$ into stainless steel cylinders (diameter $56 \mathrm{~mm}$, height $40 \mathrm{~mm}$ ) and compacted 


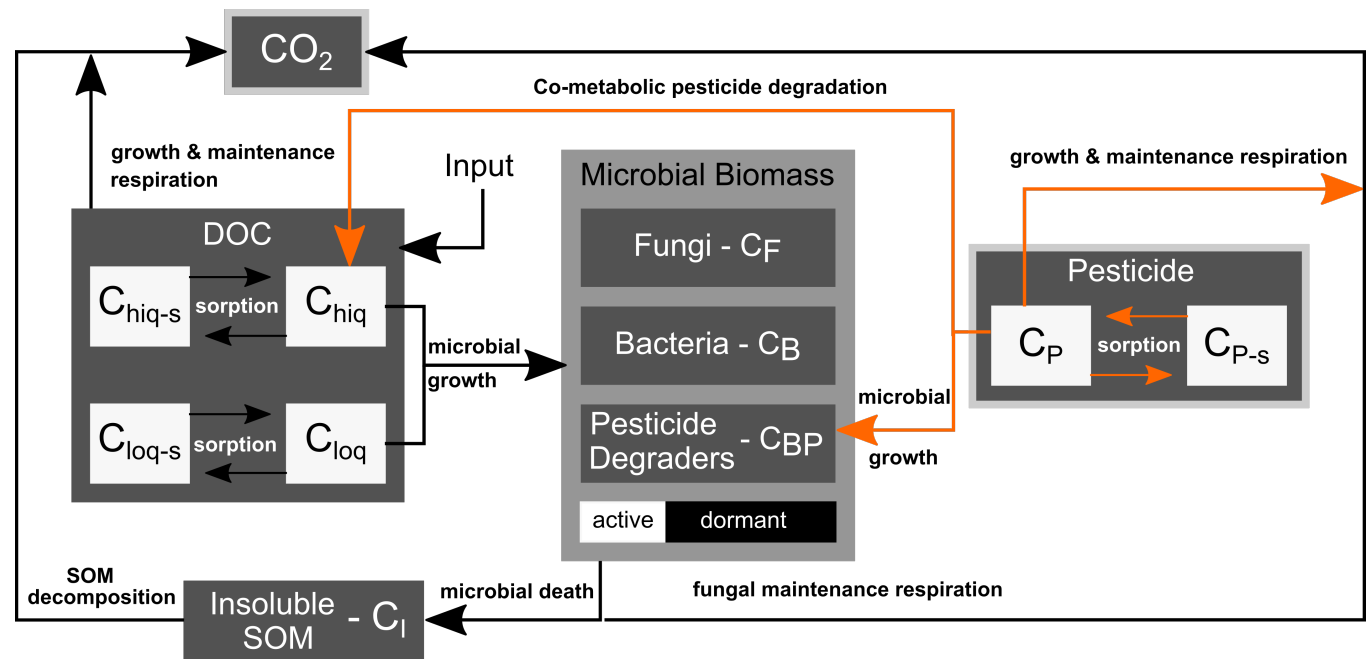

Figure 1: Diagram of the PECCAD ODE model (after Pagel et al. (2014)). Boxes symbolize $\mathrm{C}$ pools and arrows indicate $\mathrm{C}$ fluxes. The system can be observed at different resolutions: (i) using information on all available data including the dynamics of functional genes (dark gray), or (ii) bulk biomass (gray) along with measurements of dissolved organic $\mathrm{C}(\mathrm{DOC})$, insoluble soil organic matter $\left(C_{I}\right)$, total pesticide $\left(C_{P}+C_{P-s}\right)$ and heterotrophic respiration $\left(\mathrm{CO}_{2}\right)$; (iii) only with input-output information on total pesticide and $\mathrm{CO}_{2}$ (light gray). Fluxes directly related to pesticide degradation in orange. Individual $\mathrm{C}$ pools in white boxes correspond to unobserved system components. 
to a bulk density of $1.2 \mathrm{~g} \mathrm{~cm}^{-3}$. In one experimental treatment (MCPA), an MCPA solution was homogeneously added to the soil to obtain an average concentration of $53 \mathrm{\mu g}^{-1}$. In a second treatment (MCPA + Litter), the same MCPA amendment was used, but a layer consisting of $0.5 \mathrm{~g}$ maize litter was added on top of the microcosms. Four replicated microscosms of each treatment were then destructively sampled after 4.9, 7.8, 10.0, 13.9 and 22.8 days in $0-1,1-2,2-3,3-4,4-6,6-10$ and 10-20 mm layers. To obtain sufficient material for analyses and estimate measurement errors $\sigma_{m k}$, soil from associated layers of two soil cores was combined, yielding two experimental replicates. In this study, we used the data on MCPA, extractable DOC, total organic $\mathrm{C}$ (TOC), microbial biomass $\left(C_{B}\right)$, genetic abundances of bacteria (16S rRNA genes), fungi (ITS fragments), and specific MCPA degraders ( $t f d A$ genes) that was averaged over the first five soil layers (0-6 $\mathrm{mm}$ ) of the microcosms resulting in 6 data points per $\mathrm{C}$ pool. Together with heterotrophic respiration rate data measured at 13 time points over the span of the experiment, $(6 \times 7+13=55)$ data points corresponding to the $\mathrm{C}$ pools above were used to calibrate the PECCAD ODE model and estimate 59 parameters for each experimental treatment (MCPA, MCPA + Litter).

\section{Parameter estimation}

Model parameters of PECCAD ODE that have to be inferred from data can be loosely grouped into biokinetic parameters (maximum growth and decomposition rates, substrate affinity coefficients, substrate uptake efficiencies), physicochemical parameters (sorption coefficients, partitioning coefficients of C pools) and unknown initial conditions (physiological state index variables). We assumed that the residuals between measured data $y_{m k}^{D}$ and model predic- 
tions $y_{m}\left(\boldsymbol{p}, t_{k}\right)$ at time points $t_{k}$ are Gaussian with zero mean and standard deviation $\sigma_{m k}$. Thus, we obtained maximum likelihood estimates $\left(\boldsymbol{p}=\boldsymbol{p}^{*}\right)$ of model parameters by minimizing the weighted sum of squared errors $(J(\boldsymbol{p}))$ over all concentrations $M$ observed at time points $N_{t}$ :

$$
J(\boldsymbol{p})=\frac{1}{2} \sum_{m=1}^{M} \sum_{k=1}^{N_{t}}\left(\frac{y_{m k}^{D}-y_{m}\left(\boldsymbol{p}, t_{k}\right)}{\sigma_{m k}}\right)^{2} .
$$

Local sensitivity of model output with respect to changes in parameters around the best fit value $\boldsymbol{p}^{*}$ was measured by the Hessian matrix

$$
H_{i j}=\left.\frac{\partial^{2} \boldsymbol{J}}{\partial p_{i} \partial p_{j}}\right|_{\boldsymbol{p}=\boldsymbol{p}^{*}} .
$$

In parameter space, the Hessian approximates regions of constant cost as N-dimensional ellipsoids, where $N$ is the number of parameters. Principal axes of the ellipsoid are oriented along the eigenvectors of the Hessian and are generally not aligned with the bare parameter axes. The width of the ellipsoid along the principal axis is given by one divided by the square root of the corresponding eigenvalue (Bates and Watts, 1988).

\section{Identifiability analysis}

For analysis of the models by Ingwersen et al. (2008); German et al. (2012); Manzoni et al. (2014); Wang et al. (2015), we generated synthetic continuous time series data that the models can fit perfectly at respective published optimal parameter values $\boldsymbol{p}^{*}$. This type of perfect data generated from a known model is commonly used in practical identifiability analysis (Brun et al., 2001). A parameter set is said to be (locally) identifiable, if all parameters can be uniquely estimated based on perfect measurements. If certain 
parameters are not identifiable, they show large collinearity. Based on local sensitivity information of model output with respect to parameters, the collinearity index $\gamma$ for a set of model parameters is closely related to the Hessian and defined as

$$
\gamma=\frac{1}{\left.\sqrt{\min \left(E V\left[\hat{S}^{T} \hat{S}\right]\right.}\right)} .
$$

Here, the normalized sensitivity matrix $\hat{S}_{i j}=\frac{S_{i j}}{\sqrt{\sum_{j} S_{i j}^{2}}}$ with scaled entries $S_{i j}=\frac{\partial y_{i}}{\partial p_{j}} \cdot \frac{\left|y_{i}\right|}{\left|p_{j}\right|}$, contains the columns of the sensitivity matrix that correspond to the parameters included in the set, and EV denotes the eigenvalues of the matrix $\hat{S}^{T} \hat{S}$ (Soetaert et al., 2010; Sierra et al., 2015a). If $\gamma=1$, the columns of the sensitivity matrix are orthogonal, and the parameter set is identifiable. If $\gamma \rightarrow \infty$, then the columns of the sensitivity matrix are linearly dependent. A collinearity index $\gamma$ means that a change in the results caused by a change in one parameter can be compensated by the fraction $1-1 / \gamma$ by an appropriate change of the other parameters in the set. Typically, values of $\gamma>10-15$ correspond to parameter sets that are poorly identifiable (Brun et al., 2001).

\section{Information geometry}

From a geometric perspective, a model can be described as a mapping between parameter space and data space (Nielsen, 2018). The parameter space for the Monod model for microbial growth (Eqs. 2 and 3 with $I, k_{B}=0$ and $Y=$ const) with two unknown parameters corresponding to maximum growth rate $V_{\max }$ and substrate affinity $K_{S}$, for example, is two-dimensional. The experimental data constitute a single point in data space. When the 
experiment makes four measurements of microbial biomass as in Fig. 2a, the data space is four-dimensional and one can hope to find a lower dimensional representation for visualization purposes by projecting onto the principal component axes (PCA, Fig. 2c). The model manifold is the central object in our analysis (Fig. 2c). It is the collection of all points in data space that are achievable by varying the parameters of the model in parameter space. The least-squares problem (Eq. 4) can then be viewed as a geometric problem as the cost is simply given by the projection of the data point onto any point of the model manifold. The best fit is accordingly given by the point on the manifold that is closest to the data point. Typically, the manifold does not fill the entire data space due to structural model constraints on the range of possible model predictions (in this case the saturating kinetics inherent to the Monod model, Fig. 2ac). Moreover, the local eigenvalue distribution of the Hessian (Eq. 5, Fig. 2b) has been shown to correspond to the lengths of orthogonal directions on the model manifold (Transtrum et al., 2010, 2011). In the case of the Monod model, there is one long direction along which model predictions change substantially (corresponding to $\lambda_{1}=0.4$ ) and one narrow direction corresponding to $\lambda_{2}=183$. Due to the fundamental concept of its geometry, distances on the manifold are the same regardless of how the model is parameterized (e.g. changing units of model parameters from $\mathrm{mg}$ to g). From a computational point of view, sampling in possibly highdimensional parameter space can be replaced by studying the Riemannian geometry of the manifold. In particular, the model can be efficiently explored by calculating geodesic curves on the manifold and monitoring the value of the cost function (Fig. 2c). While geodesics originating at the best fit point 
277

are straight lines in data space, we see in Fig. $2 \mathrm{~b}$ that the geodesic path in the original parameter space moves along a region of constant cost until some limit is achieved. These limits correspond to a manifold boundary where the Hessian matrix (Eq. 5) has linearly dependent columns and the corresponding parameter combinations can be varied infinitely without changing the value of the cost function. In the case of the Monod model, the boundaries correspond to linear and saturating growth kinetics, i.e. one-dimensional approximations of the original two-dimensional model, respectively. 


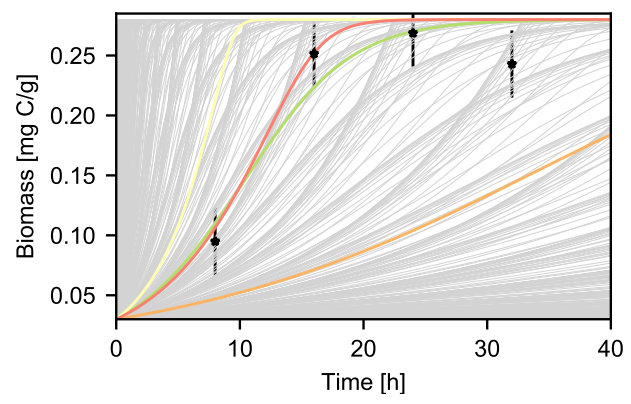

(a) Time domain

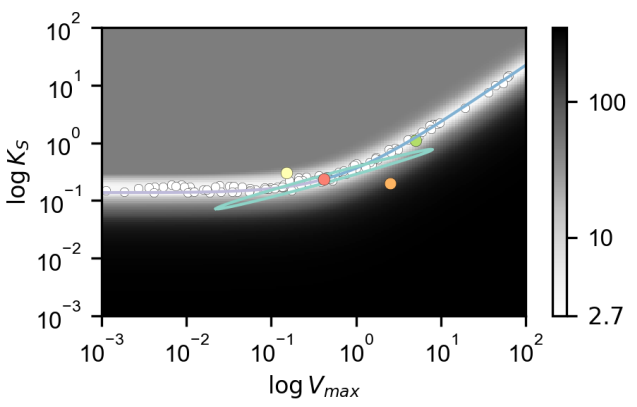

(b) Parameter space

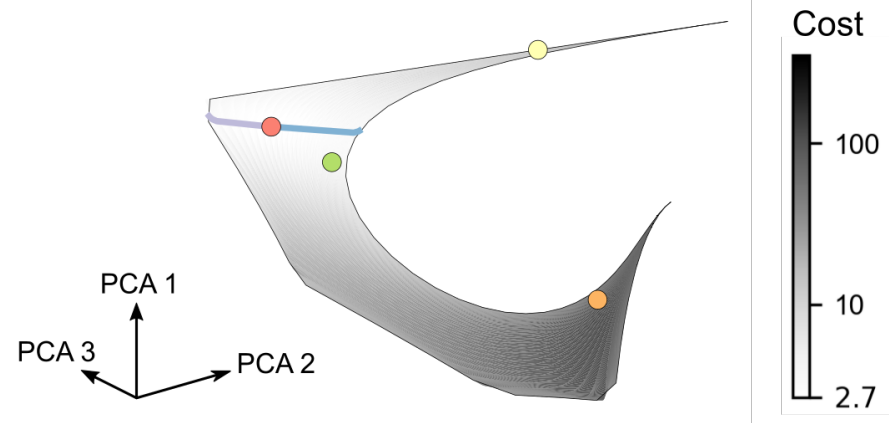

(c) Data space

Figure 2: Visualization of the least squares problem for microbial growth (Eqs. 2 and 3 with $I, k_{B}=0$ and $Y=$ const). Varying maximum growth rate $V_{\max }$ and substrate affinity $K_{S}$ generates different model trajectories (a), a cost surface in parameter space (b) and a manifold in data space (c). Time domain: the first three data points (black stars) and analyticity of the model constrain predictions of the best fit trajectory (red line) at the fourth measurement point. Data space: three-dimensional projection of all possible model predictions for substrate and biomass at time points for which experimental data is available. The first three principal components (PCA) explain $99.8 \%$ of the variance in the trajectory data. Geodesics (purple, blue) connect local information at the best-fit point (red dot) with the global boundaries of the model. Parameter space: shown is the local approximation to the Hessian (turquoise ellipse) around the best fit point (red dot) and 120 parameter samples from an MCMC ensemble (white dots). Geodesics align with the curved cost canyon in parameter space. Large regions in parameter space (black) map to small regions (corners) on the model manifold. The model manifold and the local ellipse have similar aspect ratios. 
In general, information geometry interprets a regular parameterized model with $\mathrm{N}$ parameters that is fit to $\mathrm{M}$ data points as an $\mathrm{N}$-dimensional manifold of model predictions embedded in data space of dimension M (Transtrum et al., 2011). In multi-parameter models, the width of the local eigenvalue spectrum often reflects an effective model dimensionality much lower than the number of parameters (Machta et al., 2013). For a sloppy model, the structure of the model manifold has been described as a hyper-ribbon with many exponentially narrower widths and only a few long axes (corresponding to large Hessian eigenvalues) that effectively govern model behavior. The measurement error is the yardstick of nonlinear least squares models. If any dimension of the model manifold is thinner than a standard deviation of the data, model predictions are indistinguishable from noise (White et al., 2016). That is, the corresponding nonlinear parameter combinations cannot be inferred from the data. The existence of manifold boundaries at which the Hessian is singular shows that there are parameter combinations that can be systematically removed from the model (Transtrum and Qiu, 2014).

\section{Model reduction}

The Manifold Boundary Approximation Method (MBAM; Transtrum and Qiu (2014)) reduces the number of model parameters one at a time, whilst preserving model behavior as quantified by the cost function (Eq. 4). In every reduction step, the $\mathrm{N}$-dimensional model is approximated by its (N-1)dimensional boundary. At each iteration, possible model simplifications are found numerically by solving the geodesic equation on the model manifold. Calculating the geodesic is a solved problem (Do Carmo, 2016) that returns the values of the parameters approaching a boundary: 


$$
\frac{\partial^{2} p^{i}}{\partial \tau^{2}}=\sum_{j, k} \Gamma_{j k}^{i} \cdot \frac{\partial p^{j}}{\partial \tau} \frac{\partial p^{k}}{\partial \tau} ; \Gamma_{j k}^{i}=\sum_{l, m}\left(H^{-1}\right)^{i l} \frac{\partial y_{m}}{\partial p^{l}} \frac{\partial^{2} y_{m}}{\partial p^{j} \partial p^{k}} .
$$

The model parameters $\boldsymbol{p}(\tau)$ are regarded as the coordinates of the geodesic curve with arc length $\tau$ on the model manifold and $\Gamma_{j k}^{i}$ are components of the so-called Christoffel symbols, which can be entirely expressed in terms of local parameter sensitivities.

The geodesic equation is a second order ODE with a unique solution when an initial position and velocity are provided. Initial position and initial velocity are chosen to be the best fit parameter vector and the eigenvector that corresponds to the smallest Hessian eigenvalue. The geodesic equation is integrated until a singularity is encountered at a finite $\tau_{b}$. This corresponds to a manifold boundary (for details on boundary identification, see Appendix F: Fig. F.8). At a singularity $\tau_{b}$, the solution to the geodesic equation has components that diverge, i.e. parameters that take on extreme values of $\pm \infty$. These parameter limits $\left(\lim _{\tau \rightarrow \tau_{b}} p(\tau)= \pm \infty\right)$ are directly amenable to analytic evaluation and elimination in the model.

Denoting the resulting reduced parameter vector by $\hat{\boldsymbol{p}}$, Eq. 4 with $J(\hat{\boldsymbol{p}})$ is used to recalibrate the approximate model with N-1 parameters to the data and reiterate the reduction process until the remaining manifold dimensions are larger than the scale set by experimental noise (corresponding to Hessian eigenvalues smaller than unity). Each MBAM iteration thus requires one local parameter optimization, computation of the first and second-order model derivatives with respect to the parameters along the geodesic path, as well as manual or semi-automatic symbolic evaluation of parameter limits in the model. Symbolic computation of singular limits in order to return a 
reduced model with one less parameter at each iteration can be automated (Bjork, 2018), but was performed manually in the current study. The initial parameter values are incidental to the algorithm and the final reduced model is known to be robust to the starting point (Transtrum and Qiu, 2014).

\section{Implementation}

All models analyzed in this study were implemented in the SloppyCell software (Myers et al., 2007) in order to utilize its parameter estimation and sampling routines. Equation 4 was minimized using the standard LevenbergMarquardt algorithm (Press et al., 2007) with logarithmically transformed parameter values. Local sensitivity equations for calculating the Hessian (Eq. 5) and right hand side of the geodesic ODE (Eq. 7) were solved numerically by the direct differential method (Zi, 2011), i.e., by numerically integrating the following equation for the sensitivity coefficients per parameter $S_{i}=\partial y_{i} / \partial p$ of ODE models (Eq. 1):

$$
\frac{\partial S_{i}}{\partial t}=\frac{\partial}{\partial t} \frac{\partial y_{i}}{\partial p}=\frac{\partial}{\partial p} \frac{\partial y_{i}}{\partial t}=\frac{\partial f_{i}(\boldsymbol{y}, \boldsymbol{p}, t)}{\partial p}, \quad S_{i}(0)=0 .
$$

The corresponding collinearity index $\gamma$ (Eq. 6) was calculated using the R package FME (Soetaert et al., 2010). Ensembles of parameter sets for optimization were generated by Markov Chain Monte Carlo (MCMC) importance sampling (Gutenkunst, 2007). Samples were generated from the posterior distribution corresponding to Eq. 4 with log-normal priors that restrict parameters to lie with $95 \%$ confidence within two orders of magnitude of the locally-inferred best fit values. An available Python 2.7 script (Transtrum, 2016b) was used to implement the geodesic equation (Eq. 7). 
Implementation details for the MBAM and Bayesian model calibration are provided in Appendix C and D. Algebraic details of selected MBAM model reduction steps are presented in the results section of this paper. The full code and and model SBML files (Gómez et al., 2016) used to generate all analyses is available on GitHub: https://github.com/giannamars/ Effective-Soil-Biogeochemial-Modeling.

\section{Results}

\section{Hierarchy of parameter importance in soil biogeochemical models}

All five selected biogeochemical models (a-e) show roughly evenly spread eigenvalues of the Hessian matrix over several orders of magnitude (Fig. 3). Such a characteristic local parameter sensitivity spectrum has been termed sloppy in the systems biology literature (Gutenkunst et al., 2007). The spectra indicate that even for the simplest model (German et al., 2012), there exist individual model parameters that will likely not be identifiable, even from continuous, essentially noiseless synthetic data that the models can fit perfectly at their respective published optimal parameter values. In the parameter space picture, local cost contours of these models have aspect ratios exceeding 1000. From the viewpoint of information geometry, their model manifolds in data space are globally bounded by a hierarchy of widths, with each width being smaller than the previous one by a roughly constant factor. The width of the spectra increases with increasing apparent model complexity, which is taken here as the number of model parameters. 


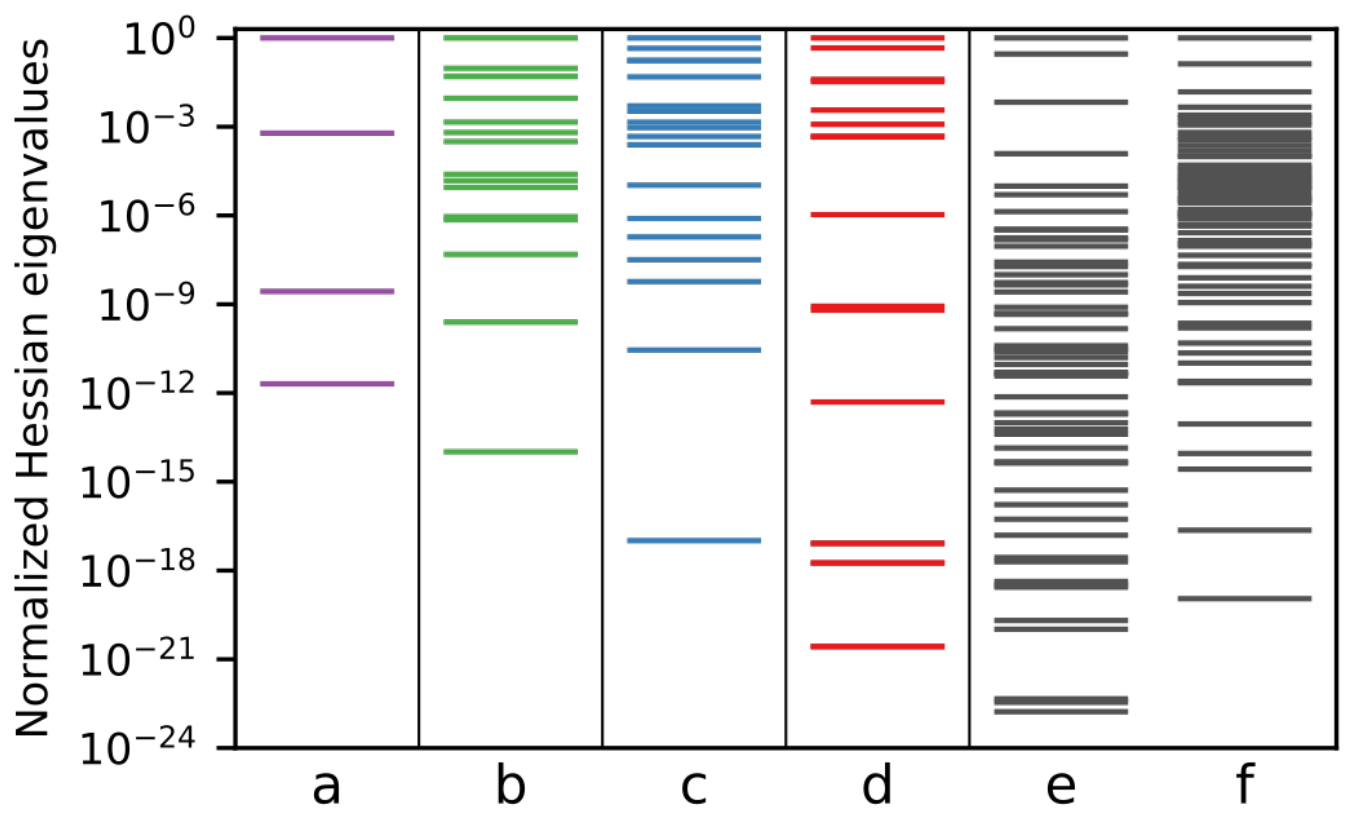

Figure 3: Normalized eigenvalue spectra of five biogeochemical models (a German et al. (2012); b Ingwersen et al. (2008); c Wang et al. (2015); d Manzoni et al. (2014); e-f Pagel et al. (2014)). The spectra are plotted from left to right in increasing order of apparent model complexity (taken as the number of unknown parameters). The eigenvalues are normalized by the maximum eigenvalue. Models a-e show a characteristic sloppy eigenvalue distribution of the Hessian for a continuous fit to synthetic data (??). Column $f$ shows the eigenvalues derived from a Principal Component Analysis of an MCMC parameter ensemble for calibration based on MCPA + Litter data. 


\section{Sloppiness and parameter identifiability analysis}

For the parameter identifiability analysis of the minimal microbial soil $\mathrm{C}$ model (Eq. 3, German et al. (2012)), we used heterotrophic respiration rate from incubation experiments $(I(t)=0)$, as well as radiocarbon $\Delta^{14} \mathrm{C}$ values of the respired CO2 over time and the initial and final soil C stock (Sierra et al., 2012) to calculate the collinearity index of model parameters. The possible number of parameter combinations to identify in the minimal model given the different data sets is 44 . Reproducing results of Sierra et al. (2015a), the collinearity index shows that it is not possible to uniquely identify all model parameters in a combination simultaneously even when using all available data sets (Fig. 4a). For sets consisting of 2 or 3 parameters, identifiability depends on the specific parameter combination as well as the specific data set. Application of the MBAM results in reduced models whose parameters are uniquely identifiable from the data (filled symbols in Fig. 4a).

Figure $4 \mathrm{~b}$ shows the parameter limits obtained by numerically integrating the geodesic equation (Eq. 7) that give rise to the model reductions for the respiration data set. The log parameter values as a function of the geodesic path $\tau$ in the first reduction (Fig. 4b, top left) show that two parameters start to diverge at the manifold boundary $(\tau \approx 1.25)$. These parameters correspond to the maximum growth rate $V_{\max }$ and the substrate affinity coefficient $K_{S}$ which diverge at the same rate, thus rendering the decomposition term linear,

$$
\frac{V_{\max } C_{S}}{K_{S}+C_{S}} \rightarrow \vartheta_{1} C_{S}
$$

where $\vartheta_{1}=V_{\max } / K_{S}$ is the emergent linear decomposition factor. The 


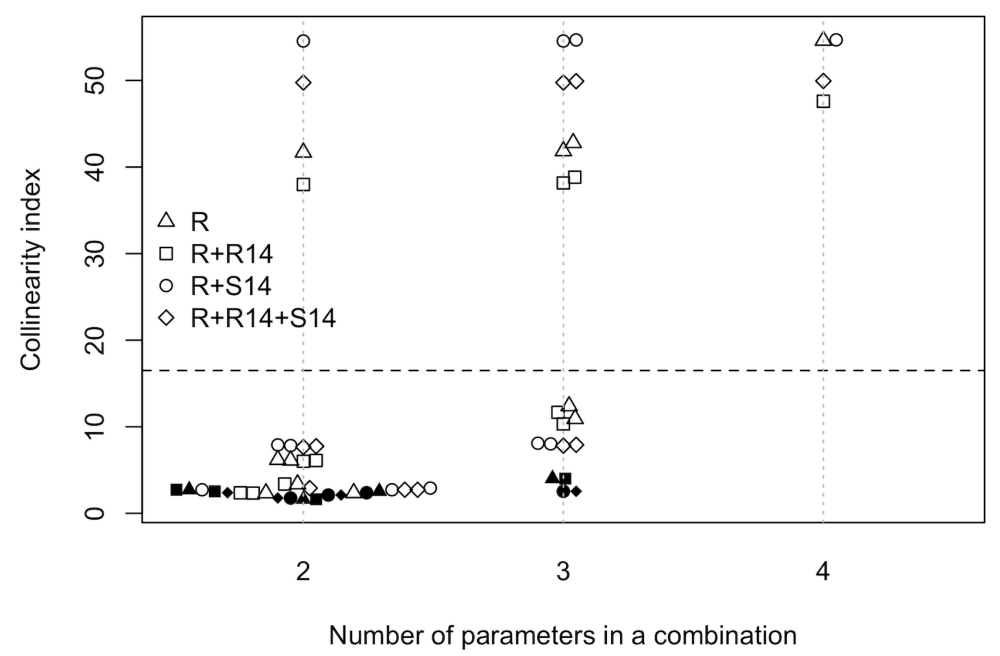

(a)
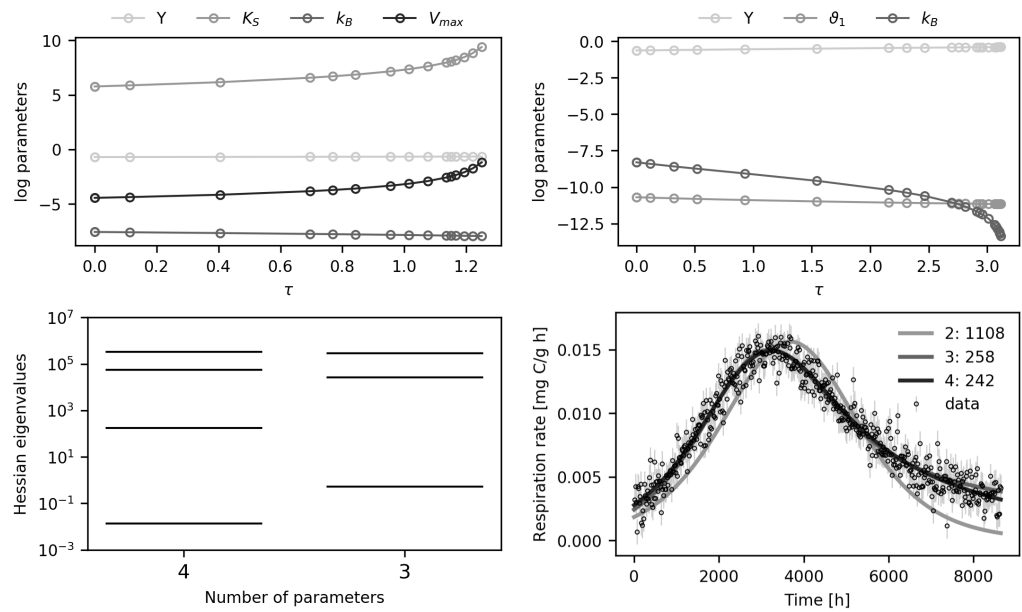

(b)

Figure 4: (a) Collinearity index $\gamma$ (Eq. 6) calculated for the minimal microbial soil C model (Eq. 3). Datasets used for the calculation of $\gamma$, R: respiration flux, $\mathrm{R}+\mathrm{R} 14$ : respiration fluxes and radiocarbon in evolved $\mathrm{CO}_{2}, \mathrm{R}+\mathrm{S} 14$ : respiration fluxes and radiocarbon in bulk soil, R + R14 + S14: all data combined. Filled symbols correspond to maximally reduced models for different data sets. (b) Model reduction on respiration flux data. Top row: geodesic paths obtained in the first two MBAM iterations. Bottom left: Hessian eigenvalues at the end of the first two MBAM iterations. Bottom right: Goodness-of-fit of reduced models. 
second MBAM iteration sends $k_{B} \rightarrow 0$ (Fig. 4b, top right), however, the corresponding Hessian eigenvalue is only marginally smaller than unity (Fig. 4b, bottom left). Hence, the first-order cycling rate of microbial biomass $k_{B}$ cannot be removed from the model without significantly changing the fit to data (Fig. 4b, bottom right). In all cases, MBAM identifies a rescaling limit in the form of equation Eq. 9 involving the parameters with highest collinearity index, thereby confirming that $V_{\max }$ and $K_{S}$ cannot be simultaneously identified from typical soil incubation data sets (Sierra et al., 2015a).

\section{Sloppiness and systematic reduction of the PECCAD ODE model}

Figure 5 shows the Hessian eigenvalues of PECCAD ODE (Fig. 1) at each stage of the reduction by the MBAM. The initial 59 parameter model is sloppy when fit to the full data set of the MCPA + Litter experiment (Fig. 5a). The eigenvalues are uniformly spaced over 22 orders of magnitude. Thirty-two unidentifiable parameters correspond to eigenvalues smaller than one, i.e., manifold widths smaller than the scale set by experimental measurement uncertainties. In each model reduction step, the smallest eigenvalue is removed from the spectrum by applying the MBAM.

\section{Model simplification and parameter limits}

Tailoring model complexity to the full observational data set (Fig. 5a) reduces the dimension of the PECCAD ODE system as well as the number of parameters (Appendix A: Table A.4; $\mathrm{M}=10, \mathrm{~N}=27$ ). ODEs for physiological state indices of bacteria and specific pesticide degraders are transformed into algebraic equations that can be substituted into the original equation system. Nine effective parameters, fungal kinetic parameters, substrate uptake 


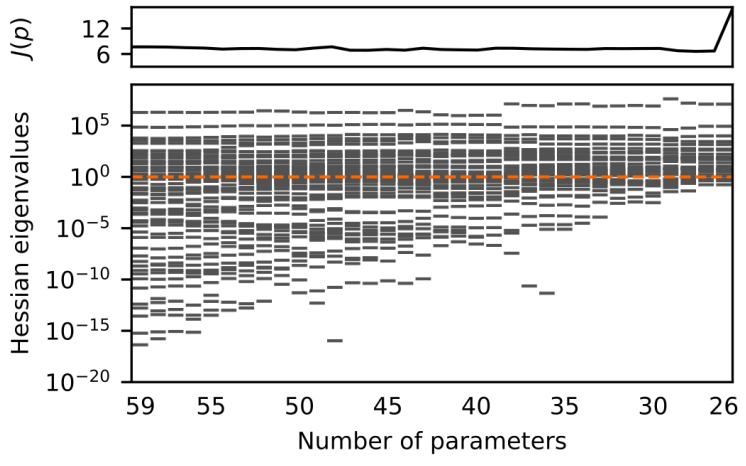

(a) Functional gene data

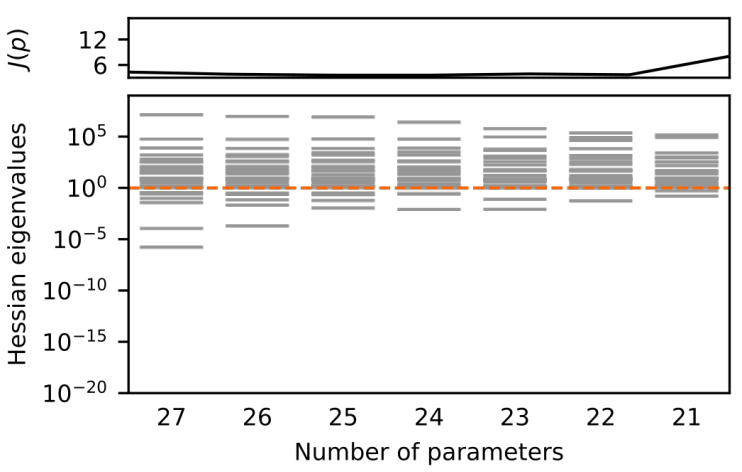

(b) Bulk data

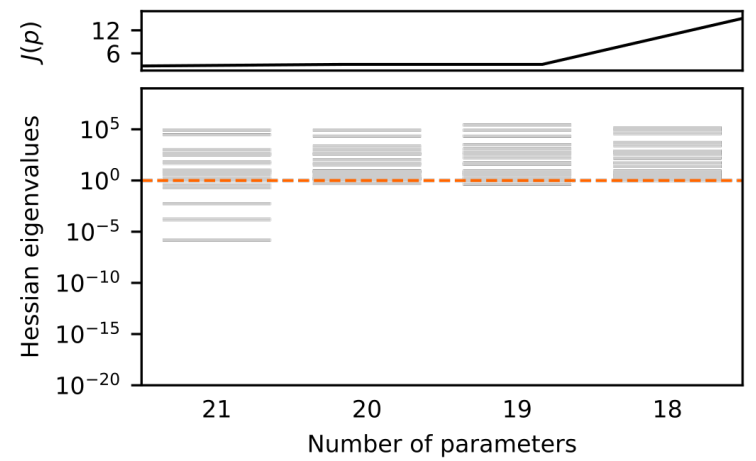

(c) Input-Output data

Figure 5: Tailoring model complexity of the PECCAD ODE model to different data sets from the Litter + MCPA experiment (Pagel et al., 2016). The MBAM removes one parameter at a time until the remaining parameters are identifiable from data to a given tolerance of $1 / \mathrm{e}$ (orange dashed line). Shown on top of the reduction spectra is the value of the cost function $J(\boldsymbol{p})$ during the iteration. (a) The full observational data set identifies a 27 parameter model that fits the data equally well. (b) Coarsening observations from functional gene measurements to bulk microbial biomass identifies a 21 parameter model governed by 7 ODEs. (c) Observing only MCPA and heterotrophic soil respiration identifies an 18 parameter ODE of dimension 6 . 
efficiencies and sorption coefficients govern the time evolution of the remaining $\mathrm{C}$ pools. The effective parameters are expressed in terms of nonlinear combinations of the original biokinetic parameters. Except for substrate uptake coefficients, only fungal parameters can be uniquely identified from the given data set. Fungal parameters related to the specific death rate are not constrained by data, but marginally important for model performance, i.e. they cannot be removed from the model without changing the value of the cost function. Except for the specific death rates of bacteria and fungi, all biokinetic functions originally formulated as multi-substrate Monod kinetics (Eq. 11) are sufficiently described by linear rather than by saturating functions of the substrate concentration.

Biokinetic functions of the PECCAD ODE model can be removed if the numerator of a rational rate expression in the original model (Appendix A: Table A.2) approaches zero at a manifold boundary. In the following, we refer to parameter limits as defined by the geodesic equation (Eq. $7, \lim _{\tau \rightarrow \tau_{b}} p(\tau)=0$, where $\tau$ denotes the affine parameterization of the geodesic and $\tau_{b}$ denotes a manifold boundary) simply as $p \rightarrow 0$. In discarding limits of this type, we find that 12 out of 22 processes describing substrate-dependent maintenance, growth, death and decomposition rates of specific functional microbial pools can be removed from the model without affecting its performance (Appendix A: Table A.4 and Fig. 5a).

Limits are less obvious when multiple parameters approach extreme values at the same rate as defined by Eq. 7. In these cases, emergent finite parameter combinations correspond to expressions such as $\infty / \infty, 0 / 0,0 \cdot \infty$ or $\infty-\infty$. As an illustration of different types of limiting processes, consider, e.g., the 
following ODE of specific pesticide degrader C:

$$
\frac{d C_{B P}}{d t}=r_{B P} C_{B P}\left(\mu_{B P, P}+\mu_{B P, h i q}+\mu_{B P, l o q}-a_{B P}\right) .
$$

450

The microbial pool changes through growth $\left(\mu_{B P, P}, \mu_{B P, h i q}, \mu_{B P, l o q}\right)$ and death $\left(a_{B P}\right)$ and depends on the physiological state index of specific pesticide degraders; this index is a dynamic variable $\left(r_{B P}\right.$, Blagodatsky and Richter (1998)). Growth is possible on $C_{P}, C_{h i q}$ and $C_{l o q}$. Simultaneous utilization of growth substrates is accordingly modeled in terms of multi-substrate Monod kinetics (Lendenmann and Egli, 1998), where $\mu_{\max -B P}$ is a maximum specific growth rate and $k_{B P, i}, i \in\{P, h i q, l o q\}$ denote substrate specific affinity constants of bacterial pesticide degraders:

$$
\mu_{B P, i}=\frac{\mu_{\max -B P} k_{B P, i} C_{i}}{\mu_{\max -B P}+k_{B P, l o q} C_{l o q}+k_{B P, h i q} C_{h i q}+k_{B P, P} C_{P}} .
$$

The death rate $\left(a_{B P}\right)$ is mediated by substrate availability in order to simulate increased microbial decay at low substrate concentrations, where $a_{\max -B P}$ likewise denotes a maximum specific death rate and $K_{a-B P, i}, i \in\{P$, hiq, loq $\}$ are substrate specific inhibition coefficients of microbial death:

$$
a_{B P}=\frac{a_{\max -B P}}{1+K_{a-B P, l o q} C_{l o q}+K_{a-B P, h i q} C_{h i q}+K_{a-B P, P} C_{P}} .
$$

We identified the discarding limits $k_{B P, P} \rightarrow 0, k_{B P, h i q} \rightarrow 0$ and $K_{a-B P, P} \rightarrow 0$. That is, the time evolution of the specific degrader pool does not explicitly depend on the pesticide concentration $C_{P}$ in the system: 


$$
\begin{aligned}
\frac{d C_{B P}}{d t} & =r_{B P} C_{B P}\left(\mu_{B P, l o q}-\tilde{a}_{B P}\right), \\
\tilde{a}_{B P} & =\frac{a_{m a x-B P}}{1+K_{a-B P, l o q} C_{l o q}+K_{a-B P, h i q} C_{h i q}} .
\end{aligned}
$$

$$
\tilde{a}_{B P}=\frac{a_{\max -B P}}{K_{a-B P, l o q}} \cdot \frac{1}{\frac{1}{K_{a-B P, l o q}}+C_{l o q}+\frac{K_{a-B P, h i q}}{K_{a-B P, l o q}} C_{h i q}} \quad \rightarrow \quad \frac{\vartheta_{1}}{C_{l o q}+\vartheta_{2} C_{h i q}}
$$

Additionally, we identified the rescaling limit, $a_{\max -B P}, K_{a-B P, h i q}, K_{a-B P, l o q} \rightarrow$ $\infty$ that enables deriving two effective finite parameter expressions $\vartheta_{1}=$ $a_{\max -B P} / K_{a-B P, l o q}, \vartheta_{2}=K_{a-B P, h i q} / K_{a-B P, l o q}$, which control the effective specific death rate $\tilde{a}_{B P}$. The rescaled expression becomes

Singular limits leading to steady-state approximations usually require evaluating more than a single biokinetic term on the right hand side of the equation system. The following identified singular limit involves five ordinary differential equations of the system and six parameter limits: $\vartheta_{1}, \mu_{\max -B P}, k_{B P, l o q}$, $k_{r-B P, h i q}, k_{r-B P, l o q}, m_{\max -B P} \rightarrow \infty$.

$$
\begin{aligned}
\frac{d C_{B P}}{d t} & =r_{B P} C_{B P}\left(\mu_{B P, l o q}-\tilde{a}_{B P}\right) \\
\frac{d r_{B P}}{d t} & =\mu_{B P, l o q}\left(\Phi_{B P}-r_{B P}\right), \\
\Phi_{B P} & =\frac{C_{h i q} / k_{r-B P, h i q}+C_{l o q} / k_{r-B P, l o q}}{1+C_{h i q} / k_{r-B P, h i q}+C_{l o q} / k_{r-B P, l o q}} \\
\frac{d C_{I}}{d t} & \propto r_{B P} C_{B P} \tilde{a}_{B P} \\
\frac{d C_{h i q}}{d t} & \propto r_{B P} C_{B P} m_{\max -B P} \\
\frac{d C_{l o q}}{d t} & \propto r_{B P} C_{B P} m_{\max -B P}
\end{aligned}
$$


Here, $\Phi_{B P}$ is a limiting factor of activity increase and $m_{\max -B P}$ is the maximum specific maintenance rate of bacterial pesticide degraders. First, if $\mu_{\max -B P}, k_{B P, l o q}, k_{r-B P, h i q}, k_{r-B P, l o q} \rightarrow \infty$, then $r_{B P} \rightarrow 0$. Because $\vartheta_{1}$, $m_{\max -B P} \rightarrow \infty$ at the same time, we see that $C_{I}, C_{h i q}$ and $C_{l o q}$ become infinitely sensitive to changes in $r_{B P}$, and the combination $r_{B P} \vartheta_{1}$ or $r_{B P} m_{\max -B P}$ remains finite. We chose to define a renormalized variable $\tilde{r}_{B P}=r_{B P} \vartheta_{1}$, thereby removing information about the absolute scale of the activity level of bacterial pesticide degraders. The equations then read:

$$
\begin{aligned}
\frac{d C_{B P}}{d t} & =\tilde{r}_{B P} C_{B P}\left(\tilde{\mu}_{B P, l o q}-\frac{1}{C_{l o q}+\vartheta_{2} C_{h i q}}\right), \\
\tilde{\mu}_{B P, l o q} & =\frac{\vartheta_{4} C_{l o q}}{\vartheta_{5}+C_{l o q}} \\
\frac{1}{\mu_{\text {max }-B P}} \frac{d \tilde{r}_{B P}}{d t} & =\frac{\tilde{\mu}_{B P, l o q}}{\vartheta_{4}}\left(\Phi_{B P} \vartheta_{1}-\tilde{r}_{B P}\right) \\
\frac{d C_{I}}{d t} & \propto \tilde{r}_{B P} C_{B P} \frac{1}{C_{l o q}+\vartheta_{2} C_{h i q}} \\
\frac{d C_{h i q}}{d t} & \propto \tilde{r}_{B P} C_{B P} \vartheta_{8} \\
\frac{d C_{l o q}}{d t} & \propto \tilde{r}_{B P} C_{B P} \vartheta_{8}
\end{aligned}
$$

with $\vartheta_{4}=\frac{\mu_{\max -B P}}{\vartheta_{1}}, \vartheta_{5}=\frac{\mu_{\max -B P}}{k_{B P, l o q}}, \vartheta_{8}=\frac{m_{\max -B P}}{\vartheta_{1}}$. Inspecting Eq. 24, we see that $\varepsilon=1 / \mu_{\max -B P}$ is a small parameter that separates the timescale of the renormalized variable $\tilde{r}_{B P}$. Evaluating this limit has the biological interpretation as a natural steady-state limit in which the physiological state of bacterial pesticide degraders is determined by the scaled substrate response function $\Phi_{B P}$ (Eq. 18; Blagodatsky and Richter (1998)). The ODE for the physiological state index of specific pesticide degraders Eq. 24 is transformed into an algebraic equation that can be substituted into the original ODE 
system:

$$
\tilde{r}_{B P}=\Phi_{B P} \vartheta_{1}
$$

As a result, singular limits identified via manifold boundaries decrease the dimension of the ODE system.

Finally, interpolating limits dictate the order of a reaction rate. The limit in which both Monod constants $\vartheta_{4}, \vartheta_{5} \rightarrow \infty$ in Eq. 23 become infinite together identifies a linear rate with emergent rate constant $\vartheta_{9}=\vartheta_{4} / \vartheta_{5}$,

$$
\tilde{\mu}_{B P, l o q}=\frac{\vartheta_{4} C_{l o q}}{\vartheta_{5}+C_{l o q}}=\frac{\vartheta_{4}}{\vartheta_{5}} \frac{C_{l o q}}{1+\frac{C_{l o q}}{\vartheta_{5}}} \quad \rightarrow \quad \vartheta_{9} C_{l o q},
$$

whereas the alternative limit $\vartheta_{5} \rightarrow 0$ would have corresponded to a saturating approximation of Monod kinetics (cf. Fig. 2).

\section{Model performance}

By design, the full and reduced models give an equally good fit within the expected variance of experimental uncertainties to data from the MCPA + Litter treatment (Fig. 6, black dots) with cost function value $J_{\text {full }}=7.6$ for the full model and $J_{\text {reduced }}=6.7$ for the reduced model. Time series generated from the reduced model (Fig. 6, red dashed lines) for fungal C, specific degrader $\mathrm{C}, \mathrm{DOC}$ and $\mathrm{CO}_{2}-\mathrm{C}$ give almost an exact match with the corresponding time series of the full model (Fig. 6, dark gray solid lines). For MCPA, the lag phase of MCPA degradation is reflected slightly better than by the reduced model. In contrast to the full model, steady-state conditions for the TOC pool are not yet reached after 25 days in the reduced model. Furthermore, bacterial C dynamics notably differ between the full and the 

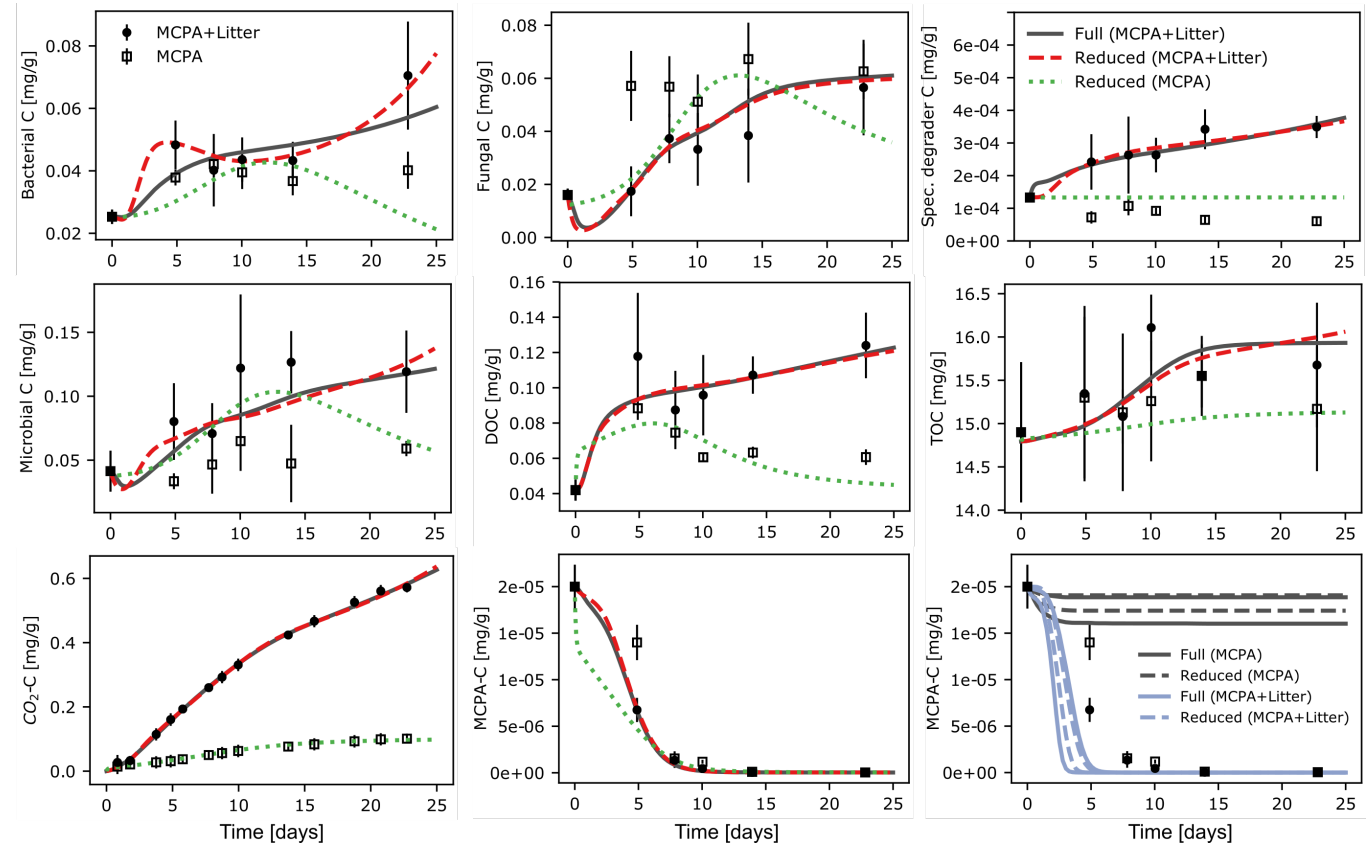

Figure 6: Model calibration and prediction. Full (dark gray solid lines) and reduced (red dashed lines) models give an equally good fit to data from the MCPA + Litter treatment (circles, $J_{\text {full }}=7.6, J_{\text {reduced }}=6.7$ ). The fit to MCPA treatment data (squares) of the reduced model (green dotted lines) is worse $\left(J_{\text {reduced }}=83.5\right)$, because microbial dynamics are not fully captured. 95\% confidence intervals for MCPA predictions between experimental treatments are shown in the bottom right panel. Predictions between experimental treatments of the full and reduced models (predicted data set in round brackets) derived from an MCMC parameter ensemble are well-constrained given the observed MCPA-C range, but do not match experimental observations. 
reduced model, because the first MBAM iteration identifies a better local cost function minimum.

The fit of the reduced model to MCPA treatment data (Fig. 6, green dotted line and black squares) is worse $\left(J_{\text {reduced,MCPA }}=83.5\right)$. The reduced model captures neither the dynamics of specific MCPA degrading bacteria nor the decelerated degradation of MCPA in the initial phase of the experiment without litter addition. When fit to MCPA treatment data, the eigenvalue spectrum of the reduced 27 parameter model broadens again and information on seven model parameters is lost (Appendix F: Fig. F.9). Model predictions of MCPA dynamics for shifted boundary conditions according to different experimental treatments are shown in the bottom right panel of Fig. 6. Full and reduced models were both calibrated based on MCPA + Litter data and used to predict the observed MCPA dynamics in the experiment without litter addition (MCPA) and vice-versa. The $95 \%$ confidence intervals for model predictions derived from a Bayesian ensemble of the full and reduced models for both data sets are informative (the limits span less than $15 \%$ of the total MCPA-C concentration range), but do not match experimental observations. When calibrated based on MCPA + Litter data, both the reduced and full models predict MCPA persistence in soil after four days when no litter is added to the system. This contrasts to the observed complete dissipation in the experiment (Fig. 6). Conversely, when calibrated based on MCPA data, both models over-predict the acceleration of MCPA degradation in the presence of additional litter $\mathrm{C}$ input into the system. 


\section{Impact of data availability on model reduction}

Using the reduced 27 parameter model (Appendix A: Table A.4) as a starting point, the effect of coarsening the observations from functional gene measurements to bulk microbial biomass and further to MCPA concentration and heterotrophic respiration is depicted in Fig. 5bc. After coarsening to bulk biomass (Fig. 5b), six eigenvalues become significantly smaller than unity. The parameter limits correspond to $\vartheta_{24}, \vartheta_{11}, \vartheta_{12}, a_{m a x-F}, K_{a-F, h i q}, K_{a-F, l o q} \rightarrow$ 0 . The resulting discarding limits render the microbial death rate linear and remove the fungal death rate as well as the dependence of $\mathrm{C}$ cycling on the dynamics of specific pesticide degraders (Appendix A: Table A.5; $\mathrm{M}=7$, $\mathrm{N}=21)$.

Coarsening the observations further to system input-output relations (only MCPA and CO2-C) identifies an 18 parameter model that describes the dynamics of MCPA degradation and heterotrophic respiration (Fig. 5c). Here, another discarding limit $\left(\vartheta_{21} \rightarrow 0\right)$ corresponds to a steady-state limit that fixes the insoluble organic matter pool $\left(C_{I}\right)$ to its initial value (Appendix A: Table A.6; $\mathrm{M}=6, \mathrm{~N}=18)$.

\section{Global sensitivity analysis}

The Morris procedure (Morris, 1991), also called the Elementary Effect Test (EET, Pianosi et al. (2016)), was applied to the parameters of the full PECCAD ODE model in order to compare sampling-based criteria for factor fixing and screening in global sensitivity applications to the results of the MBAM. The Morris Method is a derivative-based OAT (One-step-At-a-Time) method that generates two sensitivity measures for each model parameter: $\mu^{*}$, the Morris mean and $\sigma$, the standard deviation. The Morris mean is a mea- 
sure of the direct influence of a parameter on the model performance metric. The standard deviation measures nonlinear or interaction effects. Details on the parameter sampling design and interpretation of Morris pairs are provided in Appendix E. Fig. 7 shows the normalized $\ell_{2}$-norm of the Morris mean $\mu^{*}$ and standard deviation $\sigma\left(\ell_{2}=\sqrt{\mu^{* 2}+\sigma^{2}}\right)$ and the relative reduction in highest posterior density of parameter values derived from the Bayesian model calibration. Out of 20 model parameters with non-trivial $\ell_{2^{-}}$ norm $>0.01,15$ parameters agree with the MBAM results. In contrast to MBAM, $q_{\max -F}, k_{r-F, l o q}, K_{I_{F}}, k_{r-B, l o q}$ and $k_{m-B, h i q}$ have significant effects on the goodness-of-fit metric. Two parameters that are essential to the reduced model $\left(\mu_{\max -B}\right.$ and $\left.k_{B P, l o q}\right)$ were not identified by the Morris method. The results of the Bayesian model analysis shows that the $95 \%$ highest posterior density of 20 parameters still spans more than $20 \%$ of the respective prior range after optimization. No clear cutoff that defines identifiability exists.

\section{Discussion}

Parameter equifinality in soil biogeochemical modeling

This analysis highlights the tension between small-scale process complexity and emergent simplicity of model structures in soil biogeochemical modeling. A local sensitivity analysis around published optimal parameter values of five models from the literature shows that the inverse problem in soil biogeochemical modeling is extremely ill-posed (Engl et al., 2009). When comparing to similar sloppy eigenvalue distributions observed in systems biology models (Gutenkunst et al., 2007; Tönsing et al., 2014), it seems very difficult to obtain identifiable parameter sets for nonlinear soil $\mathrm{C}$ models, even when 


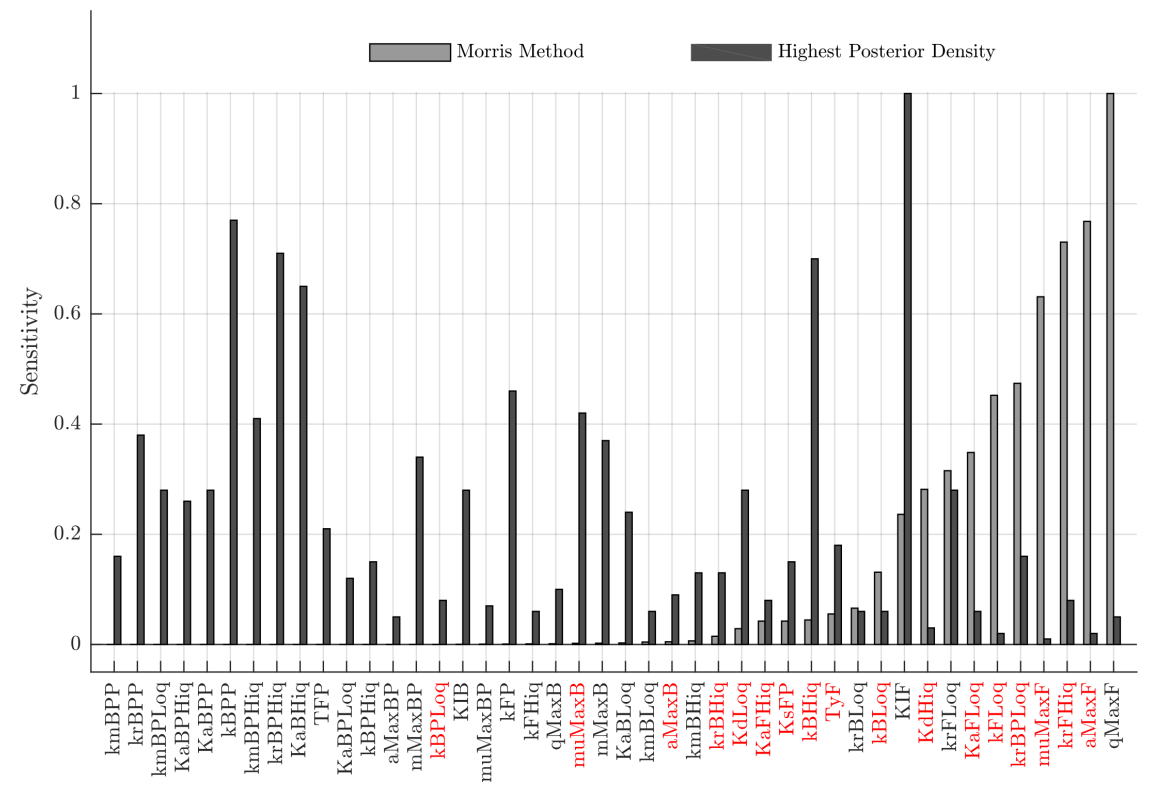

Figure 7: Comparison of MBAM results to sampling-based sensitivity metrics. Axis labels highlighted in red are PECCAD kinetic model parameters that were identified as relevant by the MBAM. The normalized $\ell_{2}$-norm of 25,000 Morris pairs (gray, sorted in ascending order) identifies a 20 parameter subset that influences the model performance metric. The $95 \%$ highest posterior density of 20 parameters spans more than $20 \%$ of their prior range after Bayesian model calibration. Overall, the screening results agree with the MBAM. Note, however, that the most influential parameter $q_{\max -F}$ identified by the Morris method and with significant reduction in highest posterior density is not part of the reduced model. 
the data are continuous and essentially noiseless. For the most complex model, we furthermore observed no difference in the spectral width of the spectrum for continuous versus real data (compare Fig. 3e and Fig. 4, left column). When nonlinearities are taken into account, the local topography of the cost landscape was confirmed by the spectrum of principal component eigenvalues of a global Markov Chain Monte Carlo parameter ensemble (Fig. 3f). According to the Cramer-Rao bound which places a lower bound on the covariance of parameter estimates, inferring the parameter combination corresponding to the smallest eigenvalue in Fig. 3 would require approximately $10^{22}$ more data than for the best-constrained combination. To put this into perspective, this would be three times as difficult as inferring microscopic details from the diffusion equation (Machta et al., 2013). Our results are consistent with previous discussions on equifinality of soil biogeochemical model parameters with respect to observations (Wetterstedt and Ågren, 2011; Sierra et al., 2015a; Wang et al., 2015; Pagel et al., 2016). For the simple microbial soil C model with nonlinear interactions (German et al., 2012), the Manifold Boundary Approximation Method confirms that only the ratio of half saturation constant and maximum reaction rate $\vartheta_{1}=V_{\max } / K_{S}$ can be identified from bulk soil incubation data (Fig. 4, Sierra et al. (2015a)).

\section{Implications of sloppiness for soil biogeochemical modeling}

One important criterion to improve mechanistic modeling frameworks for complex systems is the ability to adequately encode model complexity (Schöniger et al., 2014; Getz et al., 2018; Höge et al., 2018). For sloppy biogeochemical models the complexity is given by the effective dimensionality of the model prediction manifold. We find that the effective dimensionality of soil 
biogeochemical model predictions is consistently lower than the number of nominal model parameters, i.e. predictions from complicated soil $\mathrm{C}$ models vary in far fewer ways than their complexity would indicate. The analysis of the PECCAD ODE model shows that the full and reduced models with 59 and 27 parameters respectively fit the data equally well and make statistically almost indistinguishable predictions with low variance, despite large uncertainties in the original parameter space (Fig. 6). Although the model is formulated in terms of multi-substrate Monod kinetics (Lendenmann and Egli, 1998), it effectively acts as if most biokinetic functions were linear functions of substrate concentrations. The reverse argument is that the current trend of adding complexity to soil biogeochemical models produces diminishing returns in fidelity at the cost of decreased system understanding. This is because model behavior largely depends only upon a few effective model parameter combinations and large regions in parameter space map to small regions on the prediction manifold. In fact, information criteria that are commonly used in biogeochemical model selection scenarios likely overestimate the predictive power of models (LaMont and Wiggins, 2016; Mattingly et al., 2018). Given the current trend towards more nonlinear soil C models and the need to distinguish between competing model structures, it would be interesting to revisit recent model-data integration studies (e.g. Sulman et al. (2018)) in the presented framework.

\section{Model reduction reveals key processes and conceptual model uncertainty}

Since non-identifiable model parameters do not necessarily lead to imprecise model predictions, we find that the principle of parsimony is solely reflected in emergent soil biogeochemical model structures. As will be discussed in 
detail for the PECCAD model below, model reduction by the MBAM can reveal conceptual model uncertainty in soil biogeochemical modeling. The analysis cautions against using overly complicated models that still turn out to be structurally weak.

Possible regulation mechanisms of MCPA degradation have been extensively discussed in Poll et al. (2010); Pagel et al. (2016). Based on inverse modeling with PECCAD, Pagel et al. (2016) concluded that fungal dynamics play a crucial role for matter cycling in the detritusphere (i.e., the soil influenced by litter). They found that MCPA degradation in soil was likely predominantly regulated by co-metabolic degradation via litter-stimulated fungal growth. Uncertainty in this statement stems from the fact that their results were based on the interpretation of single parameter values with high uncertainty (Pareto ranges for 26 out of 59 biokinetic parameters were equal to their respective prior range after optimization). Systematic model reduction of PECCAD ODE by the MBAM (Appendix S1: Table A.4) reflects the reported dominance of co-metabolic over direct MCPA degradation in the study by Pagel et al. (2016).

In the reduced PECCAD ODE model, MCPA degradation is clearly controlled by litter $\mathrm{C}$ input. The fraction of $C_{\text {loq }}$ transported into the system stimulates fungal growth. The specific growth rate of fungi is simply a linear function of substrate concentration. The emergent microbial control knob of MCPA degradation is an effective renormalized rate $\left(\vartheta_{25}=\frac{k_{F, l o q}}{T_{y-F} K_{s-F, P}}\right)$ that depends on the substrate affinity of fungi to low quality $\mathrm{C}\left(k_{F, l o q}\right)$ and cometabolic pesticide transformation kinetics $\left(K_{s-F, P}\right)$, as well as the capacity of fungi to transform MCPA into high quality $\mathrm{C}$ substrates for growth $\left(T_{y-F}\right)$. 
Growth of bacteria is the only microbial process that contributes to degradation of high quality $\mathrm{C}$, whereas specific pesticide degraders exclusively grow on low quality $\mathrm{C}$. Their dynamics are otherwise detached from $\mathrm{C}$ cycling and MCPA turnover. In contrast, it has repeatedly been observed that the activity and abundance of the population of specific MCPA degraders increase in the presence of their preferred growth substrate (Poll et al. (2010); Saleh et al. (2016)). The experimental data of the Litter + MCPA treatment (total abundance of functional genes of specific MCPA degraders) does not contain enough information on the dynamics of specific pesticide degraders to accordingly constrain the model structure of the PECCAD ODE model. Most biokinetic parameters related to direct MCPA degradation are irrelevant for model behavior. As a result, the simulated specific degrader dynamics by the reduced model do not match experimental observations across different treatments, and the model fails in predicting MCPA dynamics. Similar conclusions on the representation of microbial dynamics based on computationally expensive multiobjective calibration of multimodal data ((Wöhling et al., 2013)) were drawn in the original study (Pagel et al. (2016)). Although unintuitive, data-driven model reduction highlights the need to increase the structural complexity of the PECCAD ODE model and to refine the process description of direct pesticide degradation.

Optimized parameter values of the reduced model (Appendix S1: Table A.7) categorize fungi as copiotrophic organisms ((Fierer et al., 2007)) in both experimental treatments. The value of the activity inhibition coefficient $k_{r-F, h i q}$ at the lower bound of its physiological range shows that fungi respond extremely fast to supply of high quality C. This finding is in line with (Ingw- 
ersen et al., 2008; Pagel et al., 2016), who also reported a high sensitivity of fungal activity to low concentrations of easily degradable substrates. Early onset of activity was interpreted as being stimulated by intermediate degradation products of high quality C-derived extracellular enzymes that induce enzyme production (Allison et al., 2010). Concurrently, optimized values for substrate efficiencies $\left(Y_{s}\right)$ of fungi are much higher than for bacteria and specific pesticide degraders. Mortality rates could only be estimated from MCPA treatment data (Appendix S1: Table A.7). The value of the maximum specific death rate of fungi $\left(a_{\max -F}=1.76 \mathrm{~d}^{-1}\right)$ is close to the values reported for copiotrophic organisms in other studies (Zelenev et al., 2005; Monga et al., 2014).

Overall, the results of the PECCAD ODE reduction show that the mathematical specification of biokinetic functions in terms of multi-substrate Monod kinetics is too strong an assumption. It is mostly sufficient to model $\mathrm{C}$ cycling rates as linear functions of substrate concentration. Steady-state modeling of bacterial and specific pesticide degrader activity is a nontrivial result of the reduction process. While the order of biogeochemical reaction rates changes upon model reduction, microbes still utilize multiple $\mathrm{C}$ substrates for growth. The feedback structure between microbial populations and $\mathrm{C}$ sources of different quality, originally formulated in terms of multi-substrate Monod kinetics, is preserved. As model reduction can directly alter model structure, this emphasizes our notion of soil as a complex, dynamic system. Model structure is deemphasized later in the reduction process, upon coarsegraining of observations. The steady-state assumption for the SOM pool prevalent in the early soil C modeling literature (Jenkinson, 1990; Parton 
et al., 1987; Carvalhais et al., 2008) is supported only for input-output observations (Appendix S1: Table A.6). Systematically coarsening observations enables assessing which type of mechanistic information can be transferred across the different scales of observation (Getz et al., 2018) at which the relevant research questions are being asked. For example, the fungal substrate affinity coefficient for growth on low quality carbon in PECCAD ODE is a parameter that remains relevant as the scale of observation grows (Appendix S1: Tables A.4 to A.6).

\section{Comparison of the MBAM with sampling-based global sensitivity analysis}

The results of the MBAM agree well with global sensitivity measures derived from the Morris method and Bayesian model calibration (Fig. 7). In contrast to conventional global sensitivity methods (Pianosi et al., 2016), the MBAM does not rely on sampling of the parameter space, but explores the model output space by solving the geodesic equation. We found that LatinHypercube sampling of the parameter space of the PECCAD ODE model proved difficult, because the rate of failure of numerical simulations averaged $76 \%$. Three times as many function evaluations were thus required to achieve the stated number of sensitivity evaluations. The sensitivity results are easy to translate into model simplifications because parameters that do not affect model output are identified iteratively at the respective manifold boundaries. While factor fixing in GSA methods will reduce the number of model parameters that have to be considered, e.g., in refined calibrations (Van Werkhoven et al., 2009), it makes the model conceptually simpler only if a parameter can be set to zero, thereby removing the corresponding model term. The MBAM directly acts on the model structure and thus remedies 
drawbacks of GSA methods in biogeochemical modeling by translating sensitivity measures into the nontrivial model simplifications presented in this study.

\section{Conclusions}

In this paper, we have presented an application of the Manifold Boundary Approximation Method (MBAM) to a complex soil biogeochemical model with reported parameter equifinality issues. Our study demonstrates that methods from information geometry can improve understanding of a model's structural limitations. Combining many empirical laws into complex nonlinear biogeochemical models leads to sloppiness. Sloppiness can be removed because the boundary complex of the model manifold corresponds to natural, mechanistically-meaningful limits of biogeochemical models: interpolating limits dictate the order of a biogeochemical reaction rate, singular limits lead to a separation of timescales in the system, and discarding limits remove irrelevant pathways in the model. These approximations are valid, because the prediction manifolds of biogeochemical models have a low effective dimensionality.

In our example application, the approach was used to conceptually identify missing process structures that lead to a mismatch between model predictions and experimental observations, i.e. to falsify the PECCAD ODE model structure. Due to computational accessibility for ODE models, the MBAM can be integrated into mechanistic biogeochemical modeling frameworks that require a model simplification step to recover parsimony. Whereas parameter identifiability studies fall short in distinguishing between model struc- 
tures that explain a set of observations (Luo et al., 2009), the MBAM is especially suited for the task, because it directly reveals conceptual uncertainty in the original model formulation. Future work should explore the use of the MBAM as a benchmarking algorithm for GSA parameter screening applications (Sarrazin et al., 2016) and investigate the modeling hierarchy in linear soil C models (Sierra and Müller, 2015) which start from a general model that can accommodate specific realizations of model structure for specific modeling objectives. From a computational point of view it would be interesting to compare the performance of sparse model selection techniques (Kügler et al., 2009; Zarzer, 2009; Hastie et al., 2015) when applied to sloppy models of soil biogeochemistry.

\section{Acknowledgments}

The authors thank the German Research Foundation (DFG) for financial support of the project within the Research Training Group Integrated Hydrosystem Modelling (RTG 1829) and the Collaborative Research Center CAMPOS - Catchments as Reactors: Metabolism of Pollutants on the Landscape Scale (SFB 1253) at the University of Hohenheim.

\section{References}

Allison, S.D., 2017. Building Predictive Models for Diverse Microbial Communities in Soil, in: Microbial Biomass: A Paradigm Shift in Terrestrial Biogeochemistry. World Scientific, pp. 141-166.

Allison, S.D., Weintraub, M.N., Gartner, T.B., Waldrop, M.P., 2010. 
Evolutionary-economic principles as regulators of soil enzyme production and ecosystem function, in: Soil Enzymology. Springer, pp. 229-243.

Ballantyne IV, F., Billings, S.A., 2018. Model formulation of microbial CO2 production and efficiency can significantly influence short and long term soil C projections. The ISME journal , 1.

Bates, D.M., Watts, D.G., 1988. Nonlinear regression analysis and lts applications. 519.536 B3, Wiley, New York, NY.

Baveye, P.C., Otten, W., Kravchenko, A., Balseiro-Romero, M., Beckers, E., Chalhoub, M., Darnault, C., Eickhorst, T., Garnier, P., Hapca, S., et al., 2018. Emergent properties of microbial activity in heterogeneous soil microenvironments: different research approaches are slowly converging, yet major challenges remain. Frontiers in Microbiology 9, 1929.

Beven, K., 2006. A manifesto for the equifinality thesis. Journal of Hydrology $320,18-36$.

Bjork, D.J., 2018. An algorithm for symbolic computing of singular limits of dynamical systems .

Blagodatsky, S., Richter, O., 1998. Microbial growth in soil and nitrogen turnover: a theoretical model considering the activity state of microorganisms. Soil Biology and Biochemistry 30, 1743-1755.

Bohner, G., Venkataraman, G., 2017. Identifiability, reducibility, and adaptability in allosteric macromolecules. The Journal of General Physiology $149,547-560$. 
Brun, R., Reichert, P., Künsch, H.R., 2001. Practical identifiability analysis of large environmental simulation models. Water Resources Research 37, $1015-1030$.

Carvalhais, N., Reichstein, M., Seixas, J., Collatz, G.J., Pereira, J.S., Berbigier, P., Carrara, A., Granier, A., Montagnani, L., Papale, D., et al., 2008. Implications of the carbon cycle steady state assumption for biogeochemical modeling performance and inverse parameter retrieval. Global Biogeochemical Cycles 22.

Chachra, R., Transtrum, M.K., Sethna, J.P., 2012. Structural susceptibility and separation of time scales in the van der Pol oscillator. Physical Review E 86, 026712.

Chib, S., Greenberg, E., 1995. Understanding the Metropolis-Hastings algorithm. The American Statistician 49, 327-335.

Do Carmo, M.P., 2016. Differential Geometry of Curves and Surfaces: Revised and Updated Second Edition. Courier Dover Publications.

Engl, H.W., Flamm, C., Kügler, P., Lu, J., Müller, S., Schuster, P., 2009. Inverse problems in systems biology. Inverse Problems 25, 123014.

Fierer, N., Bradford, M.A., Jackson, R.B., 2007. Toward an ecological classification of soil bacteria. Ecology 88, 1354-1364.

Georgiou, K., Abramoff, R.Z., Harte, J., Riley, W.J., Torn, M.S., 2017. Microbial community-level regulation explains soil carbon responses to longterm litter manipulations. Nature Communications 8, 1223. 
German, D.P., Marcelo, K.R., Stone, M.M., Allison, S.D., 2012. The Michaelis-Menten kinetics of soil extracellular enzymes in response to temperature: a cross-latitudinal study. Global Change Biology 18, 1468-1479.

Getz, W.M., Marshall, C.R., Carlson, C.J., Giuggioli, L., Ryan, S.J., Romañach, S.S., Boettiger, C., Chamberlain, S.D., Larsen, L., D’Odorico, P., et al., 2018. Making ecological models adequate. Ecology Letters 21, $153-166$.

Gharasoo, M., Thullner, M., Elsner, M., 2017. Introduction of a new platform for parameter estimation of kinetically complex environmental systems. Environmental Modelling \& Software 98, 12-20.

Gómez, H.F., Hucka, M., Keating, S.M., Nudelman, G., Iber, D., Sealfon, S.C., 2016. Moccasin: converting MATLAB Ode models to SBML. Bioinformatics 32, 1905-1906.

Gutenkunst, R., 2007. Sloppiness, modeling, and evolution in biochemical networks. Dissertation. Cornell University .

Gutenkunst, R.N., Waterfall, J.J., Casey, F.P., Brown, K.S., Myers, C.R., Sethna, J.P., 2007. Universally sloppy parameter sensitivities in systems biology models. PLoS Computational Biology 3, e189.

Hararuk, O., Smith, M.J., Luo, Y., 2015. Microbial models with datadriven parameters predict stronger soil carbon responses to climate change. Global Change Biology 21, 2439-2453.

Hastie, T., Tibshirani, R., Wainwright, M., 2015. Statistical learning with sparsity: the lasso and generalizations. CRC Press. 
Höge, M., Wöhling, T., Nowak, W., 2018. A primer for model selection: The decisive role of model complexity. Water Resources Research 54, 16881715 .

Houska, T., Kraft, P., Liebermann, R., Klatt, S., Kraus, D., Haas, E., Santabarbara, I., Kiese, R., Butterbach-Bahl, K., Müller, C., et al., 2017. Rejecting hydro-biogeochemical model structures by multi-criteria evaluation. Environmental Modelling \& Software 93, 1-12.

Ingwersen, J., Poll, C., Streck, T., Kandeler, E., 2008. Micro-scale modelling of carbon turnover driven by microbial succession at a biogeochemical interface. Soil Biology and Biochemistry 40, 864-878.

Iooss, B., Lemaître, P., 2015. A review on global sensitivity analysis methods, in: Uncertainty management in simulation-optimization of complex systems. Springer, pp. 101-122.

Jenkinson, D.S., 1990. The turnover of organic carbon and nitrogen in soil. Phil. Trans. R. Soc. Lond. B 329, 361-368.

Jeong, J.E., Zhuang, Q., Transtrum, M.K., Zhou, E., Qiu, P., 2018. Experimental design and model reduction in systems biology. Quantitative Biology 6, 287-306.

Keenan, T.F., Davidson, E.A., Munger, J.W., Richardson, A.D., 2013. Rate my data: quantifying the value of ecological data for the development of models of the terrestrial carbon cycle. Ecological Applications 23, 273-286.

Kuehn, C., 2016. Multiple Time Scale Dynamics. volume 1. Springer. 
Kügler, P., 2012. Moment fitting for parameter inference in repeatedly and partially observed stochastic biological models. PloS One 7, e43001.

Kügler, P., Gaubitzer, E., Müller, S., 2009. Parameter Identification for Chemical Reaction Systems Using Sparsity Enforcing Regularization: A Case Study for the Chlorite- Iodide Reaction. The Journal of Physical Chemistry A 113, 2775-2785.

LaMont, C.H., Wiggins, P.A., 2016. Information-based inference in sloppy and singular models. stat 1050, 24.

Lendenmann, U., Egli, T., 1998. Kinetic models for the growth of Escherichia coli with mixtures of sugars under carbon-limited conditions. Biotechnology and Bioengineering 59, 99-107.

Link, K., Stobb, M., Di Paola, J., Neeves, K., Fogelson, A., Sindi, S., Leiderman, K., 2018. A local and global sensitivity analysis of a mathematical model of coagulation and platelet deposition under flow. PloS One 13, e0200917.

Lombardo, D.M., Rappel, W.J., 2017. Systematic reduction of a detailed atrial myocyte model. Chaos: An Interdisciplinary Journal of Nonlinear Science 27, 093914.

Luo, Y., Weng, E., Wu, X., Gao, C., Zhou, X., Zhang, L., 2009. Parameter identifiability, constraint, and equifinality in data assimilation with ecosystem models. Ecological Applications 19, 571-574.

Luo, Z., Wang, E., Shao, Q., Conyers, M.K., Li Liu, D., 2016. Confidence in soil carbon predictions undermined by the uncertainties in observations 
and model parameterisation. Environmental Modelling \& Software 80, 26-32.

Luo, Z., Wang, E., Sun, O.J., 2017. Uncertain future soil carbon dynamics under global change predicted by models constrained by total carbon measurements. Ecological Applications 27, 1001-1009.

Machta, B.B., Chachra, R., Transtrum, M.K., Sethna, J.P., 2013. Parameter space compression underlies emergent theories and predictive models. Science 342, 604-607.

Manzoni, S., Moyano, F., Kätterer, T., Schimel, J., 2016. Modeling coupled enzymatic and solute transport controls on decomposition in drying soils. Soil Biology and Biochemistry 95, 275-287.

Manzoni, S., Porporato, A., 2009. Soil carbon and nitrogen mineralization: theory and models across scales. Soil Biology and Biochemistry 41, 13551379 .

Manzoni, S., Schaeffer, S., Katul, G., Porporato, A., Schimel, J., 2014. A theoretical analysis of microbial eco-physiological and diffusion limitations to carbon cycling in drying soils. Soil Biology and Biochemistry 73, 69-83.

Mašić, A., Udert, K.M., Villez, K., 2016. Global parameter optimization for biokinetic modeling of simple batch experiments. Environmental Modelling \& Software 85, 356-373.

Mattingly, H.H., Transtrum, M.K., Abbott, M.C., Machta, B.B., 2018. Maximizing the information learned from finite data selects a simple model. Proceedings of the National Academy of Sciences 115, 1760-1765. 
Monga, O., Garnier, P., Pot, V., Coucheney, E., Nunan, N., Otten, W., Chenu, C., 2014. Simulating microbial degradation of organic matter in a simple porous system using the 3-D diffusion-based model MOSAIC. Biogeosciences 11, 2201-2209.

Morris, M.D., 1991. Factorial sampling plans for preliminary computational experiments. Technometrics 33, 161-174.

Myers, C.R., Gutenkunst, R.N., Sethna, J.P., 2007. Python unleashed on systems biology. Computing in Science \& Engineering 9, 34-37.

Nielsen, F., 2018. An elementary introduction to information geometry. arXiv preprint arXiv:1808.08271 .

Nikšić, T., Vretenar, D., 2016. "Sloppy" nuclear energy density functionals: Effective model reduction. Physical Review C 94, 024333.

Pagel, H., Ingwersen, J., Poll, C., Kandeler, E., Streck, T., 2014. Microscale modeling of pesticide degradation coupled to carbon turnover in the detritusphere: model description and sensitivity analysis. Biogeochemistry $117,185-204$.

Pagel, H., Poll, C., Ingwersen, J., Kandeler, E., Streck, T., 2016. Modeling coupled pesticide degradation and organic matter turnover: from gene abundance to process rates. Soil Biology and Biochemistry 103, 349-364.

Paré, P.E., Wilson, A.T., Transtrum, M.K., Warnick, S.C., 2015. A unified view of balanced truncation and singular perturbation approximations, in: American Control Conference, IEEE. pp. 1989-1994. 
Parton, W., Schimel, D.S., Cole, C., Ojima, D., 1987. Analysis of factors controlling soil organic matter levels in Great Plains Grasslands 1. Soil Science Society of America Journal 51, 1173-1179.

Pianosi, F., Beven, K., Freer, J., Hall, J.W., Rougier, J., Stephenson, D.B., Wagener, T., 2016. Sensitivity analysis of environmental models: A systematic review with practical workflow. Environmental Modelling \& Software $79,214-232$.

Pianosi, F., Sarrazin, F., Wagener, T., 2015. A MATLAB toolbox for global sensitivity analysis. Environmental Modelling \& Software 70, 80-85.

Poll, C., Pagel, H., Devers-Lamrani, M., Martin-Laurent, F., Ingwersen, J., Streck, T., Kandeler, E., 2010. Regulation of bacterial and fungal MCPA degradation at the soil-litter interface. Soil Biology and Biochemistry 42, $1879-1887$.

Press, W.H., Teukolsky, S.A., Vetterling, W.T., Flannery, B.P., 2007. Numerical recipes 3rd edition: The art of scientific computing. Cambridge University Press.

Saleh, O., Pagel, H., Enowashu, E., Devers, M., Martin-Laurent, F., Streck, T., Kandeler, E., Poll, C., 2016. Evidence for the importance of litter as a co-substrate for MCPA dissipation in an agricultural soil. Environmental Science and Pollution Research 23, 4164-4175.

Sarrazin, F., Pianosi, F., Wagener, T., 2016. Global sensitivity analysis of environmental models: convergence and validation. Environmental Modelling \& Software 79, 135-152. 
Savenije, H.H., 2001. Equifinality, a blessing in disguise? Hydrological Processes 15, 2835-2838.

Schöniger, A., Wöhling, T., Samaniego, L., Nowak, W., 2014. Model selection on solid ground: Rigorous comparison of nine ways to evaluate bayesian model evidence. Water resources research 50, 9484-9513.

Sheikholeslami, R., Razavi, S., Gupta, H.V., Becker, W., Haghnegahdar, A., 2018. Global sensitivity analysis for high-dimensional problems: How to objectively group factors and measure robustness and convergence while reducing computational cost. Environmental Modelling \& Software .

Shi, Z., Crowell, S., Luo, Y., Moore, B., 2018. Model structures amplify uncertainty in predicted soil carbon responses to climate change. Nature communications 9, 2171.

Sierra, C., Müller, M., Trumbore, S., et al., 2012. Models of soil organic matter decomposition: the soilr package, version 1.0. Geoscientific Model Development 5, 1045-1060.

Sierra, C.A., Malghani, S., Müller, M., 2015a. Model structure and parameter identification of soil organic matter models. Soil Biology and Biochemistry 90, 197-203.

Sierra, C.A., Müller, M., 2015. A general mathematical framework for representing soil organic matter dynamics. Ecological Monographs 85, 505-524.

Sierra, C.A., Trumbore, S.E., Davidson, E.A., Vicca, S., Janssens, I., 2015b. Sensitivity of decomposition rates of soil organic matter with respect to 
simultaneous changes in temperature and moisture. Journal of Advances in Modeling Earth Systems 7, 335-356.

Snowden, T.J., van der Graaf, P.H., Tindall, M.J., 2017. Methods of model reduction for large-scale biological systems: a survey of current methods and trends. Bulletin of mathematical biology 79, 1449-1486.

Soetaert, K., Petzoldt, T., et al., 2010. Inverse modelling, sensitivity and monte carlo analysis in $\mathrm{r}$ using package fme. Journal of Statistical Software $33,1-28$.

Stigter, J.D., Beck, M., Molenaar, J., 2017. Assessing local structural identifiability for environmental models. Environmental Modelling \& Software 93, 398-408.

Stone, J.V., 2013. Bayes' rule: A tutorial introduction to Bayesian analysis. Sebtel Press.

Strigul, N., Dette, H., Melas, V.B., 2009. A practical guide for optimal designs of experiments in the Monod model. Environmental Modelling \& Software 24, 1019-1026.

Sulman, B.N., Moore, J.A., Abramoff, R., Averill, C., Kivlin, S., Georgiou, K., Sridhar, B., Hartman, M.D., Wang, G., Wieder, W.R., et al., 2018. Multiple models and experiments underscore large uncertainty in soil carbon dynamics. Biogeochemistry , 1-15.

Tang, J., 2015. On the relationships between michaelis-menten kinetics, reverse michaelis-menten kinetics, equilibrium chemistry approximation 
kinetics and quadratic kinetics. Geoscientific Model Development Discussions 8, 7663-7691. doi:10.5194/gmdd-8-7663-2015.

Tang, J., Riley, W., 2013. A total quasi-steady-state formulation of substrate uptake kinetics in complex networks and an example application to microbial litter decomposition. Biogeosciences 10, 8329-8351.

Tönsing, C., Timmer, J., Kreutz, C., 2014. Cause and cure of sloppiness in ordinary differential equation models. Physical Review E 90, 023303.

Transtrum, M.K., 2016a. Manifold boundaries give" gray-box" approximations of complex models. arXiv preprint arXiv:1605.08705 .

Transtrum, M.K., 2016b. MBAM Source Code. https://github.com/ mktranstrum/MBAM.

Transtrum, M.K., Machta, B.B., Sethna, J.P., 2010. Why are nonlinear fits to data so challenging? Physical Review Letters 104, 060201.

Transtrum, M.K., Machta, B.B., Sethna, J.P., 2011. Geometry of nonlinear least squares with applications to sloppy models and optimization. Physical Review E 83, 036701.

Transtrum, M.K., Qiu, P., 2014. Model reduction by manifold boundaries. Physical Review Letters 113, 098701.

Transtrum, M.K., Qiu, P., 2016. Bridging mechanistic and phenomenological models of complex biological systems. PLoS Computational Biology 12, e1004915. 
Transtrum, M.K., Sarić, A.T., Stanković, A.M., 2018. Information Geometry Approach to Verification of Dynamic Models in Power Systems. IEEE Transactions on Power Systems 33, 440-450.

van Turnhout, A.G., Kleerebezem, R., Heimovaara, T.J., 2016. A toolbox to find the best mechanistic model to predict the behavior of environmental systems. Environmental Modelling \& Software 83, 344-355.

Van Werkhoven, K., Wagener, T., Reed, P., Tang, Y., 2009. Sensitivityguided reduction of parametric dimensionality for multi-objective calibration of watershed models. Advances in Water Resources 32, 1154-1169.

Verghese, G., 2009. Getting to the gray box: Some challenges for model reduction, in: American Control Conference, IEEE. pp. 5-6.

Vogel, L., Pot, V., Makowski, D., Garnier, P., Baveye, P., 2018. To what extent do uncertainty and sensitivity analyses help unravel the influence of microscale physical and biological drivers in soil carbon dynamics models? Ecological Modelling 383, 10-22.

Von Bertalanffy, L., 1968. General System Theory. New York 41973, 40.

Wang, G., Chen, S., 2013. Evaluation of a soil greenhouse gas emission model based on bayesian inference and mcmc: Model uncertainty. Ecological modelling 253, 97-106.

Wang, G., Jagadamma, S., Mayes, M.A., Schadt, C.W., Steinweg, J.M., Gu, L., Post, W.M., 2015. Microbial dormancy improves development and experimental validation of ecosystem model. The ISME journal 9, 226. 
Wang, Y., Chen, B., Wieder, W.R., Leite, M.C., Medlyn, B.E., Rasmussen, M., Smith, M.J., Agusto, F.B., Hoffman, F., Luo, Y., 2014. Oscillatory behavior of two nonlinear microbial models of soil carbon decomposition. Biogeosciences 11, 1817-1831.

Wetterstedt, J., Ågren, G., 2011. Quality or decomposer efficiency-which is most important in the temperature response of litter decomposition? a modelling study using the glue methodology. Biogeosciences 8, 477-487.

White, A., Tolman, M., Thames, H.D., Withers, H.R., Mason, K.A., Transtrum, M.K., 2016. The limitations of model-based experimental design and parameter estimation in sloppy systems. PLoS Computational Biology 12, e1005227.

Wieder, W.R., Allison, S.D., Davidson, E.A., Georgiou, K., Hararuk, O., He, Y., Hopkins, F., Luo, Y., Smith, M.J., Sulman, B., et al., 2015. Explicitly representing soil microbial processes in Earth system models. Global Biogeochemical Cycles 29, 1782-1800.

Wöhling, T., Gayler, S., Priesack, E., Ingwersen, J., Wizemann, H.D., Högy, P., Cuntz, M., Attinger, S., Wulfmeyer, V., Streck, T., 2013. Multiresponse, multiobjective calibration as a diagnostic tool to compare accuracy and structural limitations of five coupled soil-plant models and CLM3. 5. Water Resources Research 49, 8200-8221.

Zarzer, C.A., 2009. On Tikhonov regularization with non-convex sparsity constraints. Inverse Problems 25, 025006. 
Zelenev, V., Van Bruggen, A., Semenov, A., 2005. Modeling wave-like dynamics of oligotrophic and copiotrophic bacteria along wheat roots in response to nutrient input from a growing root tip. Ecological Modelling $188,404-417$.

Zi, Z., 2011. Sensitivity analysis approaches applied to systems biology models. IET Systems Biology 5, 336-346. 
1074 Appendix A. Descriptions of the full and reduced PECCAD ODE models, initial conditions and optimized parameter

1076 values. 


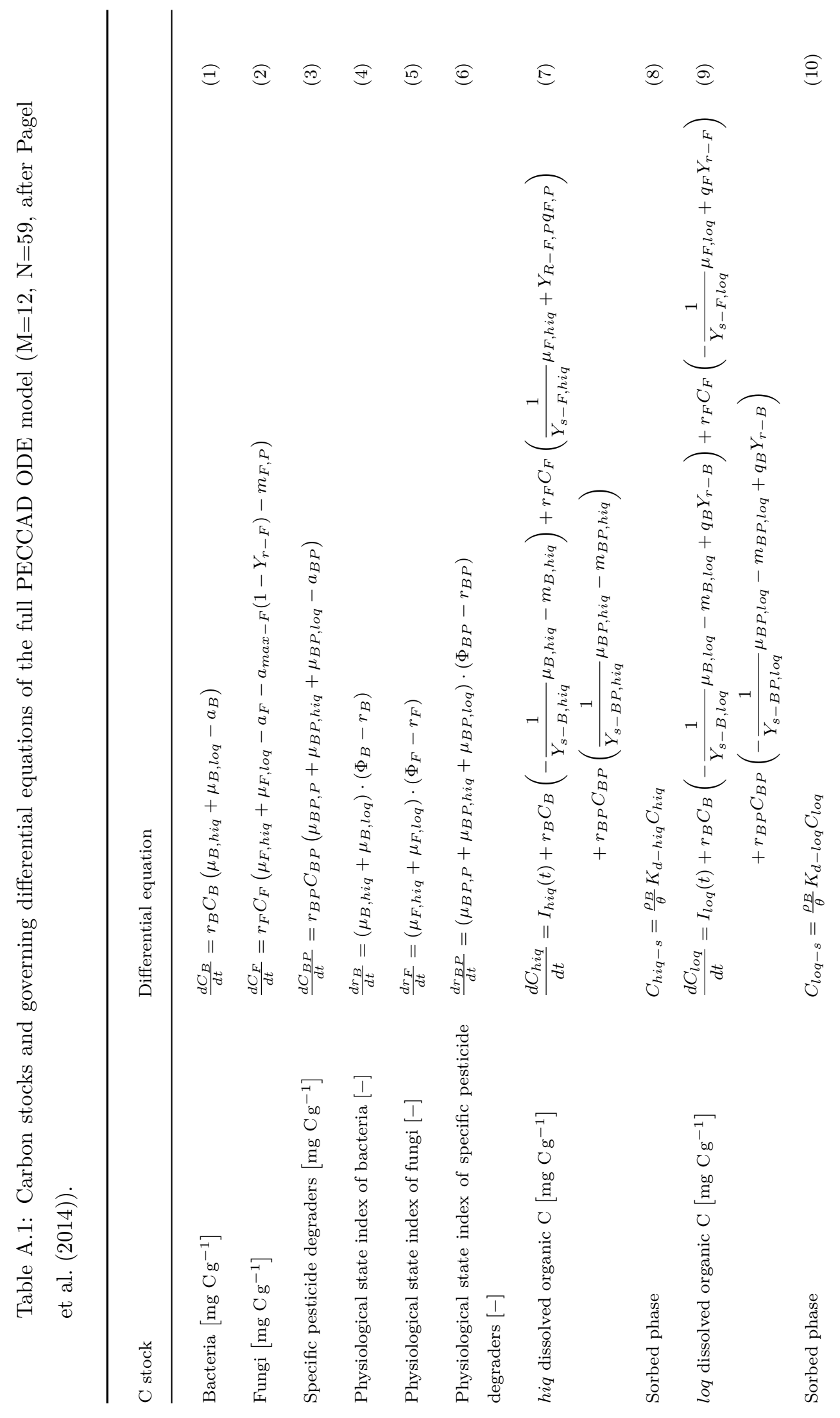




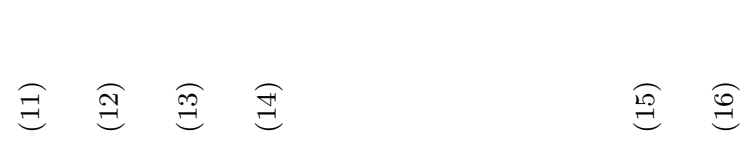
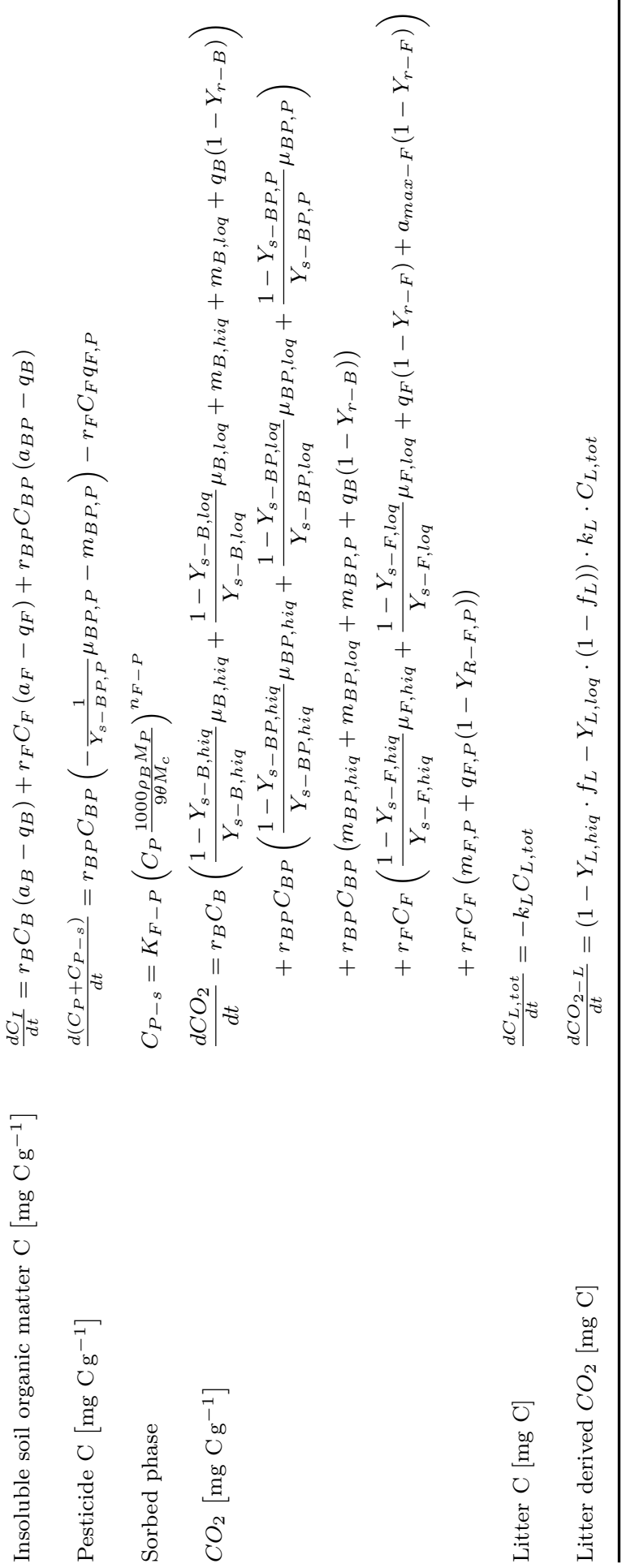


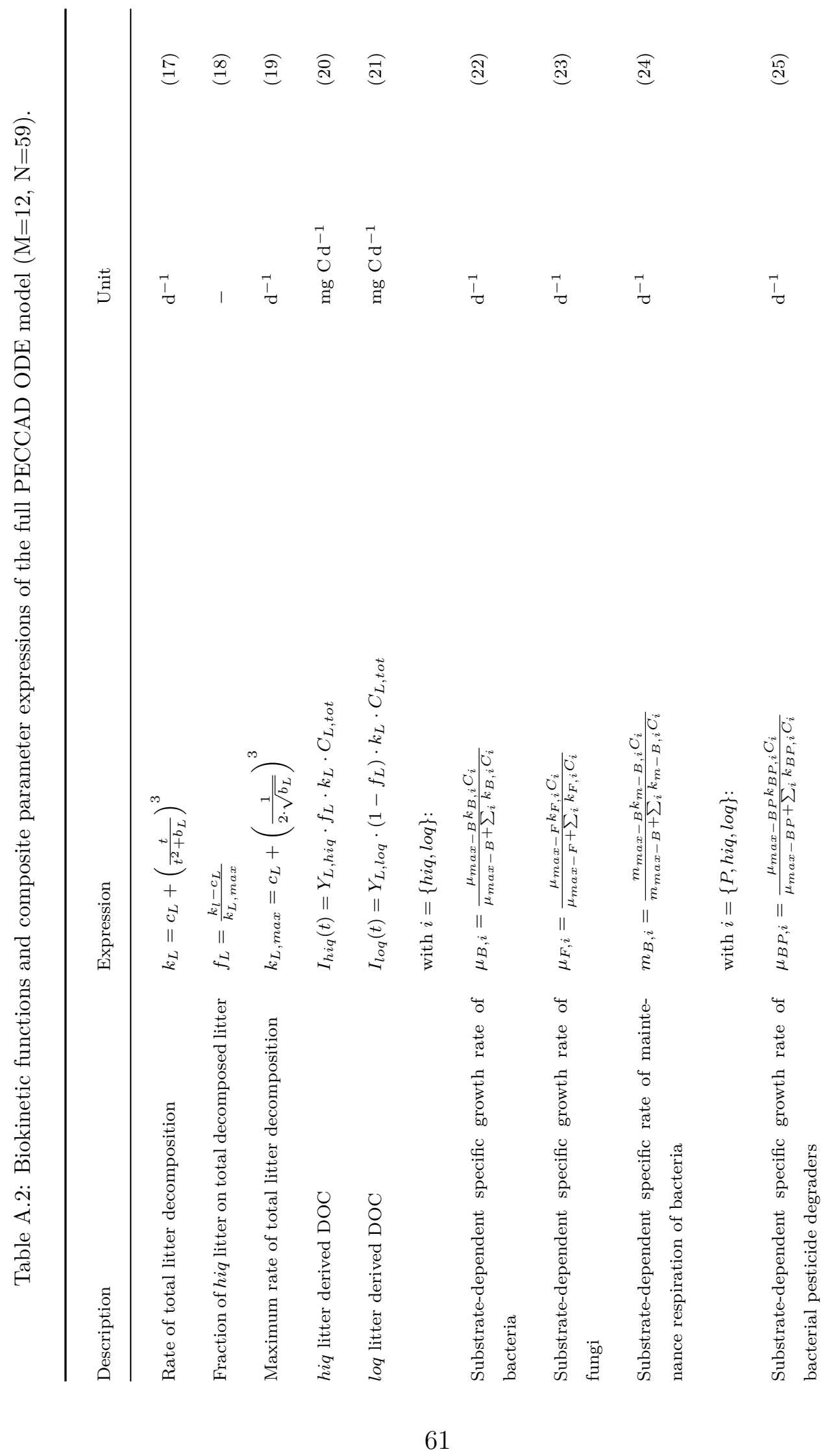




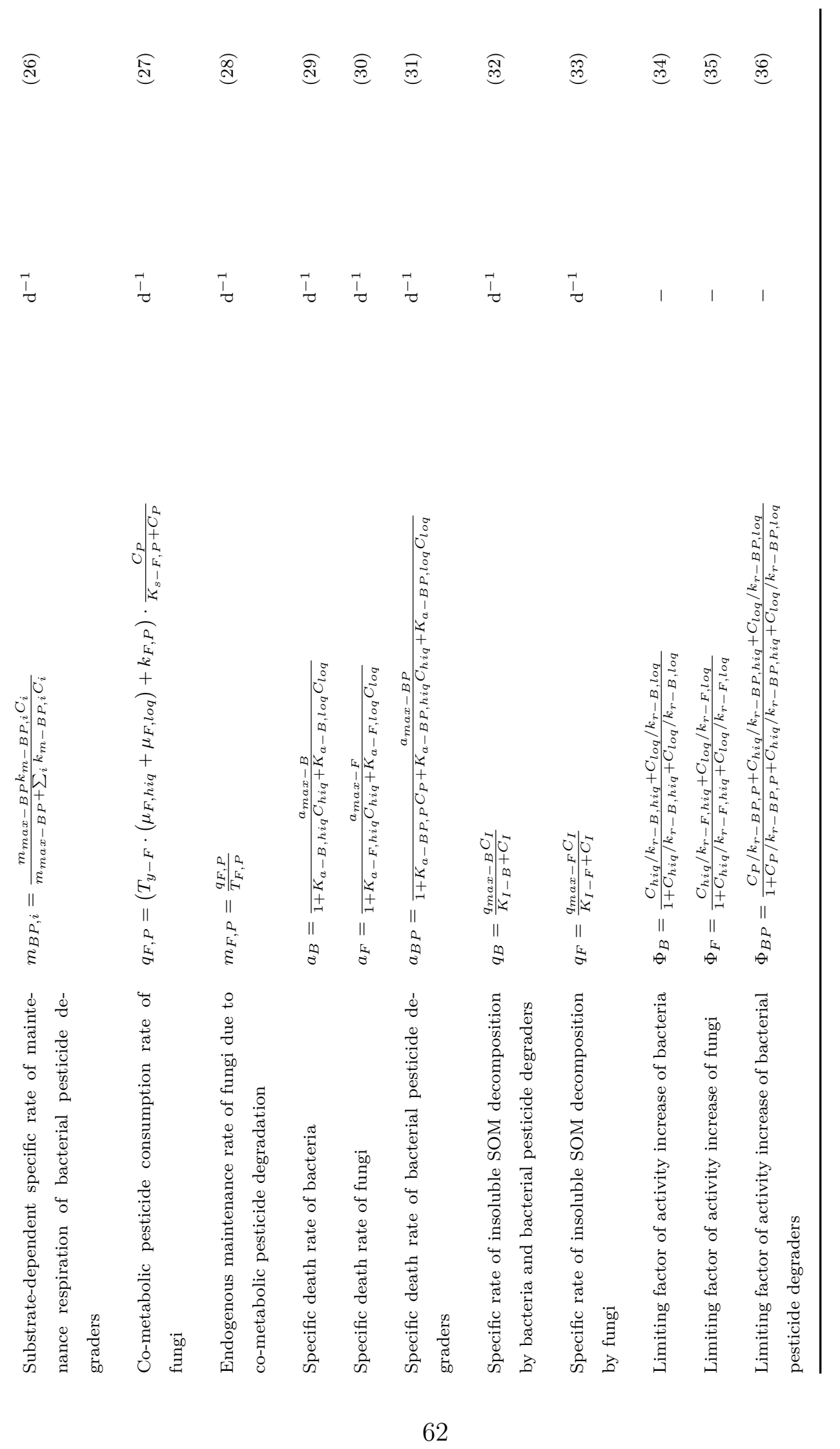


Table A.3: Model parameter symbols, descriptions, values of optimal parameters of the full PECCAD ODE model $(\mathrm{M}=12, \mathrm{~N}=59)$ calibrated based on the data of the MCPA + Litter treatment, 95\% highest posterior density interval (HDI) and units.

\begin{tabular}{|c|c|c|c|c|}
\hline Symbol & Description & $\begin{array}{l}\text { MCPA } \\
+ \\
\text { Litter }\end{array}$ & HDI & Unit \\
\hline$a_{\max -B}$ & Maximum specific death rate of bacteria & 1.21 & {$[0.004,7.89]$} & $d^{-1}$ \\
\hline $\mathrm{a}_{\max }-\mathrm{BP}$ & $\begin{array}{l}\text { Maximum specific death rate of bacterial pes- } \\
\text { ticide degraders }\end{array}$ & 0.15 & {$[0.004,3.79]$} & $\mathrm{d}^{-1}$ \\
\hline $\mathrm{a}_{\max -\mathrm{F}}$ & Maximum specific death rate of fungi & 10.88 & {$[4.70,23.94]$} & $\mathrm{d}^{-1}$ \\
\hline $\mathrm{K}_{\mathrm{a}-\mathrm{B}, \mathrm{hiq}}$ & $\begin{array}{l}\text { Inhibition coefficient of bacterial death rate in } \\
\text { response to hiq DOC }\end{array}$ & 9.74 & {$[0.023,622.48]$} & $\mathrm{g}(\mathrm{mg} \mathrm{C})^{-1}$ \\
\hline $\mathrm{K}_{\mathrm{a}-\mathrm{B}, \mathrm{loq}}$ & $\begin{array}{l}\text { Inhibition coefficient of bacterial death rate in } \\
\text { response to loq DOC }\end{array}$ & 16.68 & {$[0.39,537.70]$} & $\mathrm{g}(\mathrm{mg} \mathrm{C})^{-1}$ \\
\hline $\mathrm{K}_{\mathrm{a}-\mathrm{BP} \text {,hiq }}$ & $\begin{array}{l}\text { Inhibition coefficient of bacterial pesticide de- } \\
\text { grader death rate in response to hiq DOC }\end{array}$ & 123.96 & {$[0.235,2.64 e 3]$} & $\mathrm{g}(\mathrm{mg} \mathrm{C})^{-1}$ \\
\hline $\mathrm{K}_{\mathrm{a}-\mathrm{BP}, \mathrm{loq}}$ & $\begin{array}{l}\text { Inhibition coefficient of bacterial pesticide de- } \\
\text { grader death rate in response to loq DOC }\end{array}$ & 29.12 & {$[0.093,206.64]$} & $\mathrm{g}(\mathrm{mg} \mathrm{C})^{-1}$ \\
\hline $\mathrm{K}_{\mathrm{a}-\mathrm{BP}, \mathrm{P}}$ & $\begin{array}{l}\text { Inhibition coefficient of bacterial pesticide de- } \\
\text { grader death rate in response to pesticide }\end{array}$ & 19.41 & {$[0.147,441.90]$} & $\mathrm{g}(\mathrm{mg} \mathrm{C})^{-1}$ \\
\hline $\mathrm{K}_{\mathrm{a}-\mathrm{F}, \mathrm{hiq}}$ & $\begin{array}{l}\text { Inhibition coefficient of fungal death rate in } \\
\text { response to hiq DOC }\end{array}$ & 161.16 & {$[22.94,1.27 e 3]$} & $\mathrm{g}(\mathrm{mg} \mathrm{C})^{-1}$ \\
\hline $\mathrm{K}_{\mathrm{a}-\mathrm{F}, \mathrm{loq}}$ & $\begin{array}{l}\text { Inhibition coefficient of fungal death rate in } \\
\text { response to loq DOC }\end{array}$ & 15.92 & {$[5.73,90.0]$} & $\mathrm{g}(\mathrm{mg} \mathrm{C})^{-1}$ \\
\hline $\mathrm{k}_{\mathrm{B}, \mathrm{hiq}}$ & $\begin{array}{l}\text { hiq DOC growth substrate affinity coefficient } \\
\text { of bacteria }\end{array}$ & 231.20 & {$[20.02,1.95 e 3]$} & $g(m g C)^{-1} d^{-1}$ \\
\hline $\mathrm{k}_{\mathrm{B}, \mathrm{loq}}$ & $\begin{array}{l}\text { loq DOC growth substrate affinity coefficient } \\
\text { of bacteria }\end{array}$ & 5.83 & {$[0.18,25.43]$} & $g(m g C)^{-1} d^{-1}$ \\
\hline $\mathrm{k}_{\mathrm{BP}, \mathrm{hiq}}$ & $\begin{array}{l}\text { hiq DOC growth substrate affinity coefficient } \\
\text { of bacterial pesticide degraders }\end{array}$ & 513.89 & {$[1.54,4.38 e 3]$} & $\mathrm{g}(\mathrm{mg} \mathrm{C})^{-1} \mathrm{~d}^{-1}$ \\
\hline $\mathrm{k}_{\mathrm{BP}, \mathrm{loq}}$ & $\begin{array}{l}\text { loq DOC growth substrate affinity coefficient } \\
\text { of bacterial pesticide degraders }\end{array}$ & 335.55 & {$[12.25,1.07 e 3]$} & $\mathrm{g}(\mathrm{mg} \mathrm{C})^{-1} \mathrm{~d}^{-1}$ \\
\hline
\end{tabular}




\begin{tabular}{|c|c|c|c|c|}
\hline $\mathrm{k}_{\mathrm{BP}, \mathrm{P}}$ & $\begin{array}{l}\text { pesticide growth substrate affinity coefficient } \\
\text { of bacterial pesticide degraders }\end{array}$ & 461.64 & {$\left[1.43,3.52 e^{4}\right]$} & $\mathrm{g}(\mathrm{mg} \mathrm{C})^{-1} \mathrm{~d}^{-1}$ \\
\hline $\mathrm{K}_{\mathrm{d}-\mathrm{hiq}}$ & Linear sorption coefficient of hiq DOC & 1.13 & {$[0.115,3.574]$} & $\mathrm{mm}^{3} \mathrm{mg}^{-1}$ \\
\hline $\mathrm{K}_{\mathrm{d}-\mathrm{loq}}$ & Linear sorption coefficient of loq DOC & 70.76 & {$[13.15,2.32 e 3]$} & - \\
\hline $\mathrm{k}_{\mathrm{F}, \mathrm{hiq}}$ & $\begin{array}{l}\text { hiq DOC growth substrate affinity coefficient } \\
\text { of fungi }\end{array}$ & 0.96 & {$\left[2 e^{-3}, 27.28\right]$} & $g(m g C)^{-1} d^{-1}$ \\
\hline $\mathrm{k}_{\mathrm{F}, \mathrm{loq}}$ & $\begin{array}{l}\text { loq DOC growth substrate affinity coefficient } \\
\text { of fungi }\end{array}$ & 79.17 & {$[22.54,147.99]$} & $g(m g C)^{-1} d^{-1}$ \\
\hline $\mathrm{k}_{\mathrm{F}, \mathrm{P}}$ & $\begin{array}{l}\text { Maximum specific rate of pesticide utilization } \\
\text { in the absence of growth substrates of fungi }\end{array}$ & 1.02 & {$[1 e-4,47.26]$} & $\mathrm{d}^{-1}$ \\
\hline $\mathrm{K}_{\mathrm{I}-\mathrm{B}}$ & $\begin{array}{l}\text { Substrate affinity coefficient of insoluble or- } \\
\text { ganic matter decomposition kinetics of bacte- } \\
\text { ria and bacterial pesticide degraders }\end{array}$ & 65.19 & {$\left[0.16,2.3 e^{3}\right]$} & $\mathrm{g}(\mathrm{mg} \mathrm{C})^{-1}$ \\
\hline $\mathrm{K}_{\mathrm{I}-\mathrm{F}}$ & $\begin{array}{l}\text { Substrate affinity coefficient of insoluble or- } \\
\text { ganic matter decomposition kinetics of fungi }\end{array}$ & 54.24 & {$[0.07,14.5 e 3]$} & $\mathrm{g}(\mathrm{mg} C)^{-1}$ \\
\hline $\mathrm{k}_{\mathrm{m}-\mathrm{B}, \mathrm{hiq}}$ & $\begin{array}{l}\text { hiq DOC maintenance substrate affinity coef- } \\
\text { ficient of bacteria }\end{array}$ & 652.74 & {$\left[0.69,8.0 e^{4}\right]$} & $g(m g C)^{-1} d^{-1}$ \\
\hline $\mathrm{k}_{\mathrm{m}-\mathrm{B}, \mathrm{loq}}$ & $\begin{array}{l}\text { loq DOC maintenance substrate affinity coef- } \\
\text { ficient of bacteria }\end{array}$ & 221.47 & {$\left[4.87,1.3 e^{3}\right]$} & $g(m g C)^{-1} d^{-1}$ \\
\hline $\mathrm{k}_{\mathrm{m}-\mathrm{BP}, \mathrm{hiq}}$ & $\begin{array}{l}\text { hiq DOC maintenance substrate affinity coef- } \\
\text { ficient of bacterial pesticide degraders }\end{array}$ & 269.72 & {$\left[0.90,10.9 e^{3}\right]$} & $g(m g C)^{-1} d^{-1}$ \\
\hline $\mathrm{k}_{\mathrm{m}-\mathrm{BP}, \mathrm{loq}}$ & $\begin{array}{l}\text { loq DOC maintenance substrate affinity coef- } \\
\text { ficient of bacterial pesticide degraders }\end{array}$ & 1365.72 & {$\left[4.55,3.8 e^{5}\right]$} & $g(m g C)^{-1} d^{-1}$ \\
\hline $\mathrm{k}_{\mathrm{m}-\mathrm{BP}, \mathrm{P}}$ & $\begin{array}{l}\text { pesticide maintenance substrate affinity coeffi- } \\
\text { cient of bacterial pesticide degraders }\end{array}$ & 679.53 & {$\left[0.252,1.1 e^{4}\right]$} & $\mathrm{g}(\mathrm{mg} \mathrm{C})^{-1} \mathrm{~d}^{-1}$ \\
\hline $\mathrm{k}_{\mathrm{r}-\mathrm{B}, \mathrm{hiq}}$ & $\begin{array}{l}\text { Inhibition coefficient of bacterial activity in re- } \\
\text { sponse to hiq DOC }\end{array}$ & 0.432 & {$[0.06,8.31]$} & $\mathrm{mg} \mathrm{Cg}{ }^{-1}$ \\
\hline $\mathrm{k}_{\mathrm{r}-\mathrm{B}, \mathrm{loq}}$ & $\begin{array}{l}\text { Inhibition coefficient of bacterial activity in re- } \\
\text { sponse to loq DOC }\end{array}$ & 1.25 & {$[0.25,9.74]$} & $\mathrm{mg} \mathrm{Cg}^{-1}$ \\
\hline $\mathrm{k}_{\mathrm{r}-\mathrm{BP}, \mathrm{hiq}}$ & $\begin{array}{l}\text { Inhibition coefficient of bacterial pesticide de- } \\
\text { grader activity in response to hiq DOC }\end{array}$ & 0.91 & {$[0.27,602.62]$} & $\mathrm{mg} \mathrm{Cg}{ }^{-1}$ \\
\hline $\mathrm{k}_{\mathrm{r}-\mathrm{BP}, \mathrm{loq}}$ & $\begin{array}{l}\text { Inhibition coefficient of bacterial pesticide de- } \\
\text { grader activity in response to loq DOC }\end{array}$ & 25.09 & {$[0.43,26.57]$} & $\mathrm{mg} \mathrm{Cg}^{-1}$ \\
\hline $\mathrm{k}_{\mathrm{r}-\mathrm{BP}, \mathrm{P}}$ & $\begin{array}{l}\text { Inhibition coefficient of bacterial pesticide de- } \\
\text { grader activity in response to pesticide }\end{array}$ & 4.08 & {$[0.013,154.35]$} & $\operatorname{mg~} \mathrm{Cg}^{-1}$ \\
\hline
\end{tabular}




\begin{tabular}{|c|c|c|c|c|}
\hline $\mathrm{k}_{\mathrm{r}-\mathrm{F}, \mathrm{hiq}}$ & $\begin{array}{l}\text { Inhibition coefficient of fungal activity in re- } \\
\text { sponse to hiq DOC }\end{array}$ & $9.41 e^{-5}$ & {$[2.05,100] e^{-5}$} & $\mathrm{mg} \mathrm{Cg}^{-1}$ \\
\hline $\mathrm{k}_{\mathrm{r}-\mathrm{F}, \mathrm{loq}}$ & $\begin{array}{l}\text { Inhibition coefficient of fungal activity in re- } \\
\text { sponse to loq DOC }\end{array}$ & 122.20 & {$\left[2.41,2.1 e^{4}\right]$} & $\operatorname{mg~Cg}{ }^{-1}$ \\
\hline $\mathrm{K}_{\mathrm{S}-\mathrm{F}, \mathrm{P}}$ & $\begin{array}{l}\text { Substrate affinity coefficient of fungal co- } \\
\text { metabolic pesticide transformation kinetic }\end{array}$ & 0.004 & {$[3,63] e^{-3}$} & $\mathrm{mg} \mathrm{Cg}^{-1}$ \\
\hline $\mathrm{m}_{\max -\mathrm{B}}$ & $\begin{array}{l}\text { Maximum specific maintenance rate of bacte- } \\
\text { ria }\end{array}$ & 3.08 & {$[0.93,181.96]$} & $d^{-1}$ \\
\hline $\mathrm{m}_{\max }-\mathrm{BP}$ & $\begin{array}{l}\text { Maximum specific maintenance rate of bacte- } \\
\text { rial pesticide degraders }\end{array}$ & 3.94 & {$[0.01,133.18]$} & $d^{-1}$ \\
\hline$\mu_{\max -\mathrm{B}}$ & Maximum specific growth rate of bacteria & 68.60 & {$\left[3.02,2.5 e^{3}\right]$} & $d^{-1}$ \\
\hline$\mu_{\max -\mathrm{BP}}$ & $\begin{array}{l}\text { Maximum specific growth rate of bacterial pes- } \\
\text { ticide degraders }\end{array}$ & 8.41 & {$[0.47,28.91]$} & $d^{-1}$ \\
\hline$\mu_{\max -\mathrm{F}}$ & Maximum specific growth rate of fungi & 9.42 & {$[3.32,16.50]$} & $d^{-1}$ \\
\hline$q_{\max -B}$ & $\begin{array}{l}\text { Maximum specific decomposition rate of insol- } \\
\text { uble organic matter of bacteria and bacterial } \\
\text { pesticide degraders }\end{array}$ & 5.84 & {$[0.034,47.13]$} & $d^{-1}$ \\
\hline $\mathrm{qmax}-\mathrm{F}$ & $\begin{array}{l}\text { Maximum specific decomposition rate of insol- } \\
\text { uble organic matter of fungi }\end{array}$ & 1.19 & {$[0.2,5.87]$} & $\mathrm{d}^{-1}$ \\
\hline $\mathrm{T}_{\mathrm{F}, \mathrm{P}}$ & $\begin{array}{l}\text { Co-metabolic pesticide transformation capac- } \\
\text { ity of fungi }\end{array}$ & 4968.68 & {$\left[56.56,1.03 e^{5}\right]$} & - \\
\hline $\mathrm{T}_{\mathrm{y}-\mathrm{F}}$ & $\begin{array}{l}\text { Growth substrate transformation capacity of } \\
\text { fungi }\end{array}$ & 140.88 & {$\left[4.19,252 e^{3}\right]$} & - \\
\hline $\mathrm{Y}_{\mathrm{L}, \mathrm{hiq}}$ & $\begin{array}{l}\text { Fraction of the decomposed hiq litter trans- } \\
\text { ferred to soil }\end{array}$ & 0.36 & {$[0.113,0.701]$} & - \\
\hline $\mathrm{Y}_{\mathrm{L}, \mathrm{loq}}$ & $\begin{array}{l}\text { Fraction of the decomposed loq litter trans- } \\
\text { ferred to soil }\end{array}$ & 0.84 & {$[0.722,0.983]$} & - \\
\hline$Y_{r-B}$ & $\begin{array}{l}\text { Efficiency of insoluble organic matter decom- } \\
\text { position by bacteria and bacterial pesticide de- } \\
\text { graders }\end{array}$ & 0.700 & {$[0.507,1.0]$} & - \\
\hline $\mathrm{Y}_{\mathrm{r}-\mathrm{F}}$ & $\begin{array}{l}\text { Efficiency of insoluble organic matter decom- } \\
\text { position by fungi }\end{array}$ & 0.990 & {$[0.982,0.997]$} & - \\
\hline$Y_{R-F, P}$ & $\begin{array}{l}\text { Efficiency of co-metabolic pesticide transfor- } \\
\text { mation by fungi }\end{array}$ & 0.515 & {$[0.298,1.0]$} & - \\
\hline
\end{tabular}




\begin{tabular}{|c|c|c|c|c|}
\hline $\mathrm{Y}_{\mathrm{s}-\mathrm{B} \text {,hiq }}$ & $\begin{array}{l}\text { Substrate uptake efficiency of hiq DOC by bac- } \\
\text { teria }\end{array}$ & 0.173 & {$[0.075,0.306]$} & - \\
\hline $\mathrm{Y}_{\mathrm{s}-\mathrm{B}, \mathrm{loq}}$ & $\begin{array}{l}\text { Substrate uptake efficiency of loq DOC by bac- } \\
\text { teria }\end{array}$ & 0.503 & {$[0.260,0.854]$} & - \\
\hline$Y_{s-B P, h i q}$ & $\begin{array}{l}\text { Substrate uptake efficiency of hiq DOC by bac- } \\
\text { terial pesticide degraders }\end{array}$ & 0.500 & {$[0.205,0.876]$} & - \\
\hline $\mathrm{Y}_{\mathrm{s}-\mathrm{BP}, \mathrm{loq}}$ & $\begin{array}{l}\text { Substrate uptake efficiency of loq DOC by bac- } \\
\text { terial pesticide degraders }\end{array}$ & 0.200 & {$[0.033,0.771]$} & - \\
\hline $\mathrm{Y}_{\mathrm{s}-\mathrm{BP}, \mathrm{P}}$ & $\begin{array}{l}\text { Substrate uptake efficiency of pesticide by bac- } \\
\text { terial pesticide degraders }\end{array}$ & 0.900 & {$[0.835,0.974]$} & - \\
\hline $\mathrm{Y}_{\mathrm{S}-\mathrm{F}, \mathrm{hiq}}$ & $\begin{array}{l}\text { Substrate uptake efficiency of hiq DOC by } \\
\text { fungi }\end{array}$ & 0.113 & {$[0.011,0.622]$} & - \\
\hline$Y_{\mathrm{S}-\mathrm{F}, \mathrm{loq}}$ & $\begin{array}{l}\text { Substrate uptake efficiency of loq DOC by } \\
\text { fungi }\end{array}$ & 0.909 & {$[0.824,0.952]$} & - \\
\hline $\mathrm{r}_{\mathrm{B} 0}$ & Initial physiological state index of bacteria & 0.058 & {$[0.004,0.139]$} & - \\
\hline $\mathrm{r}_{\mathrm{BP} 0}$ & $\begin{array}{l}\text { Initial physiological state index of bacterial } \\
\text { pesticide degraders }\end{array}$ & 0.296 & {$[0.057,0.336]$} & - \\
\hline $\mathrm{r}_{\mathrm{F} 0}$ & Initial physiological state index of fungi & 0.116 & {$[0.004,0.348]$} & - \\
\hline
\end{tabular}




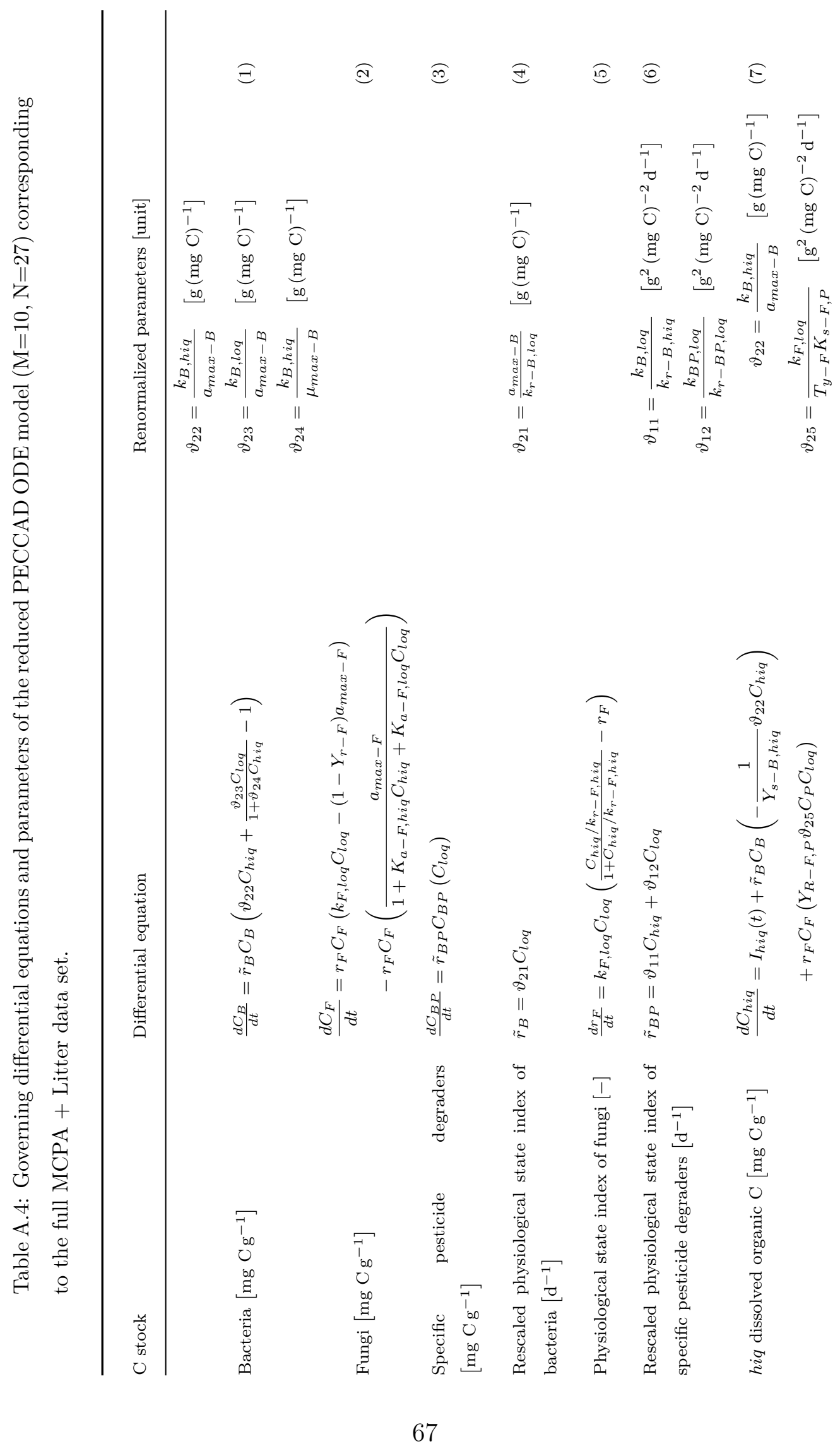



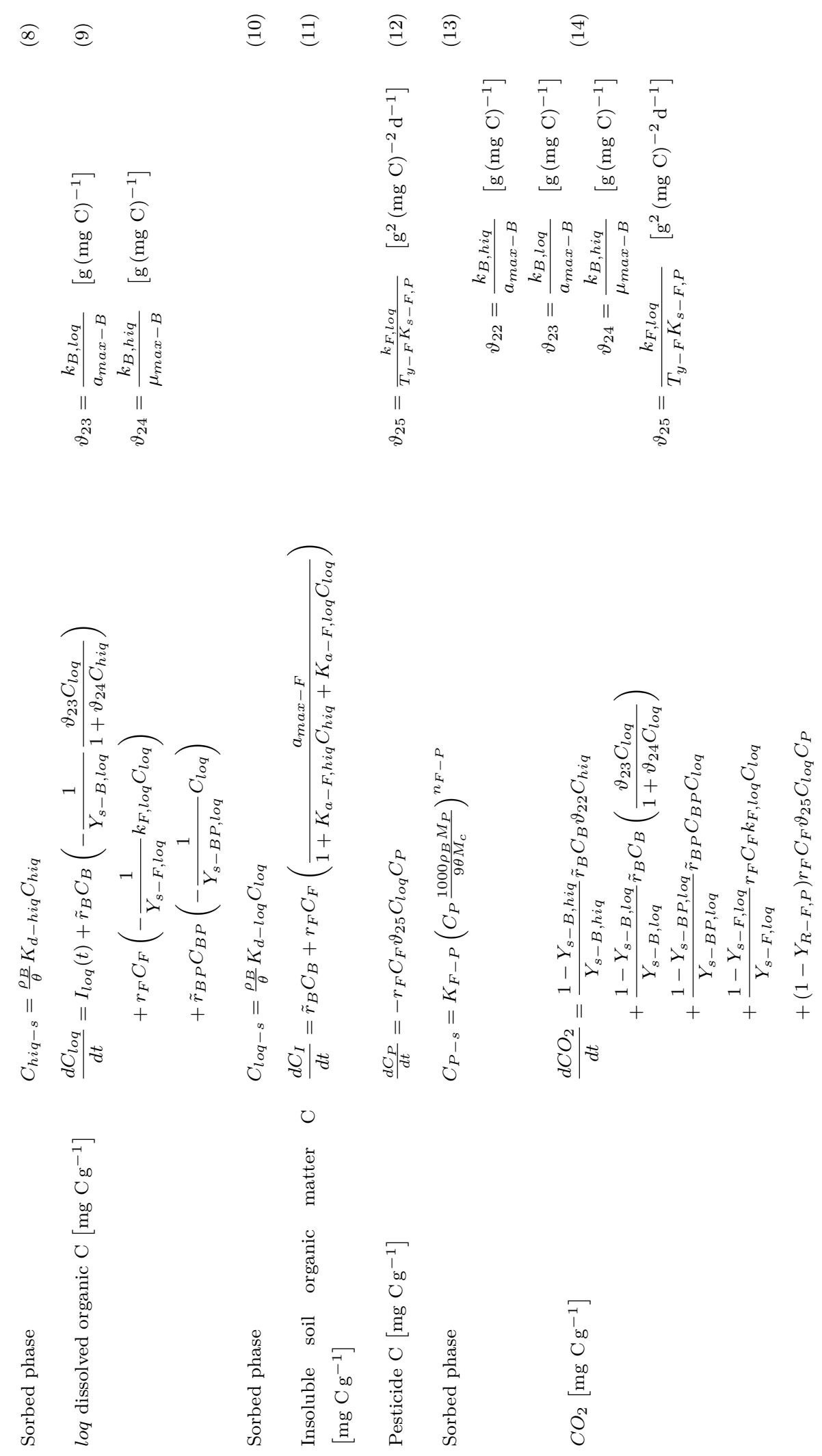


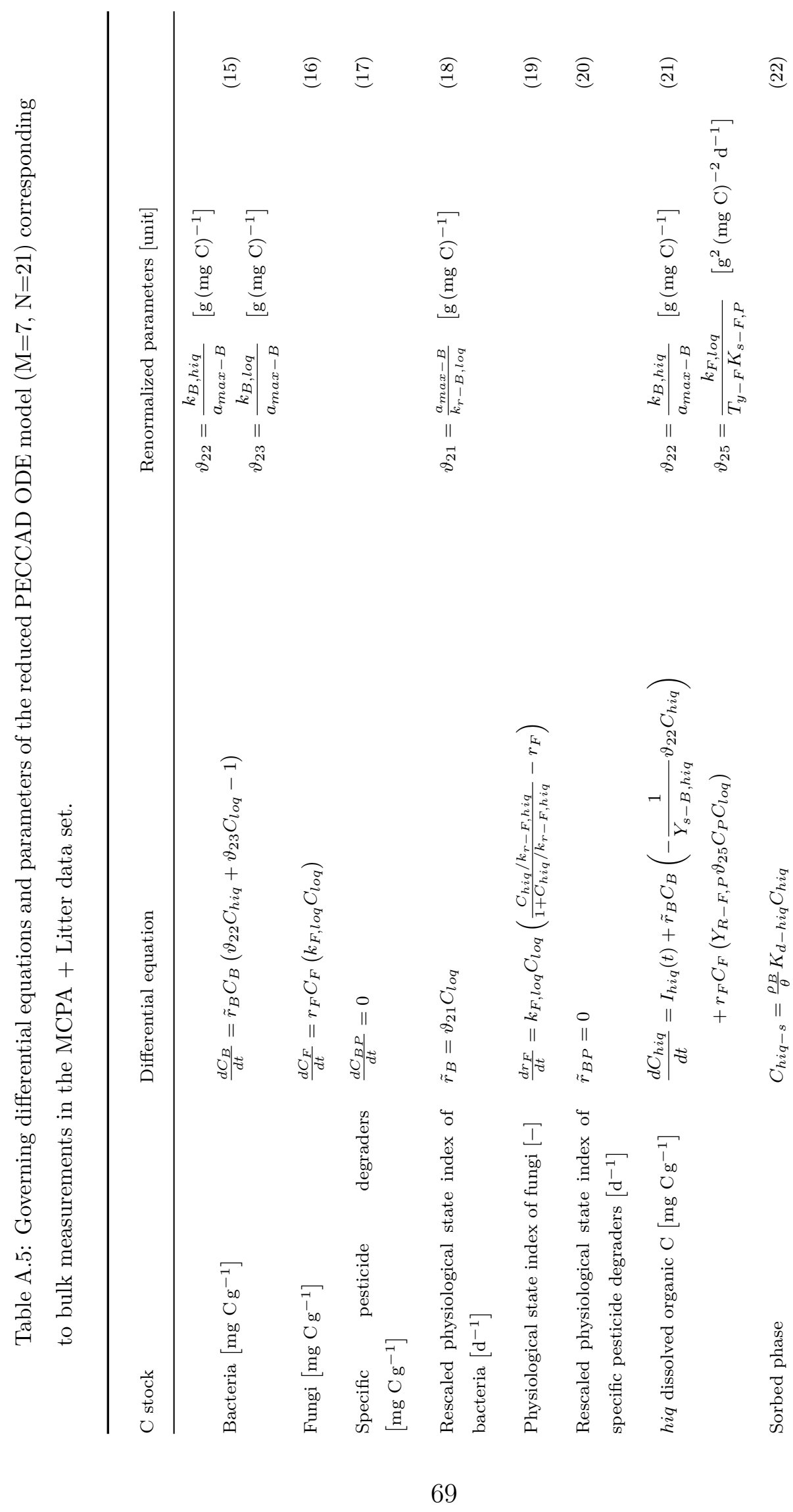




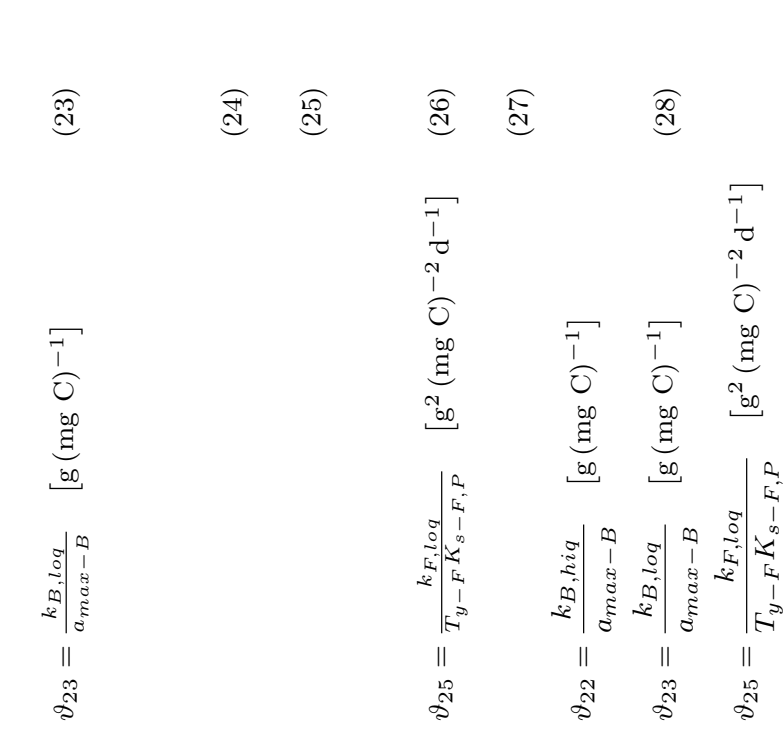

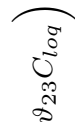

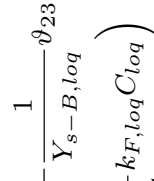

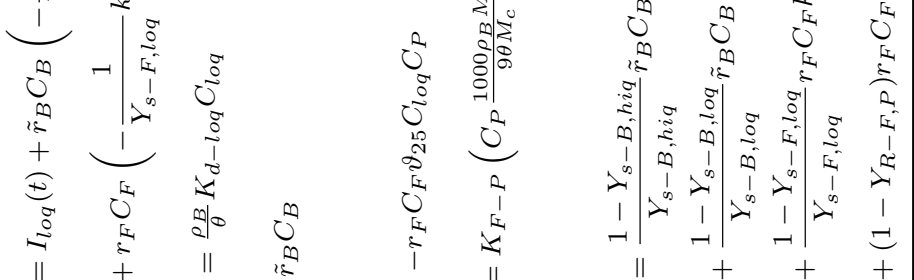

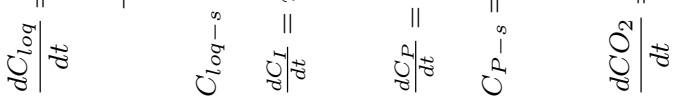

$\begin{array}{ll}T_{1} & \vec{\Phi} \\ 0 & \stackrel{0}{0}\end{array}$

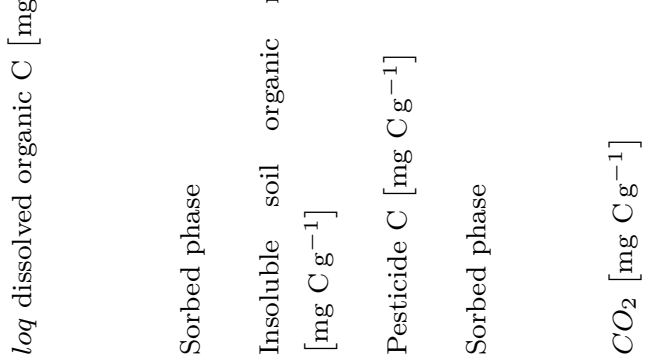




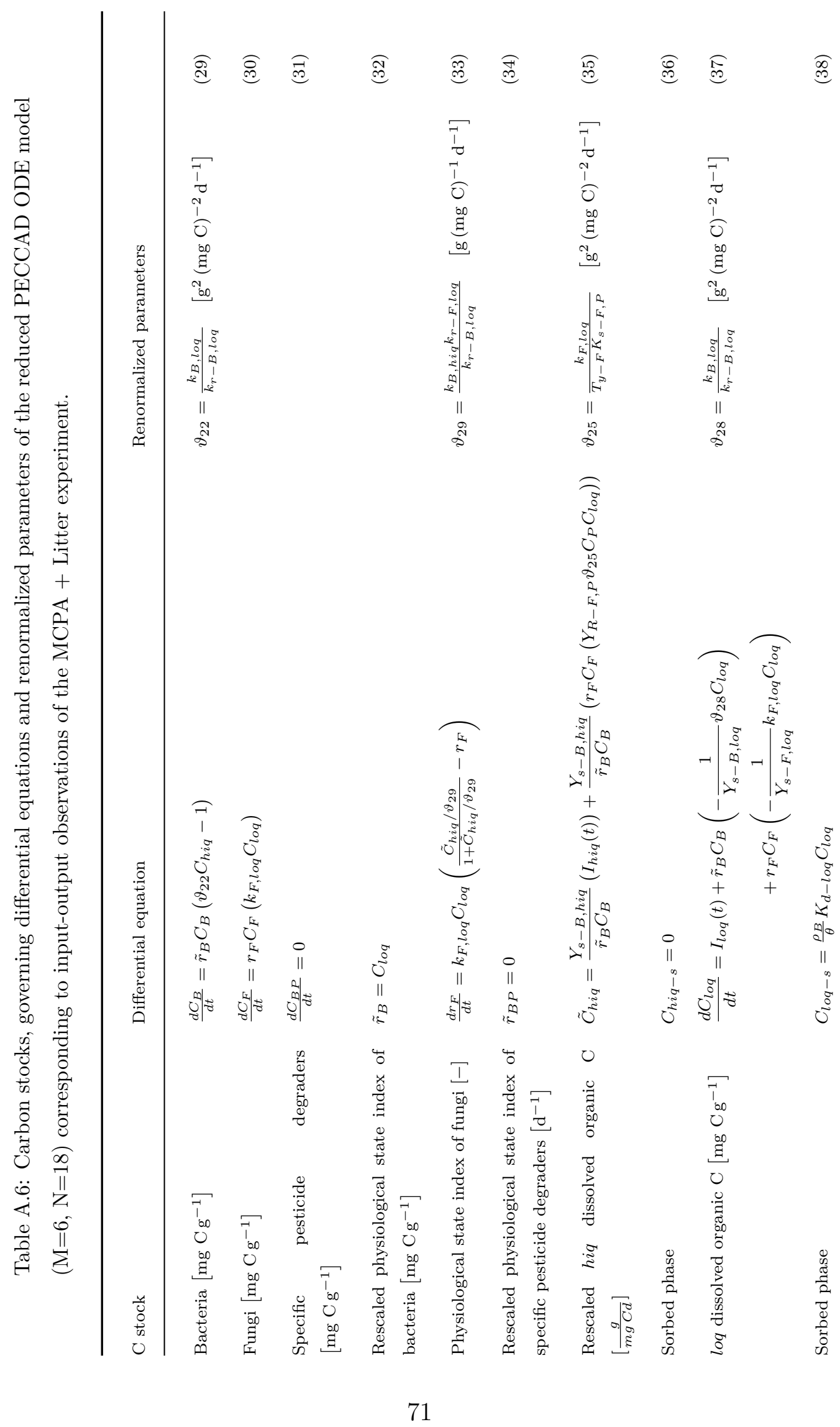




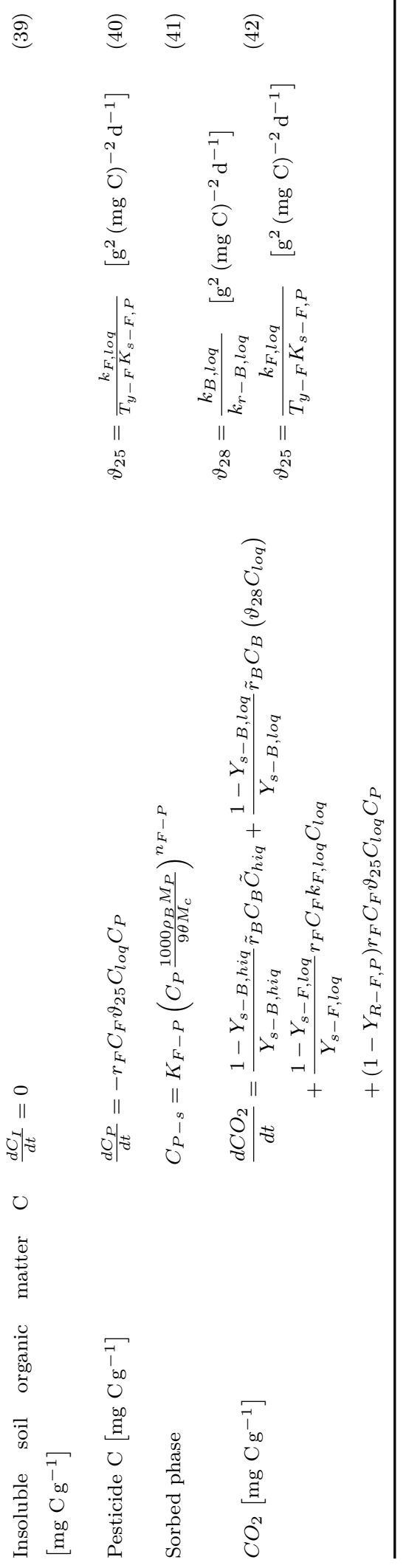


Table A.7: Model parameter symbols, descriptions, values of optimal parameters of the reduced PECCAD ODE model $(\mathrm{M}=10, \mathrm{~N}=27)$ calibrated based on the data of two experimental treatments (MCPA + Litter, MCPA), 95\% highest posterior density intervals (HDI) and units.

\begin{tabular}{|c|c|c|c|c|c|c|}
\hline Symbol & Description & $\begin{array}{l}\text { MCPA } \\
+ \\
\text { Litter }\end{array}$ & HDI & MCPA & HDI & Unit \\
\hline $\mathrm{a}_{\max -\mathrm{F}}$ & $\begin{array}{l}\text { Maximum specific } \\
\text { death rate of fungi }\end{array}$ & 43.05 & {$[6.80,125.8]$} & 1.76 & {$[0.90,5.06]$} & $d^{-1}$ \\
\hline $\mathrm{K}_{\mathrm{a}-\mathrm{F}, \mathrm{hiq}}$ & $\begin{array}{l}\text { Inhibition coef- } \\
\text { ficient of fungal } \\
\text { death rate in } \\
\text { response to hiq } \\
\text { DOC }\end{array}$ & 3765.66 & {$\left[382.79,4.03 e^{3}\right]$} & 78.39 & {$[17.82,189.75]$} & $\mathrm{g}(\mathrm{mg} \mathrm{C})^{-1}$ \\
\hline $\mathrm{K}_{\mathrm{a}-\mathrm{F}, \mathrm{loq}}$ & $\begin{array}{l}\text { Inhibition coef- } \\
\text { ficient of fungal } \\
\text { death rate in } \\
\text { response to loq } \\
\text { DOC }\end{array}$ & 134.37 & {$[21.55,970.46]$} & 26.25 & {$[3.07,132.17]$} & $\mathrm{g}(\mathrm{mg} \mathrm{C})^{-1}$ \\
\hline $\mathrm{K}_{\mathrm{d}-\mathrm{hiq}}$ & $\begin{array}{l}\text { Linear sorption } \\
\text { coefficient of hiq } \\
\text { DOC }\end{array}$ & 1.79 & {$[0.046,3.63]$} & $1 e-3$ & {$[0.1,3] e^{-3}$} & $\mathrm{~mm}^{3} \mathrm{mg}^{-1}$ \\
\hline $\mathrm{K}_{\mathrm{d}-\mathrm{loq}}$ & $\begin{array}{l}\text { Linear sorption } \\
\text { coefficient of loq } \\
\text { DOC }\end{array}$ & 36.46 & {$[7.46,70.29]$} & 280.18 & {$\left[86.94,3.6 e^{5}\right]$} & - \\
\hline $\mathrm{k}_{\mathrm{F}, \mathrm{loq}}$ & $\begin{array}{l}\text { loq DOC growth } \\
\text { substrate affinity } \\
\text { coefficient of fungi }\end{array}$ & 32.68 & {$[11.09,38.30]$} & 14.40 & {$[8.98,19.61]$} & $g(m g C)^{-1} d^{-1}$ \\
\hline $\mathrm{k}_{\mathrm{r}-\mathrm{F}, \mathrm{hiq}}$ & $\begin{array}{l}\text { Inhibition coef- } \\
\text { ficient of fungal } \\
\text { activity in response } \\
\text { to hiq DOC }\end{array}$ & $3.6 e^{-5}$ & {$[0.03,1.4] e^{-4}$} & $5.2 e^{-3}$ & {$[3,10] e^{-3}$} & $\operatorname{mg~Cg}{ }^{-1}$ \\
\hline
\end{tabular}




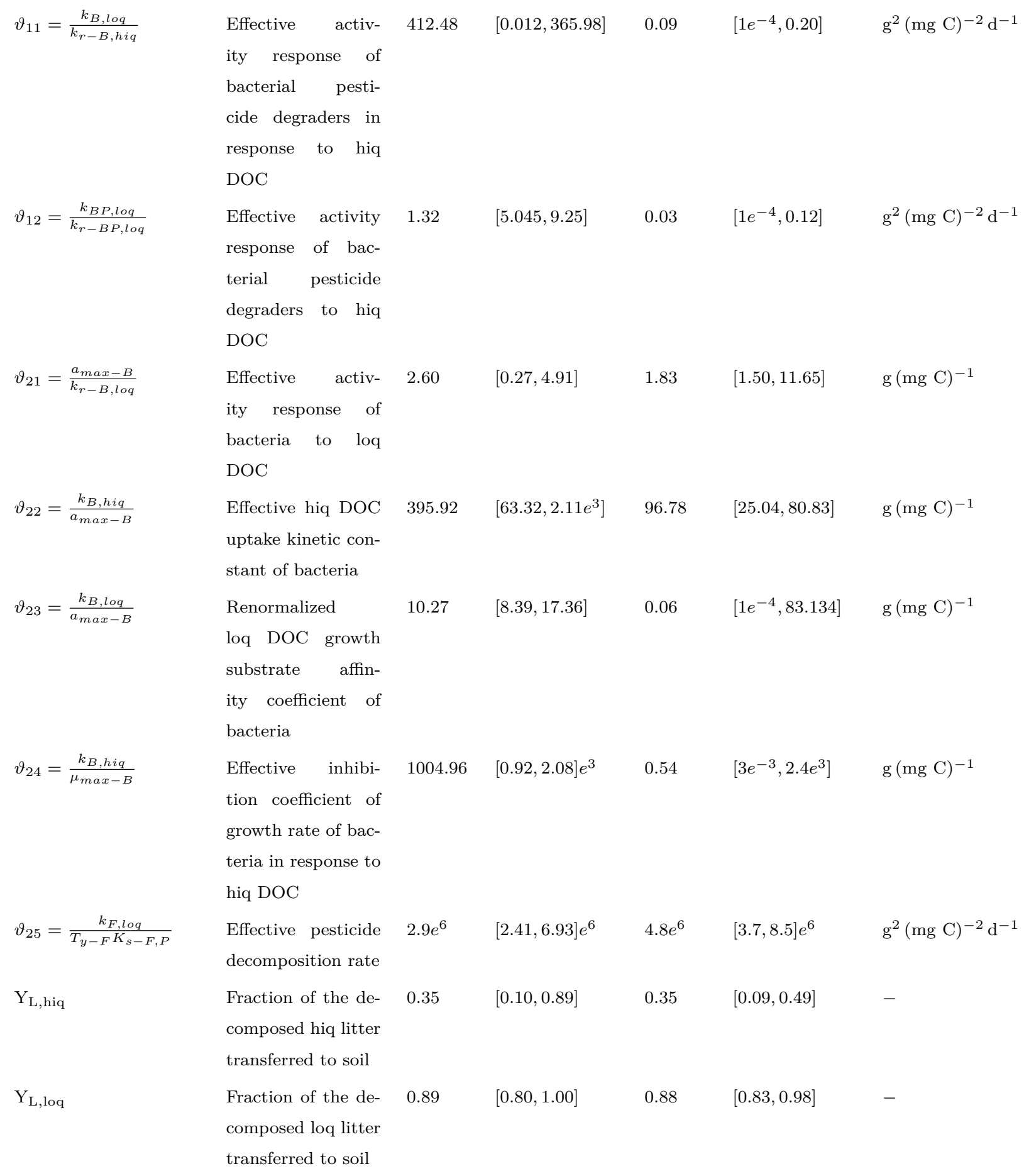




\begin{tabular}{|c|c|c|c|c|c|c|}
\hline$Y_{r-B}$ & $\begin{array}{l}\text { Efficiency of in- } \\
\text { soluble organic } \\
\text { matter decompo- } \\
\text { sition by bacteria } \\
\text { and bacterial } \\
\text { pesticide degraders }\end{array}$ & 0.75 & {$[0.56,0.98]$} & 0.75 & {$[0.60,0.86]$} & - \\
\hline$Y_{r-F}$ & $\begin{array}{l}\text { Efficiency of insol- } \\
\text { uble organic mat- } \\
\text { ter decomposition } \\
\text { by fungi } 0.99\end{array}$ & 0.99 & {$[0.98,1.0]$} & 0.99 & {$[0.993,0.998]$} & - \\
\hline $\mathrm{Y}_{\mathrm{R}-\mathrm{F}, \mathrm{P}}$ & $\begin{array}{l}\text { Efficiency of co- } \\
\text { metabolic pesticide } \\
\text { transformation by } \\
\text { fungi }\end{array}$ & 0.45 & {$[0.20,0.86]$} & 0.83 & {$[0.81,1.0]$} & - \\
\hline $\mathrm{Y}_{\mathrm{s}-\mathrm{B}, \mathrm{hiq}}$ & $\begin{array}{l}\text { Substrate uptake } \\
\text { efficiency of hiq } \\
\text { DOC by bacteria }\end{array}$ & 0.34 & {$[0.14,0.44]$} & 0.28 & {$[0.35,0.83]$} & - \\
\hline$Y_{\mathrm{s}-\mathrm{B}, \mathrm{loq}}$ & $\begin{array}{l}\text { Substrate uptake } \\
\text { efficiency of loq } \\
\text { DOC by bacteria }\end{array}$ & 0.54 & {$[0.25,0.62]$} & 0.63 & {$[0.62,0.99]$} & - \\
\hline $\mathrm{Y}_{\mathrm{s}-\mathrm{BP}, \mathrm{loq}}$ & $\begin{array}{l}\text { Substrate uptake } \\
\text { efficiency of loq } \\
\text { DOC by bacterial } \\
\text { pesticide degraders }\end{array}$ & 0.21 & {$[0.03,0.75]$} & 0.21 & {$[0.05,0.39]$} & - \\
\hline $\mathrm{Y}_{\mathrm{s}-\mathrm{F}, \mathrm{loq}}$ & $\begin{array}{l}\text { Substrate uptake } \\
\text { efficiency of loq } \\
\text { DOC by fungi }\end{array}$ & 0.92 & {$[0.85,0.98]$} & 1.0 & {$[0.93,1.0]$} & - \\
\hline $\mathrm{r}_{\mathrm{F} 0}$ & $\begin{array}{l}\text { Initial physiologi- } \\
\text { cal state index of } \\
\text { fungi }\end{array}$ & 0.46 & {$[0.15,0.81]$} & $3.4 e^{-3}$ & {$[0.1,7] e^{-3}$} & - \\
\hline
\end{tabular}




\section{Appendix B. Biogeochemical model definitions, initial conditions and parameter values.}

Table B.1: Model parameter symbols, descriptions, base values of parameters of the minimal microbial soil carbon model $(\mathrm{M}=2, \mathrm{~N}=4$; (German et al., 2012, Table 3)).

\begin{tabular}{llcl}
\hline Symbol & Description & Value & Unit \\
\hline $\mathrm{V}_{\max }$ & Maximum cycling rate of soil carbon & 0.0019 & $\mathrm{~h}^{-1} \mathrm{~cm}^{-3} \mathrm{mg}^{-1}$ \\
$\mathrm{~K}_{\mathrm{S}}$ & Half-saturation constant & 1.24 & $\mathrm{mg} \mathrm{cm}^{-3}$ \\
$\mathrm{k}_{\mathrm{B}}$ & First-order cycling rate for microbial biomass & 0.0005 & $\mathrm{~h}^{-1}$ \\
$\mathrm{Y}$ & Microbial carbon use efficiency & 0.134 & - \\
$\mathrm{I}$ & External carbon input & 0.001 & $\mathrm{mg} \mathrm{cm}^{-3} \mathrm{~h}^{-1}$ \\
$\mathrm{C}_{\mathrm{B}}(0)$ & Initial microbial biomass carbon & 2.0 & $\mathrm{mg} \mathrm{cm}^{-3}$ \\
$\mathrm{C}_{\mathrm{S}}(0)$ & Initial soil organic carbon & 100.0 & $\mathrm{mg} \mathrm{cm}^{-3}$ \\
\hline
\end{tabular}


Table B.2: Carbon stocks and governing differential equations of the extended NICA model $(\mathrm{M}=10, \mathrm{~N}=15)$.

\begin{tabular}{ll}
\hline C stock & Differential equation \\
\hline i-s microbial biomass $\left[\mathrm{mg} \mathrm{Cg}^{-1}\right]$ & $\frac{d C_{b, i s}}{d t}=r_{i s} C_{b, i s}\left(\mu\left(C_{s, i s}\right)-a\left(C_{s, i s}\right)\right)$ \\
l-s microbial biomass $\left[\mathrm{mg} \mathrm{Cg}^{-1}\right]$ & $\frac{d C_{b, l s}}{d t}=r_{l s} C_{b, l s}\left(\mu\left(C_{s, l s}\right)-a\left(C_{s, l s}\right)\right)$ \\
Physiological state index of i-s decomposer $[-]$ & $\frac{d r_{i s}}{d t}=\mu\left(C_{s, i s}\right) \cdot\left(\Phi\left(C_{s, i s}\right)-r_{i s}\right)$ \\
Physiological state index of l-s decomposer $[-]$ & $\frac{d r_{l s}}{d t}=\mu\left(C_{s, l s}\right) \cdot\left(\Phi\left(C_{s, l s}\right)-r_{l s}\right)$ \\
i-s dissolved organic C $\left[\mathrm{mg} \mathrm{Cg}^{-1}\right]$ & $\frac{d C_{s, i s}}{d t}=r_{i s} C_{b, i s}\left(\frac{1}{Y_{s}} \mu\left(C_{s, i s}\right)-m\left(C_{s, i s}\right)\right)+I_{i s}$ \\
l-s dissolved organic C $\left[\mathrm{mg} \mathrm{Cg}^{-1}\right]$ & $\frac{d C_{s, l s}}{d t}=r_{l s} C_{b, l s}\left(\frac{1}{Y_{s}} \mu\left(C_{s, l s}\right)-q\left(C_{h}\right) Y_{r}\right)+I_{l s}$ \\
Insoluble soil organic matter $\left[\mathrm{mg} \mathrm{Cg}^{-1}\right]$ & $\frac{d C_{h}}{d t}=r_{i s} C_{b, i s} a\left(C_{s, i s}\right)+r_{l s} C_{b, l s}\left(a\left(C_{s, l s}\right)-q\left(C_{h}\right)\right)$ \\
\hline
\end{tabular}


Table B.3: Biokinetic functions and composite parameter expressions of the extended NICA model $(\mathrm{M}=10, \mathrm{~N}=15)$.

\begin{tabular}{|c|c|c|c|}
\hline Description & Expression & Unit & \\
\hline Specific rate of initial-stage decomposer growth & $\mu\left(C_{s, i s}\right)=\frac{\mu_{\max , i s} C_{s, i s}}{C_{s, i s}+K_{s, i s}}$ & $\mathrm{~d}^{-1}$ & $(8)$ \\
\hline Specific rate of late-stage decomposer growth & $\mu\left(C_{s, l s}\right)=\frac{\mu_{\max , l_{s} C_{s, l s}}}{C_{s, l s}+K_{s, l s}}$ & $\mathrm{~d}^{-1}$ & $(9)$ \\
\hline Specific rate of organic matter decomposition & $q\left(C_{h}\right)=\frac{q_{\max } C_{h}}{C_{h}+K_{h}}$ & $\mathrm{~d}^{-1}$ & $(10)$ \\
\hline $\begin{array}{l}\text { Substrate-dependent specific death rate of initial-stage } \\
\text { decomposer }\end{array}$ & $a\left(C_{s, i s}\right)=\frac{a_{\max }}{1+K_{a, i s} C_{s, i s}}$ & $\mathrm{~d}^{-1}$ & $(11)$ \\
\hline $\begin{array}{l}\text { Substrate-dependent specific death rate of late-stage } \\
\text { decomposer }\end{array}$ & $a\left(C_{s, l s}\right)=\frac{a_{\max }}{1+K_{a, l s} C_{s, l s}}$ & $\mathrm{~d}^{-1}$ & $(12)$ \\
\hline $\begin{array}{l}\text { Specific rate of maintenance respiration of initial-stage } \\
\text { decomposer }\end{array}$ & $m\left(C_{s, i s}\right)=\frac{m_{\max } C_{s, i s}}{K_{m}+C_{s, i s}}$ & $\mathrm{~d}^{-1}$ & $(13)$ \\
\hline $\begin{array}{l}\text { Limiting factor for activity increase of initial-stage de- } \\
\text { composer }\end{array}$ & $\Phi\left(C_{s, i s}\right)=\frac{C_{s, i s}}{k_{r C, i s}+C_{s, i s}}$ & - & $(14)$ \\
\hline $\begin{array}{l}\text { Limiting factor for activity increase of late-stage de- } \\
\text { composer }\end{array}$ & $\Phi\left(C_{s, l s}\right)=\frac{C_{s, l s}}{k_{r C, l s}+C_{s, l s}}$ & - & $(15)$ \\
\hline
\end{tabular}


Table B.4: Model parameter symbols, descriptions, base values of parameters of the extended NICA model ( $\mathrm{M}=10, \mathrm{~N}=15$; (Ingwersen et al., 2008, Table 2)).

\begin{tabular}{|c|c|c|c|}
\hline Symbol & Description & Value & Unit \\
\hline$\mu_{\max , \text { is }}$ & $\begin{array}{l}\text { Maximum specific growth rate of initial-stage } \\
\text { decomposer }\end{array}$ & 25.5 & $\mathrm{~d}^{-1}$ \\
\hline$\mu_{\max , 1 \mathrm{~s}}$ & $\begin{array}{l}\text { Maximum specific growth rate of late-stage de- } \\
\text { composer }\end{array}$ & 2.59 & $\mathrm{~d}^{-1}$ \\
\hline qmax & $\begin{array}{l}\text { Maximum specific rate of organic matter de- } \\
\text { composition }\end{array}$ & 1.62 & $\mathrm{~d}^{-1}$ \\
\hline$a_{\max }$ & $\begin{array}{l}\text { Maximum specific death/reutilization rate of } \\
\text { decomposer }\end{array}$ & 1.309 & $d^{-1}$ \\
\hline $\mathrm{m}_{\max }$ & $\begin{array}{l}\text { Maximum specific maintenance rate of initial- } \\
\text { stage decomposer }\end{array}$ & 0.25 & $d^{-1}$ \\
\hline $\mathrm{K}_{\mathrm{s}, \text { is }}$ & $\begin{array}{l}\text { Michaelis-Menten constant for initial-stage de- } \\
\text { composer growth }\end{array}$ & 0.264 & $\mathrm{mg} \mathrm{Cg}{ }^{-1}$ \\
\hline $\mathrm{K}_{\mathrm{s}, \mathrm{ls}}$ & $\begin{array}{l}\text { Michaelis-Menten constant for late-stage de- } \\
\text { composer growth }\end{array}$ & 0.264 & $\operatorname{mg~} \mathrm{Cg}^{-1}$ \\
\hline $\mathrm{K}_{\mathrm{h}}$ & $\begin{array}{l}\text { Michaelis-Menten constant for organic matter } \\
\text { decomposition }\end{array}$ & 13.75 & $\operatorname{mg~Cg}{ }^{-1}$ \\
\hline $\mathrm{K}_{\mathrm{m}}$ & $\begin{array}{l}\text { Michaelis-Menten constant for maintenance } \\
\text { respiration of initial-stage decomposer }\end{array}$ & 0.001 & $\operatorname{mg~} \mathrm{Cg}^{-1}$ \\
\hline $\mathrm{k}_{\mathrm{rC}, \text { is }}$ & $\begin{array}{l}\text { Inhibition constant for C-dependent initial- } \\
\text { stage decomposer activity }\end{array}$ & 1.3 & $\operatorname{mg~Cg}{ }^{-1}$ \\
\hline $\mathrm{k}_{\mathrm{rC}, \mathrm{ls}}$ & $\begin{array}{l}\text { Inhibition constant for C-dependent late-stage } \\
\text { decomposer activity }\end{array}$ & 1.3 & $\mathrm{mg} \mathrm{Cg}^{-1}$ \\
\hline $\mathrm{K}_{\mathrm{a}, \text { is }}$ & $\begin{array}{l}\text { Inhibition constant for initial-stage decom- } \\
\text { poser death rate }\end{array}$ & 12.425 & $\mathrm{~g}(\mathrm{mg} \mathrm{C})^{-1}$ \\
\hline $\mathrm{K}_{\mathrm{a}, \mathrm{ls}}$ & $\begin{array}{l}\text { Inhibition constant for late-stage decomposer } \\
\text { death rate }\end{array}$ & 12.425 & $\mathrm{~g}(\mathrm{mg} \mathrm{C})^{-1}$ \\
\hline $\mathrm{Y}_{\mathrm{S}}$ & Efficiency of substrate uptake & 0.848 & - \\
\hline $\mathrm{Y}_{\mathrm{r}}$ & $\begin{array}{l}\text { Efficiency of organic matter mineralisation and } \\
\text { biomass reutilisation }\end{array}$ & 0.50 & - \\
\hline $\mathrm{I}_{\mathrm{is}}$ & i-s litter carbon input & 0.001 & $\mathrm{mg} \mathrm{Cg}{ }^{-1} \mathrm{~d}^{-1}$ \\
\hline
\end{tabular}


$\mathrm{I}_{\mathrm{ls}} \quad$ l-s litter carbon input

$\operatorname{mg~} \mathrm{Cg}^{-1} \mathrm{~d}^{-1}$ 
Table B.5: Carbon stocks and governing differential equations of the MEND model $(\mathrm{M}=10$, $\mathrm{N}=19$ ).

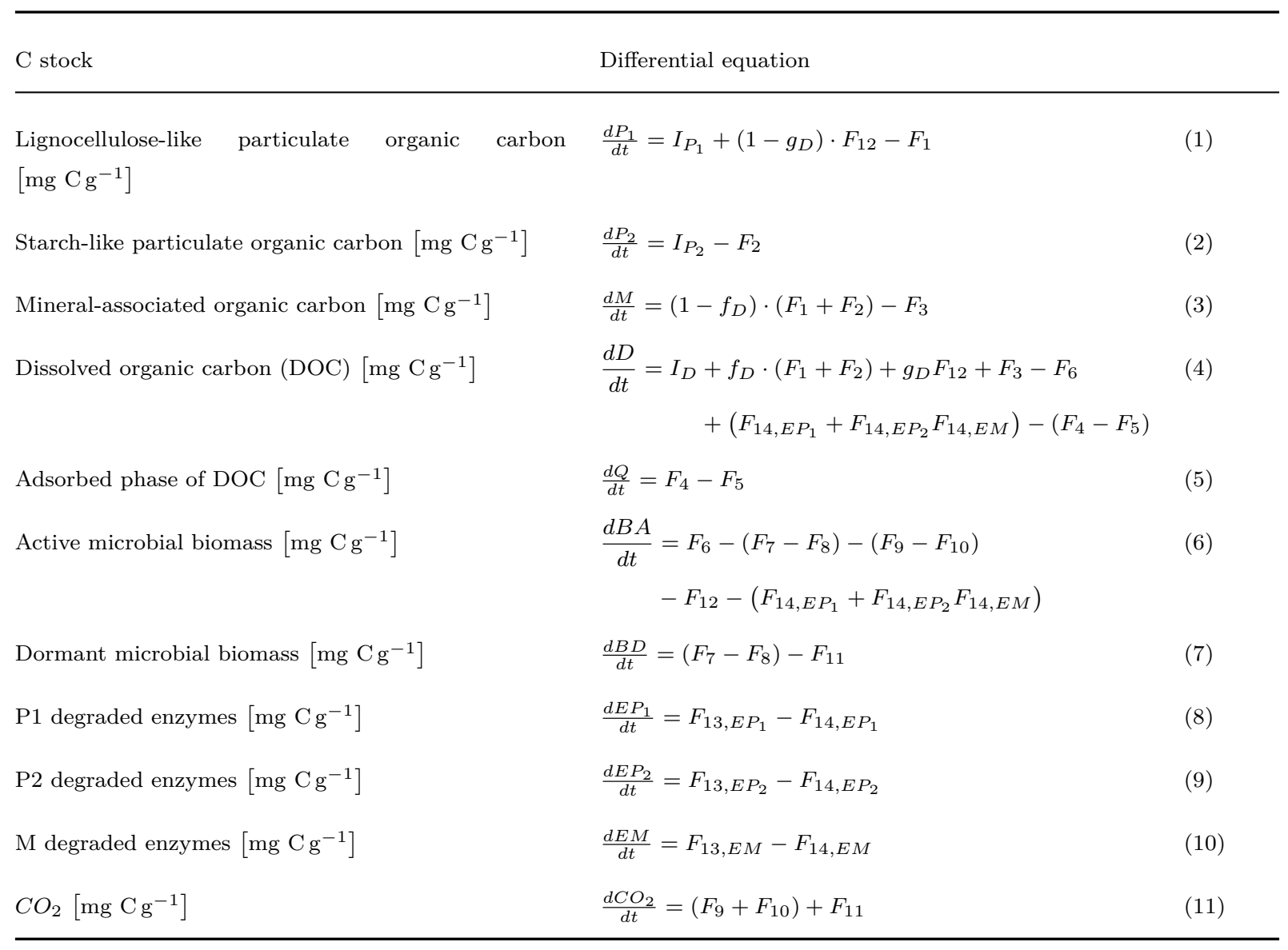


Table B.6: Biokinetic functions and composite parameter expressions of the MEND model $(\mathrm{M}=10, \mathrm{~N}=19)$.

\begin{tabular}{|c|c|c|}
\hline Description & Expression & \\
\hline P1 decomposition & $F_{1}=\frac{V_{P_{1}} \cdot E P_{1} \cdot P_{1}}{K_{P_{1}}+P_{1}}$ & $(12)$ \\
\hline P2 decomposition & $F_{2}=\frac{V_{P_{2}} \cdot E P_{2} \cdot P_{2}}{K_{P_{2}}+P_{2}}$ & (13) \\
\hline Mineral-associated organic carbon decomposition & $F_{3}=\frac{V_{M} \cdot E M \cdot M}{K_{M}+M}$ & $(14)$ \\
\hline Adsorption of DOC & $F_{4}=K_{a d s} \cdot\left(1-Q / Q_{\max }\right) \cdot D$ & $(15)$ \\
\hline Desorption of DOC & $F_{5}=K_{d e s} \cdot\left(Q / Q_{\max }\right)$ & $(16)$ \\
\hline DOC uptake by microbes & $F_{6}=\frac{1}{Y_{G}}\left(V_{D}+m_{R}\right) \frac{D \cdot B A}{K_{D}+D}$ & $(17)$ \\
\hline Dormancy flux & $F_{7}=\left(1-\frac{D}{K_{D}+D}\right) \cdot m_{R} \cdot B A$ & $(18)$ \\
\hline Reactivation flux & $F_{8}=\frac{D}{K_{D}+D} \cdot m_{R} \cdot B D$ & (19) \\
\hline BA growth respiration & $F_{9}=\left(\frac{1}{Y_{G}}-1\right) \frac{V_{D} \cdot B A \cdot D}{K_{D}+D}$ & $(20)$ \\
\hline BA maintenance respiration & $F_{1} 0=\left(\frac{1}{Y_{G}}-1\right) \frac{m_{R} \cdot B A \cdot D}{K_{D}+D}$ & $(21)$ \\
\hline BD maintenance respiration & $F_{1} 1=\beta \cdot m_{R} \cdot B D$ & $(22)$ \\
\hline BA mortality & $F_{1} 2=\left(1-p_{E P}-p_{E M}\right) \cdot m_{R} \cdot B A$ & $(23)$ \\
\hline Synthesis of enzymes for P1 & $F_{13, E P_{1}}=\frac{P_{1}}{P_{1}+P_{2}} \cdot p_{E P} \cdot m_{R} \cdot B A$ & $(24)$ \\
\hline Synthesis of enzymes for P2 & $F_{13, E P_{2}}=\frac{P_{2}}{P_{1}+P_{2}} \cdot p_{E P} \cdot m_{R} \cdot B A$ & $(25)$ \\
\hline Synthesis of enzymes for $\mathrm{M}$ & $F_{13, E M}=p_{E M} \cdot m_{R} \cdot B A$ & $(26)$ \\
\hline \multirow[t]{3}{*}{ Turnover of enzymes } & $F_{14, E P_{1}}=r_{E} \cdot E P_{1}$ & $(27)$ \\
\hline & $F_{14, E P_{2}}=r_{E} \cdot E P_{2}$ & \\
\hline & $F_{14, E M}=r_{E} \cdot E M$ & \\
\hline
\end{tabular}


Table B.7: Model parameter symbols, descriptions, base values of parameters of the MEND model ( $M=10, N=19$; (Wang et al., 2015, Figure S2, Gelisol)).

\begin{tabular}{|c|c|c|c|}
\hline Symbol & Description & Value & Unit \\
\hline $\mathrm{V}_{\mathrm{P} 1}$ & Maximum specific decomposition rate for $\mathrm{P} 1$ & 1.6 & $\mathrm{~h}^{-1}$ \\
\hline $\mathrm{V}_{\mathrm{P} 2}$ & Maximum specific decomposition rate for $\mathrm{P} 2$ & 38.0 & $\mathrm{~h}^{-1}$ \\
\hline $\mathrm{K}_{\mathrm{P} 1}$ & Half-saturation constant for P1 decomposition & 50.0 & $\mathrm{mg} \mathrm{Cg}{ }^{-1}$ \\
\hline $\mathrm{K}_{\mathrm{P} 2}$ & Half-saturation constant for P2 decomposition & 18.0 & $\operatorname{mg~} \mathrm{Cg}^{-1}$ \\
\hline $\mathrm{V}_{\mathrm{M}}$ & Maximum specific decomposition rate for $\mathrm{M}$ & 1.1 & $\mathrm{~h}^{-1}$ \\
\hline $\mathrm{K}_{\mathrm{M}}$ & Half-saturation constant for $\mathrm{M}$ decomposition & 455.0 & $\mathrm{mg} \mathrm{Cg}{ }^{-1}$ \\
\hline $\mathrm{V}_{\mathrm{D}}$ & Maximum specific uptake rate of D for growth & 0.04 & $\mathrm{~h}^{-1}$ \\
\hline $\mathrm{K}_{\mathrm{M}}$ & Half-saturation constant for uptake of D & 0.19 & $\mathrm{mg} \mathrm{Cg}{ }^{-1}$ \\
\hline $\mathrm{m}_{\mathrm{R}}$ & Specific maintenance rate of $\mathrm{BA}$ & 0.033 & $\mathrm{~h}^{-1}$ \\
\hline$\beta$ & Ratio of dormant maintenance rate to $m_{R}$ & 0.001 & - \\
\hline $\mathrm{Y}_{\mathrm{G}}$ & True growth yield & 0.27 & - \\
\hline$f_{D}$ & $\begin{array}{l}\text { Fraction of decomposed } \mathrm{P} 1 \text { and } \mathrm{P} 2 \text { allocated } \\
\text { to } \mathrm{D}\end{array}$ & 0.7 & - \\
\hline$g_{D}$ & Fraction of dead BA allocated to D & 0.3 & - \\
\hline pEP & Fraction of $m_{R}$ for production of EP1 and EP2 & 0.05 & - \\
\hline PEM & Fraction of $m_{R}$ for production of EM & 0.05 & - \\
\hline $\mathrm{r}_{\mathrm{E}}$ & Turnover rate of $\mathrm{EP} 1, \mathrm{EP} 2$, and $\mathrm{EM}$ & 0.0025 & $\mathrm{~h}^{-1}$ \\
\hline$Q_{\max }$ & Maximum DOC sorption capacity & 3.5 & $\mathrm{mg} \mathrm{Cg}{ }^{-1}$ \\
\hline $\mathrm{K}_{\mathrm{des}}$ & Desorption rate & 0.048 & $\mathrm{mg} \mathrm{Cg}{ }^{-1} \mathrm{~h}^{-1}$ \\
\hline$K_{\text {ads }}$ & Adsorption rate & 0.48 & $\mathrm{~h}^{-1}$ \\
\hline
\end{tabular}


Table B.8: Carbon stocks and governing differential equations of the trait-based microbial soil carbon model ( $\mathrm{M}=7, \mathrm{~N}=24$; (Manzoni et al., 2014)).

\begin{tabular}{ll}
\hline C stock & Differential equation \\
\hline Stable soil organic C substrates $\left[\mathrm{g} \mathrm{C} \mathrm{m}^{-3}\right]$ & $\frac{d C_{S}}{d t}=I_{L}-D$ \\
Soluble organic C $\left[\mathrm{g} \mathrm{C} \mathrm{m}^{-3}\right]$ & $\frac{d C_{D}}{d t}=D+M_{B}(1+\gamma)+M_{B, D}(1+\gamma)$ \\
& $\quad+E_{D}+P_{D \rightarrow A \gamma}-U-L_{D}$ \\
Enzymatic C $\left[\mathrm{g} \mathrm{C} \mathrm{m}^{-3}\right]$ & $\frac{d C_{E}}{d t}=E_{P}-E_{D}-L_{E}$ \\
$\mathrm{C}$ in active microbial biomass $\left[\mathrm{g} \mathrm{C} \mathrm{m}^{-3}\right]$ & $\frac{d C_{B}}{d t}=\frac{e U-R_{M}-E_{P}+P_{D \rightarrow A}-P_{A \rightarrow D}-M_{B}}{1+\gamma}$ \\
$\mathrm{C}$ in dormant microbial biomass $\left[\mathrm{g} \mathrm{C} \mathrm{m}^{-3}\right]$ & $\frac{d C_{B, D}}{d t}=P_{A \rightarrow D}-P_{D \rightarrow A}-M_{B, D}$ \\
\hline
\end{tabular}


Table B.9: Biokinetic functions and composite parameter expressions of the trait-based microbial soil carbon model $(\mathrm{M}=7, \mathrm{~N}=24)$.

\begin{tabular}{|c|c|c|c|}
\hline Description & Expression & Unit & \\
\hline Microbial uptake & $U=h_{D}(s) C_{D}$ & $\mathrm{~g} \mathrm{C} \mathrm{m}^{-3} \mathrm{~d}^{-1}$ & $(6)$ \\
\hline Mortality of active microbial biomass & $M_{B}=k_{B} C_{B}$ & $\mathrm{~g} \mathrm{C} \mathrm{m}^{-3} \mathrm{~d}^{-1}$ & $(7)$ \\
\hline $\begin{array}{l}\text { Mortality of dormant microbial } \\
\text { biomass }\end{array}$ & $M_{B, D}=k_{B} / 10 \cdot C_{B, D}$ & $\mathrm{~g} \mathrm{Cm}^{-3} \mathrm{~d}^{-1}$ & $(8)$ \\
\hline Enzyme decay rate & $E_{D}=k_{E} \cdot C_{E}$ & $\mathrm{~g} \mathrm{C} \mathrm{m}^{-3} \mathrm{~d}^{-1}$ & $(9)$ \\
\hline Enzyme production rate & $E_{P}=h_{E}(s)\left(C_{E, 0}-C_{E}\right)$ & $\mathrm{g} \mathrm{C} \mathrm{m}^{-3} \mathrm{~d}^{-1}$ & $(10)$ \\
\hline $\begin{array}{l}\text { Transfer from dormant to active pop- } \\
\text { ulation }\end{array}$ & $P_{D \rightarrow A}=k_{D \rightarrow A} f_{D \rightarrow A}(\psi) C_{B, D}$ & $\mathrm{~g} \mathrm{Cm}^{-3} \mathrm{~d}^{-1}$ & $(11)$ \\
\hline $\begin{array}{l}\text { Transfer from active to dormant pop- } \\
\text { ulation }\end{array}$ & $P_{A \rightarrow D}=k_{A \rightarrow D} f_{A \rightarrow D}(\psi) C_{B}$ & $\mathrm{~g} \mathrm{C} \mathrm{m}{ }^{-3} \mathrm{~d}^{-1}$ & $(12)$ \\
\hline Maintenance respiration & $R_{M}=k_{M} C_{B}$ & $\mathrm{~g} \mathrm{C} \mathrm{m}^{-3} \mathrm{~d}^{-1}$ & $(13)$ \\
\hline Leaching of dissolved organic $\mathrm{C}$ & $L_{D}=C_{D} L_{s} Z_{r}^{-1} \cdot\left(\rho_{b} K_{d}+n \cdot s\right)^{-1}$ & $\mathrm{~g} \mathrm{C} \mathrm{m}^{-3} \mathrm{~d}^{-1}$ & $(14)$ \\
\hline Leaching of enzymes & $L_{E}=L_{s} C_{E} Z_{r}^{-1} \cdot\left(\rho_{b} K_{d}+n \cdot s\right)^{-1}$ & $\mathrm{~g} \mathrm{C} \mathrm{m}^{-3} \mathrm{~d}^{-1}$ & $(15)$ \\
\hline $\begin{array}{l}\text { Transfer coefficient for dissolved or- } \\
\text { ganic C }\end{array}$ & $h_{D}(s)=\delta^{-2} D_{D}(s) \cdot\left(\rho_{b} K_{d}+n \cdot s\right)^{-1} \nu$ & $d^{-1}$ & (16) \\
\hline $\begin{array}{l}\text { Diffusivity of dissolved organic } \mathrm{C} \text { in } \\
\text { bulk soil }\end{array}$ & $\begin{array}{l}D_{D}(s)=\left(\left(s_{t h}-s\right) \cdot\left(-1+s_{t h}\right)^{-1}\right)^{m 2} \cdot D_{D, 0} \cdot \\
n^{m 1} \cdot\left(1-s_{t h}\right)^{m 1}\end{array}$ & $\mathrm{~m}^{2} \mathrm{~s}^{-1}$ & $(17)$ \\
\hline Transfer coefficient for enzymes & $h_{E}(s)=\delta^{-2} D_{E}(s) \cdot\left(\rho_{b} K_{d}+n \cdot s\right)^{-1} \nu$ & $d^{-1}$ & (18) \\
\hline Diffusivity of enzymes in bulk soil & $\begin{array}{l}D_{D}(s)=\left(\left(s_{t h}-s\right) \cdot\left(-1+s_{t h}\right)^{-1}\right)^{m 2} \cdot D_{E, 0} \\
n^{m 1} \cdot\left(1-s_{t h}\right)^{m 1}\end{array}$ & $\mathrm{~m}^{2} \mathrm{~s}^{-1}$ & (19) \\
\hline $\begin{array}{l}\text { Switching function for active-dormant } \\
\text { state transition }\end{array}$ & $f_{A \rightarrow D}(\psi)=\frac{(-\psi)^{w}}{(-\psi)^{w}+\left(-\psi_{A \rightarrow D}\right)^{w}}$ & - & $(20)$ \\
\hline
\end{tabular}


Switching function for dormant-active

$f_{D \rightarrow A}(\psi)=\frac{\left(-\psi_{D \rightarrow A}\right)^{w}}{(-\psi)^{w}+\left(-\psi_{D \rightarrow A}\right)^{w}}$

state transition

Soil matric potential

$\psi=s^{-b} \cdot \psi_{\text {sat }}$

$\mathrm{MPa}$ 
Table B.10: Model parameter symbols, descriptions, base values of parameters of the trait-based microbial soil carbon model ( $\mathrm{M}=7, \mathrm{~N}=24$; (Manzoni et al., 2014, Table 2)).

\begin{tabular}{|c|c|c|c|}
\hline Symbol & Description & Value & Unit \\
\hline $\mathrm{b}$ & Exponent of the water retention curve & 4.9 & - \\
\hline $\mathrm{C}_{\mathrm{E}, 0}$ & $\begin{array}{l}\text { Enzyme concentration outside the microbial } \\
\text { cell }\end{array}$ & 1.0 & $\mathrm{~g} \mathrm{C} \mathrm{m}^{-3}$ \\
\hline $\mathrm{D}_{\mathrm{D}, 0}$ & Diffusivity of dissolved organic $\mathrm{C}$ in pure water & $8.1 e^{-10}$ & $\mathrm{~m}^{2} \mathrm{~s}^{-1}$ \\
\hline$\delta$ & $\begin{array}{l}\text { Characteristic distance between microbial cells } \\
\text { and substrate }\end{array}$ & $1 e^{-4}$ & $\mathrm{~m}$ \\
\hline e & Growth efficiency & 0.5 & - \\
\hline$\gamma$ & $\begin{array}{l}\text { Fixed ratio for constitutive osmolyte produc- } \\
\text { tion }\end{array}$ & 0.026 & - \\
\hline $\mathrm{I}_{\mathrm{L}}$ & Litter carbon input (fixed) & 0.9 & $\mathrm{~g} \mathrm{Cm}^{-3} \mathrm{~d}^{-1}$ \\
\hline $\mathrm{k}_{\mathrm{A} \rightarrow \mathrm{D}}$ & $\begin{array}{l}\text { Maximum rate of transition from active to dor- } \\
\text { mant state }\end{array}$ & 1.0 & $d^{-1}$ \\
\hline $\mathrm{k}_{\mathrm{B}}$ & Mortality rate of active population & 0.012 & $d^{-1}$ \\
\hline $\mathrm{K}_{\mathrm{d}}$ & Solid-liquid partition coefficient & $1 e-5$ & $\mathrm{~m}^{3} \mathrm{~g}^{-1}$ \\
\hline $\mathrm{k}_{\mathrm{D}}$ & Maximum rate of decomposition & $1 e-3$ & $d^{-1}$ \\
\hline $\mathrm{k}_{\mathrm{D} \rightarrow \mathrm{A}}$ & $\begin{array}{l}\text { Maximum rate of transition from dormant to } \\
\text { active state }\end{array}$ & $k_{A \rightarrow D}$ & $d^{-1}$ \\
\hline $\mathrm{k}_{\mathrm{E}}$ & Enzyme de-activation rate & $5 e-4$ & $d^{-1}$ \\
\hline $\mathrm{k}_{\mathrm{M}}$ & Maintenance respiration rate & 0.022 & $d^{-1}$ \\
\hline $\mathrm{m}_{1}$ & Empirical exponent & 1.5 & - \\
\hline $\mathrm{m}_{2}$ & Empirical exponent & 2.5 & - \\
\hline $\mathrm{n}$ & Soil porosity & 0.43 & - \\
\hline$\nu$ & Scaling coefficient & 6.0 & - \\
\hline$\psi_{\mathrm{A} \rightarrow \mathrm{D}}$ & $\begin{array}{l}\text { Water potential at } 50 \% \text { of the Maximum rate } \\
k_{A \rightarrow D}\end{array}$ & 0.4 & $\mathrm{MPa}$ \\
\hline$\psi_{\text {sat }}$ & Soil water potential at saturation & -0.002 & $\mathrm{MPa}$ \\
\hline$\rho_{\mathrm{b}}$ & Soil bulk density & $1.2 e^{6}$ & $\mathrm{~g} \mathrm{~m}^{-3}$ \\
\hline s & Soil moisture & 0.6 & - \\
\hline $\mathrm{s}_{\text {th }}$ & Diffusion threshold & 0.18 & - \\
\hline
\end{tabular}




\section{Appendix C. Model Reduction}

A numerical solution to the geodesic equation requires calculating local sensitivity information and inversion of the Hessian matrix at every iteration step. Calculation of the Christoffel symbols $\Gamma$ requires second-order sensitivities. For large models it is computationally advantageous to approximate the contraction of the second derivatives of the residual vector with the geodesic velocities by a finite difference approximation of the resulting second directional derivative (Transtrum et al., 2018). The geodesic ODE then reads (Transtrum and Qiu, 2016)

$$
\begin{aligned}
& \frac{\partial p^{i}}{\partial \tau}=v^{i} \\
& \frac{\partial v^{i}}{\partial \tau}=\sum_{l, m}\left(H^{-1}\right)^{i l} \frac{\partial r_{m}}{\partial p^{l}} A_{m}(v)
\end{aligned}
$$

where $A_{m}(v)$ is the second directional derivative

$$
A_{m}(v)=\sum_{j k} \frac{\partial p^{j}}{\partial \tau} \frac{\partial p^{k}}{\partial \tau} \frac{\partial^{2} r_{m}}{\partial p^{j} \partial p^{k}}
$$

with finite difference approximation $(h=0.01)$

$$
A_{m}(v)=\lim _{h \rightarrow 0} \frac{r_{m}(\boldsymbol{p}+h \boldsymbol{v})+r_{m}(\boldsymbol{p}-h \boldsymbol{v})-2 r_{m}(\boldsymbol{p})}{h^{2}} .
$$

The geodesic ODE has to be integrated until a manifold boundary is identified. However, the eigendirection on the manifold that causes an almost imperceptible change to the model performance metric (corresponding to the smallest Hessian eigenvector $\boldsymbol{v}_{\mathbf{0}}$ ) can only be determined up to a constant sign from the singular value decomposition of the Jacobian matrix (either $\boldsymbol{v}_{\mathbf{0}}$ 
or $\left.-\boldsymbol{v}_{\mathbf{0}}\right)$. In practice, the direction is chosen in which the parameter velocity initially increases. Four criteria can be used to discern whether a boundary has been reached. A boundary is defined by the Hessian becoming singular. As can be seen from the initial and final plots of Hessian eigenvalues, the smallest eigenvalue separates from the others and approaches numerical zero. The eigenvector corresponding to the smallest eigenvalue initially contains a mixture of factors, but is rotated from its initial direction to reveal the important linear combination of parameters at the boundary. As the geodesic approaches a boundary, model parameters asymptotically approach the limit that is defined by the boundary (e.g., parameters approach infinity, $\lim _{\tau \rightarrow \tau_{b}} p(\tau)=\infty$ ). Accordingly, the corresponding parameter velocities (the rates of parameter change along the manifold path) diverge. The most robust indicator of limiting behavior turned out to be the increase in parameter velocity compared to the initial velocity (Appendix F: Fig. F.8).

\section{Appendix D. Bayesian Optimization}

Bayesian inference consists of conditioning a prior probability distribution of model parameters on the data (Stone, 2013). Mathematically, Bayes theorem for conditional probabilities is stated as:

$$
P\left(\boldsymbol{\vartheta} \mid \boldsymbol{y}^{\boldsymbol{D}}\right)=\frac{P\left(\boldsymbol{y}^{\boldsymbol{D}} \mid \boldsymbol{\vartheta}\right) P(\boldsymbol{\vartheta})}{P\left(\boldsymbol{y}^{\boldsymbol{D}}\right)} \propto P\left(\boldsymbol{y}^{\boldsymbol{D}} \mid \boldsymbol{\vartheta}\right) P(\boldsymbol{\vartheta}) .
$$

$P\left(\boldsymbol{y}^{D} \mid \boldsymbol{\vartheta}\right)$ is the likelihood that the model will produce the data $\boldsymbol{y}^{\boldsymbol{D}}$ given parameters $\boldsymbol{\vartheta} . P(\boldsymbol{\vartheta})$ is the prior probability distribution of model parameters. Together, likelihood and prior encode the belief of the modeler about observations of the biogeochemical system. $P\left(\boldsymbol{y}^{\boldsymbol{D}}\right)$ is the evidence of the data. 
This evidence is a normalization constant unimportant in global sensitivity applications.

For the Metropolis-Hastings algorithm (Chib and Greenberg, 1995) that samples the posterior distribution of sloppy models, Gutenkunst (2007) suggests to sample the candidate parameter vector from a multivariate Gaussian distribution, the inverse covariance matrix of which is the Hessian matrix. The acceptance probability that satisfies detailed balance reads:

$$
\alpha=\min \left(\frac{P\left(\boldsymbol{\vartheta}_{c} \mid \boldsymbol{y}^{\boldsymbol{D}}\right)}{P\left(\boldsymbol{\vartheta}_{i} \mid \boldsymbol{y}^{\boldsymbol{D}}\right)} \cdot \frac{\left|\boldsymbol{H}_{c}\right| \exp \left(-\frac{1}{2}\left(\boldsymbol{\vartheta}_{c}-\boldsymbol{\vartheta}_{i}\right)^{T} \boldsymbol{H}_{c}\left(\boldsymbol{\vartheta}_{c}-\boldsymbol{\vartheta}_{i}\right)\right)}{\left|\boldsymbol{H}_{i}\right| \exp \left(-\frac{1}{2}\left(\boldsymbol{\vartheta}_{c}-\boldsymbol{\vartheta}_{i}\right)^{T} \boldsymbol{H}_{i}\left(\boldsymbol{\vartheta}_{c}-\boldsymbol{\vartheta}_{i}\right)\right)}, 1\right) .
$$

Here, $\boldsymbol{H}_{c}$ and $\boldsymbol{H}_{i}$ are the Hessian matrices calculated at the candidate $\boldsymbol{\vartheta}_{c}$ and current $\boldsymbol{\vartheta}_{i}$ sample points. $|\boldsymbol{H}| \equiv \operatorname{det} \boldsymbol{H}$ is the determinant of $\boldsymbol{H}$. The idea behind the importance sampling scheme is to avoid steps in stiff directions in parameter space that would yield low acceptance probabilities. We performed $10^{6}$-step importance-sampled MCMC runs. Log-normal priors (the $95 \%$ confidence interval of the normal distribution of $\log \boldsymbol{\vartheta}$ with expectation value $\boldsymbol{\nu}=\boldsymbol{\vartheta}^{*}$, where $\boldsymbol{\vartheta}^{*}$ are locally optimal values, and standard deviation $\sigma=100\left(\boldsymbol{\vartheta}^{*}\right)$ is the interval $\left.[\boldsymbol{\nu} / \sigma, \boldsymbol{\nu} \cdot \sigma]\right)$ were used as priors for kinetic (yield) parameters. The autocorrelation function of the cost for the full and reduced PECCAD models calibrated based on the MCPA + Litter data was calculated (Appendix F: Fig. F.10). The number of MCMC steps in one correlation time theoretically scales with the square of the number of model parameters. For the full (reduced) model, the correlation time is 1.2e4 (1e3), suggesting that ensemble members 1.2e4 (1e3) steps apart are statistically independent. 83 (100) independent samples from the posterior distribution were used for post-processing. 
A comparison of the marginal posterior distributions of model parameters with the marginal prior parameter distributions can be used to assess the learning effect of the Bayesian inference process. Narrower marginal posterior distributions compared to the priors indicate good identifiability of model parameters. Large shifts in the maximum a posteriori probability estimate (MAP), i.e. the mode of the marginal posterior distribution, compared to the MAP of the priors, should prompt a check of prior information. The highest posterior density region is the set of most probable parameter values that constitute $100 \cdot(1-\alpha) \%$ of the posterior mass. For a given $\alpha$, the integral

$$
1-\alpha=\int_{\boldsymbol{\vartheta}: p\left(\boldsymbol{\vartheta} \mid \boldsymbol{y}^{D}\right)>p^{* *}} p\left(\boldsymbol{\vartheta} \mid \boldsymbol{y}^{\boldsymbol{D}}\right) d \boldsymbol{\vartheta}
$$

defines the set of highest posterior densities $C_{\alpha}(D) \equiv\left\{\boldsymbol{\vartheta}: p\left(\boldsymbol{\vartheta} \mid \boldsymbol{y}^{\boldsymbol{D}}\right) \geq p^{* *}\right\}$.

\section{Appendix E.}

\section{Method of Morris}

The Morris method (Morris, 1991), also called the Elementary Effect Test (EET, Pianosi et al. (2016)) for global sensitivity analysis, is a derivativebased OAT (One-step-At-a-Time) method that generates two sensitivity measures for each model parameter: $\mu^{*}$, the Morris mean and $\sigma$, the standard deviation.

In an OAT design, each parameter is locally varied for a point in parameter space, while the other parameters are fixed to a nominal value, and the change in model output is recorded. If $J$ denotes the model performance metric, the finite difference

$$
E E_{i}=\frac{J\left(\vartheta_{1}, \ldots, \vartheta_{i-1}, \vartheta_{i}+\Delta \vartheta_{i}, \vartheta_{i+1}, \ldots, \vartheta_{n}\right)-J\left(\vartheta_{1}, \ldots, \vartheta_{n}\right)}{\Delta \vartheta_{i}}
$$


is called the Elementary Effect (EE) for parameter $i, i \in\{1, \ldots, N\}$. The EE is the ratio between the variation in the model performance metric due to local variation of the parameter and the variation in the parameter itself. In order to obtain a global sensitivity measure, the absolute values of $r$ different EEs for each parameter are computed and averaged to the Morris mean

$$
\mu_{i}^{*}=\frac{1}{r} \sum_{j=1}^{r}\left|E E_{i}\right|^{j}
$$

with standard deviation

$$
\sigma_{i}=\sqrt{\frac{1}{r-1} \sum_{j=1}^{r}\left(E E_{i}^{j}-\mu_{i}^{*}\right)^{2}} .
$$

State-of-the-art versions of the Morris method mainly differ in the sampling strategies used to select initial and consecutive points in parameter space for variation (Pianosi et al., 2016). We used the implemented radial-design from the MATLAB SAFE toolbox (Pianosi et al., 2015).

Due to the comparatively low computational cost of $r \cdot(N+1)$ model evaluations, variants of the Morris method are often used for screening purposes of model input variability. Typically, parameters are grouped into three categories depending on their Morris mean and standard deviation $\left\{\mu_{i}^{*}, \sigma_{i}\right\}$ (Iooss and Lemaître, 2015). The larger $\mu_{i}^{*}$, the larger the effect of the $i$-th parameter on the model performance metric. $\sigma_{i}$ is a measure for nonlinearity or interaction effects for the $i$-th parameter. If $\sigma_{i}$ is small, the EEs for the $i$-th parameter do not vary significantly over support points in parameter space. If the effect of a small perturbation of a parameter is the same everywhere, a linear relationship between parameter and model performance metric is likely. A parameter with large $\sigma_{i}$ will have non-linear or interaction 
effects. Different sets of Morris mean and standard deviation hence correspond to parameters that have negligible effect on the model performance metric (both $\mu_{i}^{*}, \sigma_{i}$ small), those that have a linear effect $\left(\mu_{i}^{*}>\sigma_{i}\right.$, with $\sigma_{i}$ small) and those with significant interaction effects $\left(\mu_{i}^{*}<\sigma_{i}\right.$, with both $\mu_{i}^{*}, \sigma_{i}$ large).

Following the GSA approach in Link et al. (2018), Morris mean and standard deviation were restricted to the unit square by normalizing with the largest value observed:

$$
\hat{\mu}_{i}^{*}=\frac{\mu_{i}^{*}}{\max _{i} \mu_{i}^{*}}, \quad \hat{\sigma}_{i}=\frac{\sigma_{i}}{\max _{i} \sigma_{i}} .
$$

The $\ell_{2}$-norm of normalized Morris pairs was subsequently used to screen for model parameters that have a negligible effect on the model performance metric. The lower and upper bounds for uniform Latin Hypercube sampling of model parameters were set to $50 \%$ and $200 \%$ of the best fit parameter value. 25,000 trajectories were sampled, corresponding to 2.64 million model evaluations. The robustness of Morris pairs was checked by bootstrapping and convergence analysis (Appendix F: Fig. F.11). 
${ }_{1118}$ Appendix F. Supplementary Figures 


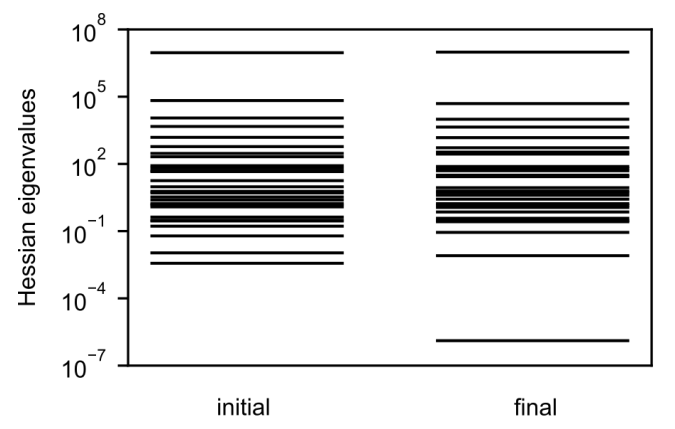

(a) Hessian eigenvalues

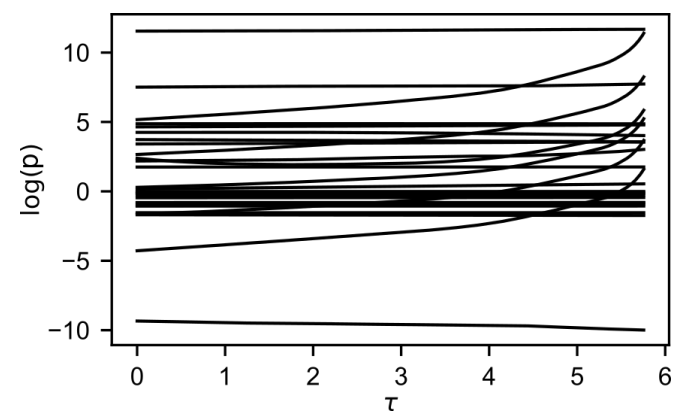

(c) Parameter limits

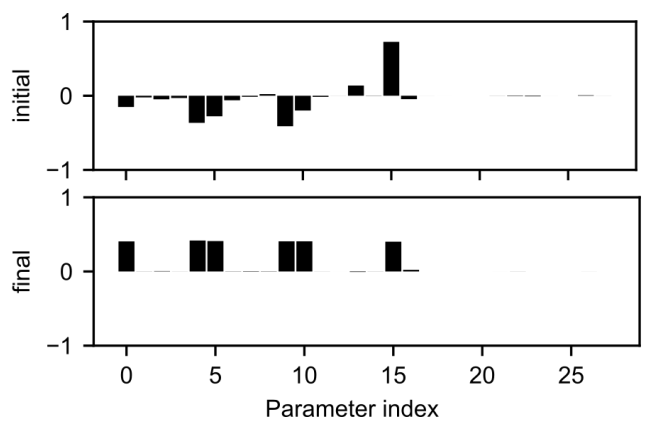

(b) Hessian eigenvector components

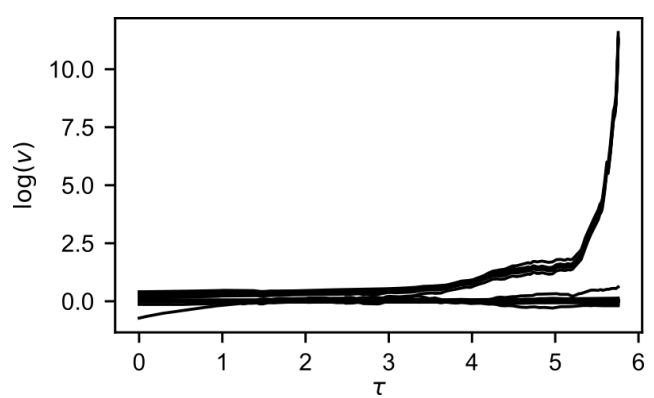

(d) Velocity limits

Figure F.8: Identifying manifold boundaries. In the semilogarithmic plots (bottom) the geodesic paths on the model manifold are parameterized by $\tau$. For the logarithm of model parameters $p$ (c) and parameter velocities $v=\partial p / \partial \tau(\mathrm{d})$, one curve is plotted per parameter (in this case 28). As the geodesic approaches a boundary (approximately at $\tau=\tau_{b} \approx 5.8$ ), six parameter values and the corresponding velocities diverge. Other model parameters slightly compensate for the limit at the boundary. The eigendirection vector (b) and Hessian eigenvalues (a) at the start and end of the geodesic path are shown (initial/final). Once a boundary is reached, the smallest eigenvalue separates and approaches numerical zero. The final parameter space velocity vector contains only components corresponding to the parameters that take on extreme values. The geodesic ODE (Eq. 7) was integrated until the norm of the velocity vector increased by a constant factor: $k=\left|\boldsymbol{v}_{\mathbf{0}}\right| /\left|\boldsymbol{v}_{\boldsymbol{b}}\right|=25$. A singular limit in PECCAD ODE was subsequently identified (Eq. 28). 


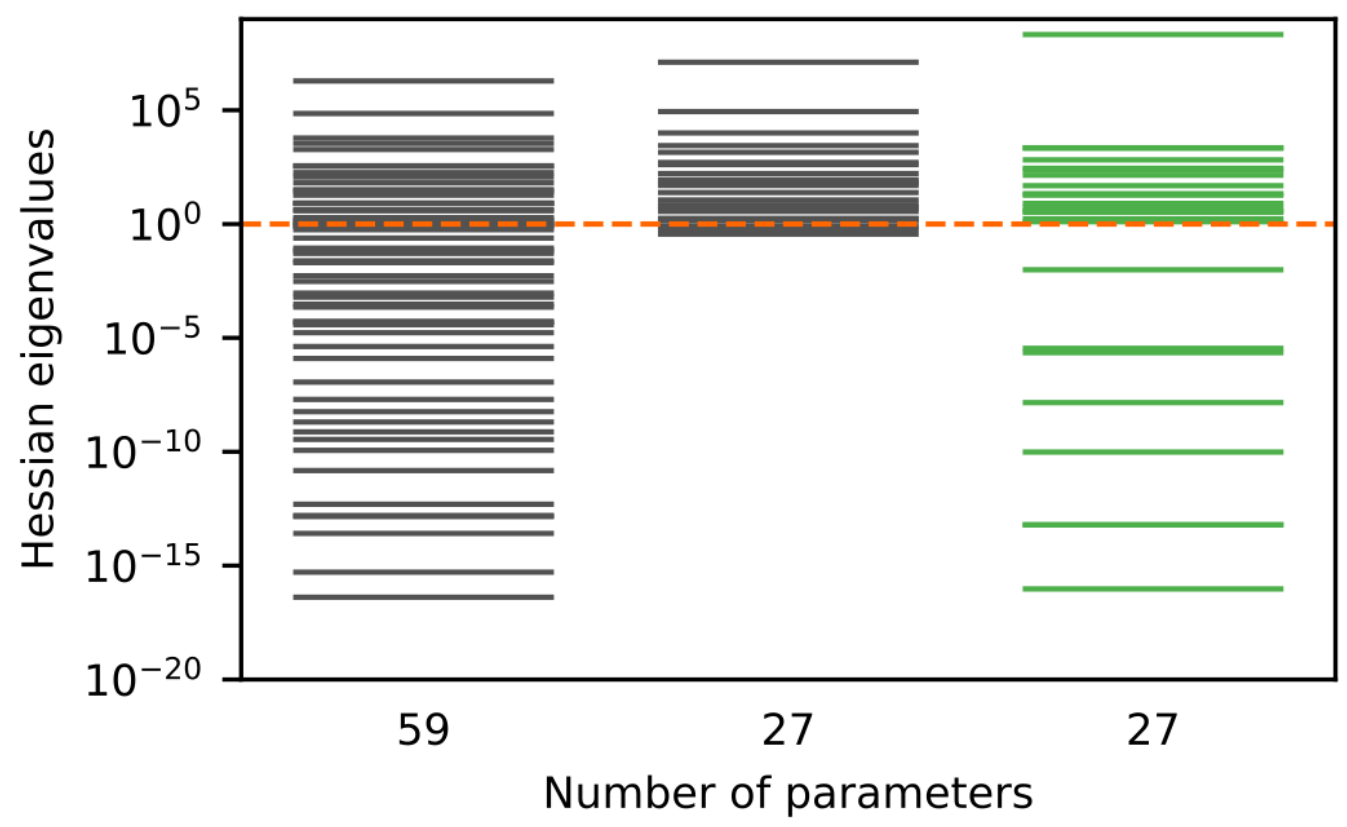

Figure F.9: Quantifying information in MCPA data. Upon fitting the reduced 27 parameter model (Appendix A: Table A.4) to the MCPA experimental treatment, the Hessian eigenvalue spectrum broadens again and information on 7 model parameters is lost. 


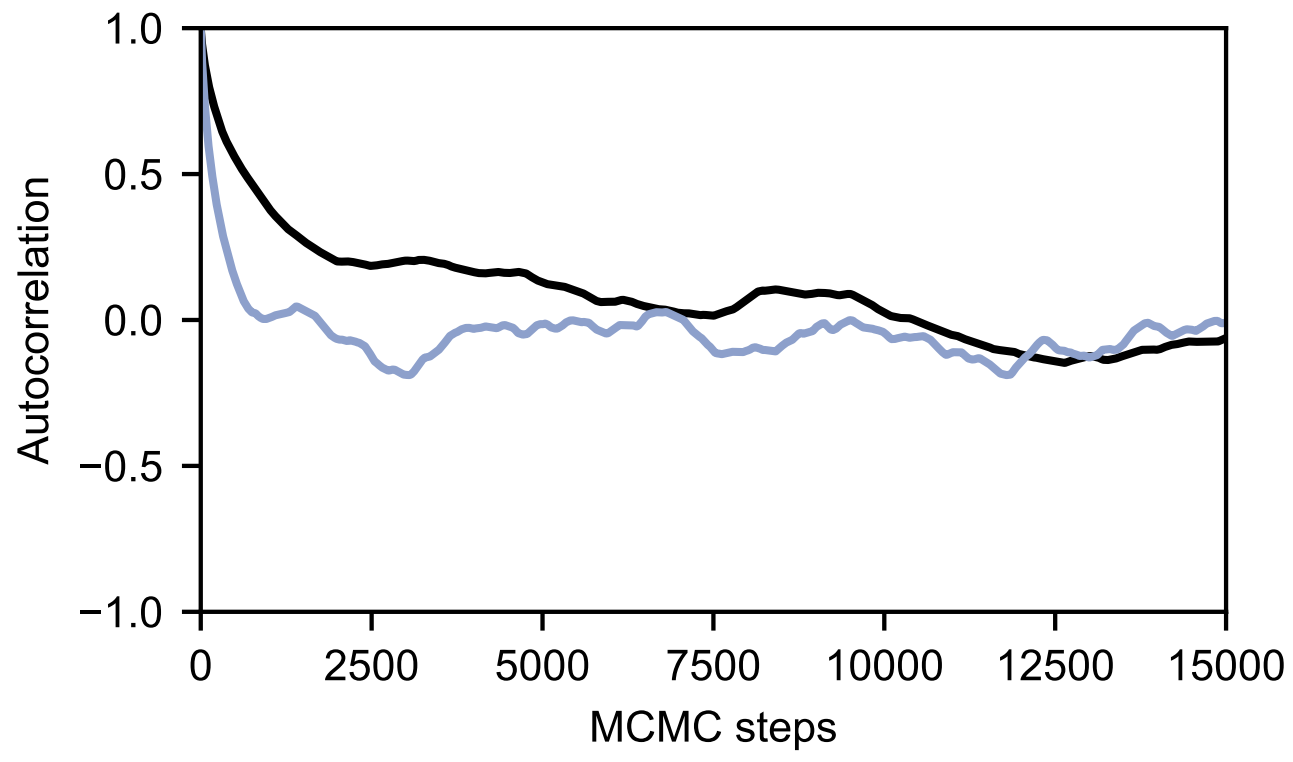

Figure F.10: Performance of the MCMC algorithm. Shown are the autocorrelation functions from 1e6 MCMC runs for the full (black, Appendix A: Table A.1) and reduced (purple, Appendix A: Table A.4) PECCAD ODE model. The autocorrelation time for the reduced model is shorter by a factor of 12 . 


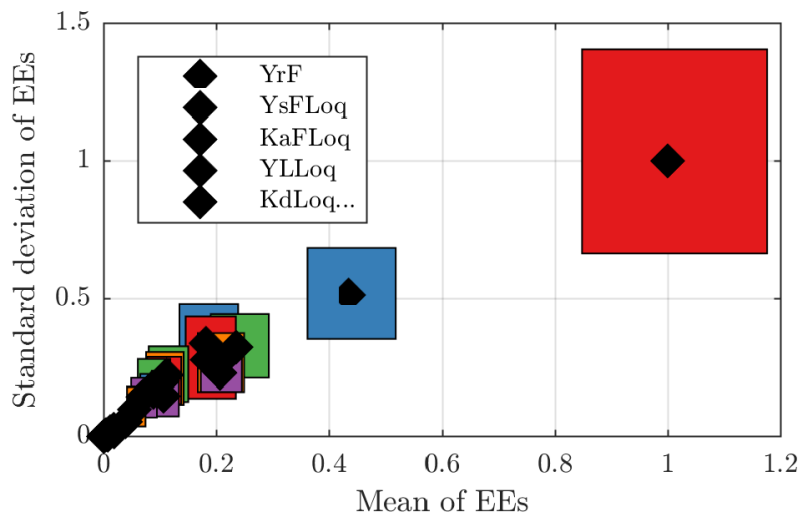

(a) EET plot

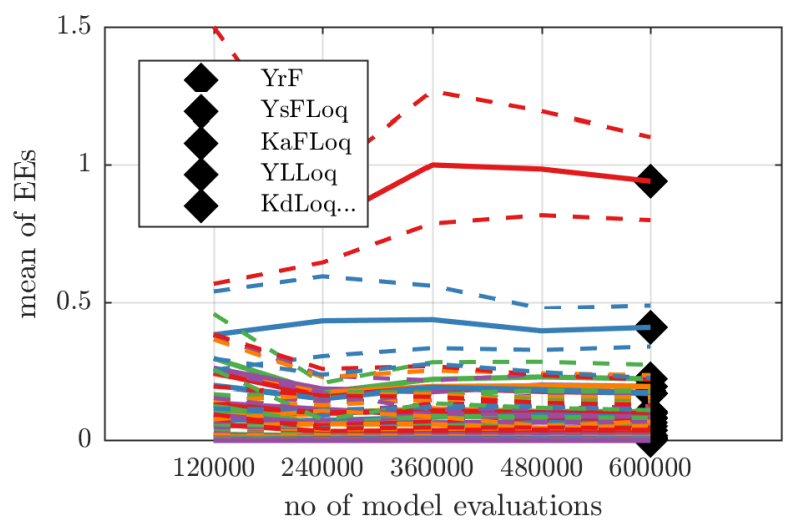

(b) Convergence

Figure F.11: Elementary Effects Test (EET). (a) Plot of the average of EEs against their standard deviation with confidence intervals derived from 3000 bootstrap resamplings. (b) Convergence plot for the mean of EEs and confidence intervals derived from 3000 bootstrap resamplings evaluated for different sample sizes. 